Andrews University

Digital Commons @ Andrews University

\title{
An Exploratory Analysis of Conflict in African Immigrant and African American Marriages
}

Cornelius Ayodeji Osuntade

Andrews University, osuntade@andrews.edu

Follow this and additional works at: https://digitalcommons.andrews.edu/dissertations

Part of the African American Studies Commons, and the Family, Life Course, and Society Commons

\section{Recommended Citation}

Osuntade, Cornelius Ayodeji, "An Exploratory Analysis of Conflict in African Immigrant and African American Marriages" (2021). Dissertations. 1752.

https://digitalcommons.andrews.edu/dissertations/1752

https://dx.doi.org/10.32597/dissertations/1752

This Dissertation is brought to you for free and open access by the Graduate Research at Digital Commons @ Andrews University. It has been accepted for inclusion in Dissertations by an authorized administrator of Digital Commons@ Andrews University. For more information, please contact repository@andrews.edu. 
ABSTRACT

AN EXPLORATORY ANALYSIS OF CONFLICT IN AFRICAN IMMIGRANT AND AFRICAN AMERICAN MARRIAGES

by

Cornelius Ayodeji Osuntade

Adviser: David Sedlacek 


\title{
ABSTRACT OF GRADUATE STUDENT RESEARCH
}

\author{
Dissertation \\ Andrews University \\ Seventh-day Adventist Theological Seminary
}

Title: AN EXPLORATORY ANALYSIS OF CONFLICT IN AFRICAN IMMIGRANT AND AFRICAN AMERICAN MARRIAGES

Name of researcher: Cornelius Ayodeji Osuntade

Name and degree of faculty adviser: David Sedlacek, Ph.D.

Date completed: March 2021

\section{Problem}

There has been a high level of marital conflict in immigrant families from patriarchal cultures. There are negative attitudes toward women that contribute to couple conflict. Coupled with this are issues relating to immigration challenges that confront marriage stability among immigrant couples in North America. In the same vein, African American couples experience conflicts that militate against the stability of their marriages. Most of these marital upheavals stem from historical antecedents relating to this ethnic group, as well as the societal dialectics confronting them. By and large, regarding couple conflict, a better understanding of the challenges facing African 
immigrant couples, and the impact of the African heritage on African American couples, are germane to this study.

\section{Method}

This was a non-experimental comparative exploratory study of conflict in African immigrant and African American marriages in terms of their scores on the Conflict Tactics Scale (CTS2) and its subscales. This involved administering a combined questionnaire comprised of the CTS2, Attitude Toward Women Scale (AWS), and a short immigration questionnaire specific to African immigrants. The target populations for this research work fell into two groups: African immigrant and African American ethnic groups living in North America. A One-Way MANCOVA was conducted to determine the effect of ethnicity on each of the five conflict tactics (negotiation: self and partner; physical assault: self and partner; injury: self and partner; psychological aggression: self and partner; and sexual coercion: self and partner) after controlling for attitude towards women. A Pearson bivariate correlation analysis was used to test whether there was a significant bivariate relationship between attitude towards women and the total score of conflict tactics self and total partner. Analyses were carried out using the IBM Statistical Package for the Social Sciences (SPSS). Descriptive statistics were used to describe the responses of African immigrants to the Immigrant Questionnaire.

\section{Results}

In testing for the hypotheses, the main effect of ethnicity [Wilks' Lambda $=.868$, $\mathrm{F}(5,171)=5.192$, sig. $=.000$, multivariate eta squared $=.132]$ indicated a significant effect on the combined conflict tactics. The covariate attitude towards women had a 
significant influence on the combined dependent variables [Wilks' Lambda $=.864, \mathrm{~F}(5$, $171)=5.368$, sig. $=.000$, multivariate eta squared $=.136$, power $=.99]$. Univariate ANOVA results indicated that ethnicity had a significantly small effect on psychological aggression $($ self $)[F(1,175)=8.395$, sig. $=.004$, partial eta squared $=.046$, power $=.82]$, sexual coercion $($ self $)[F(1,175)=6.888$, sig. $=.009$, partial eta squared $=.038$, power $=$ .74]. The covariate attitude towards women had a significant effect on negotiation (self) $[\mathrm{F}(1,175)=6.133$, sig. $=.014$, partial eta squared $=.034$, power $=.69]$, physical assault $($ self $)[F(1,175)=9.597$, sig. $=.002$, partial eta squared $=.052$, power $=.87]$, injury (self) $[\mathrm{F}(1,175)=10.898$, sig. $=.001$, partial eta squared $=.059$, power $=.91]$, and sexual coercion $($ self $)[F(1,175)=11.960$, sig. $=.001$, partial eta squared $=.064$, power $=.93]$. Similarly, the main effect of ethnicity [Wilks' Lambda $=.895$, F $(5,181)=4.246$, sig. $=$ .001 , multivariate eta squared $=.105$, power $=.96]$ indicated a significant effect on the combined conflict tactics. The covariate attitude towards women had a significant influence on the combined dependent variables [Wilks' Lambda $=.916, \mathrm{~F}(5,181)=$ $3.131, \mathrm{sig} .=.007$, multivariate eta squared $=.084$, power $=.89]$. Univariate ANOVA results indicated that ethnicity had a significantly small effect on psychological aggression $($ partner $)[\mathrm{F}(1,185)=4.371, \mathrm{sig} .=.038$, partial eta squared $=.023$, power $=$ $.55]$, sexual coercion (partner) $[\mathrm{F}(1,185)=4.010$, sig. $=.047$, partial eta squared $=.021$, power $=.52]$. The covariate attitude towards women had a significant effect on physical assault $($ partner $)[F(1,185)=6.790$, sig. $=.010$, partial eta squared $=.035$, power $=.74]$, injury $($ partner $)[F(1,185)=6.499$, sig. $=.012$, partial eta squared $=.034$, power $=.72]$, and sexual coercion $($ partner $)[F(1,185)=9.946$, sig. $=.002$, partial eta squared $=.051$, power $=.88]$. It is further revealed that there is no significant correlation between attitude 
towards women and total CT scores (self) [Pearson $\mathrm{r}=-.02$, sig. $=.762, \mathrm{~N}=178$ ], with related results showing that there was no significant correlation coefficient between attitude towards women and total CT scores (partner) [Pearson $\mathrm{r}=-.06$, sig. $=.417, \mathrm{~N}=$ 188]. The results of the immigration questionnaire showed that immigration and acculturation issues had a significant effect on the marriages of African immigrants in the US.

\section{Conclusions}

This study has established the reality that marital conflict is ubiquitous. The pertinent question is this: How do couples react to conflict? The reaction of couples to conflict determines the outcome to conflicts. It should be well noted that because the quality and stability of marriage and family lives are especially important in building and maintaining a healthy society, it is, therefore, to reduce conflict and violence in homes and among couples. We must work towards establishing a good community with a minimal level of violence. The task now is to underscore the point that families should be permeated by love and nurturing thoughtfulness, as opposed to the horrific psychological abuse, battering, and killing that are a tragic part of couple conflict and domestic violence. Through the cooperation of everyone; the intervention of marriage and family resource persons and counselors; and through the assistance of national governments, national organizations, and different international agencies, brilliant, practical, and meaningful approaches to bringing about the prevention and control of conflict and violence in marriage relationships can be engendered. 
Andrews University

Seventh-day Adventist Theological Seminary

\title{
AN EXPLORATORY ANALYSIS OF CONFLICT IN AFRICAN \\ IMMIGRANT AND AFRICAN AMERICAN MARRIAGES
}

\author{
A Dissertation \\ Presented in Partial Fulfillment \\ of the Requirements for the Degree \\ Doctor of Philosophy
}

by

Cornelius Ayodeji Osuntade

March 2021 
(C) Copyright by Cornelius Ayodeji Osuntade 2021

All Rights Reserved 


\title{
AN EXPLORATORY ANALYSIS OF CONFLICT IN AFRICAN \\ IMMIGRANT AND AFRICAN AMERICAN MARRIAGES
}

\author{
A dissertation \\ presented in partial fulfillment \\ of the requirements for the degree \\ Doctor of Philosophy
}

by

Cornelius Ayodeji Osuntade

\section{APPROVAL BY THE COMMITTEE:}

Faculty Adviser, David Sedlacek

Professor of Family and Discipleship

Tevni Grajales

Professor of Research and Statistical Methodology

Boubakar Sanou

Associate Professor of World Mission and Leadership

Alina Baltazar

Associate Professor \& MSW Program Director of Social Work

Perry Downs

Professor Emeritus of Educational Ministries

Trinity Evangelical Divinity School
Director of Discipleship \& Religious Education Program

Jasmine J. Fraser

Dean, SDA Theological Seminary

Jiří Moskala 


\section{DEDICATION}

This dissertation is especially dedicated first and foremost to God Almighty, who, through Jesus Christ, His Son, and the Holy Spirit, made it possible for me to finish writing this dissertation. I owe my success and living to the Trinity. My heartfelt thanks to You my Jehovah Nissi, and my Jehovah Raah.

This dissertation is dedicated next to my beautiful and loving wife, Oluwasayo Omokunmi Osuntade (Nee Gade), for being so resilient in sacrificing herself and everything we have on the altar to make sure I completed this degree.

I also dedicate this study to my children, Martins Osuntade, Chelliot Osuntade, and Julianah Osuntade, for standing by me and enduring the journey with me.

Finally, I dedicate this research work to my one and only sibling, Isaac Osuntade, who cared enough to "evict us forcefully" from Nigeria when I refused to pick up the visa to come to the United States, and supported us with all the resources we needed to start life in America. 


\section{TABLE OF CONTENTS}

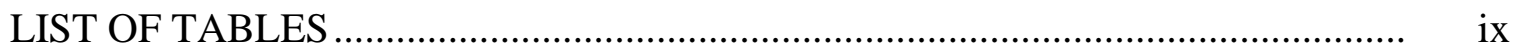

LIST OF ABBREVIATIONS .......................................................................

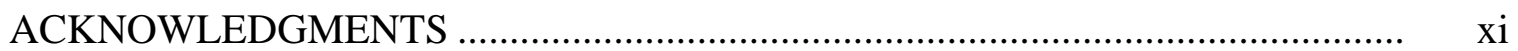

\section{Chapter}

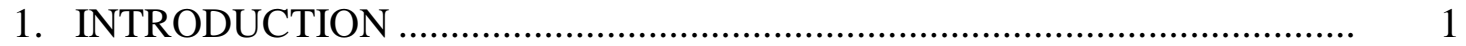

Background to the Study ............................................................................ 7

Statement of the Problem........................................................................ 11

Purpose of the Study ........................................................................... 11

Rationale for the Study .................................................................. 12

Significance of the Study ................................................................... 13

Conceptual Framework .......................................................................... 14

Brief Developmental History of Conflict Tactics Scale (CTS2) and

Attitudes Towards Women Scale (AWS) ......................................... 18

Conflict Tactics Scale ................................................................... 18

Attitudes Toward Women Scale ...................................................... 18

Research Questions ........................................................................... 18

Limitations .............................................................................. 19

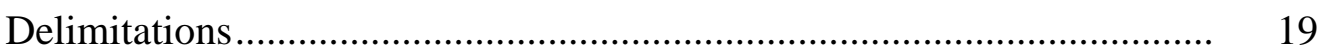

Definition of Terms.................................................................... 20

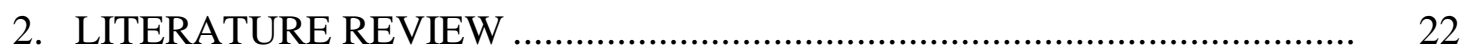

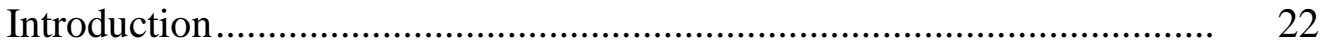

African Immigrants ................................................................ 22

African Americans ................................................................... 25

Africans and African Americans Cultural Affinities ............................ 28

Literature Review: Areas of Coverage …………………………….... $\quad 30$

Theological Foundations of Marriage ................................................ $\quad 30$

An Overview of Conflict and Catharsis Theories............................... 48

A Brief Exploration of What Conflict is All About: Biblical

and Contemporary Insights ........................................................ 53

Biblical Insights …….............................................................. 53

Contemporary Insights .............................................................. 56 
Support System for Africans' and African Americans' Marriages

and Families

Support System for Africans' Marriages and Families...................... 60

Non-Governmental Organizations ............................................ 60

Kinship Connection .......................................................... 61

Elders' Council ...................................................................... 62

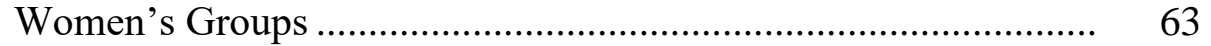

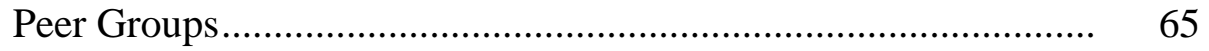

Churches ............................................................................ 65

Support System for African Americans’ Marriages and Families...... 68

Kinship Connection .............................................................. 68

Churches ................................................................................ 69

Cohabitation, Divorce, and Decline in Marriage among African

Americans and African Immigrants........................................ 71

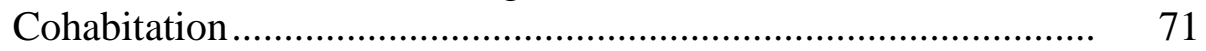

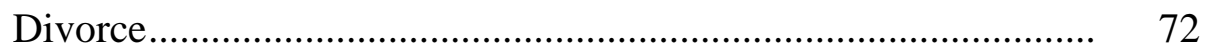

Decline in Marriage ...................................................................... 74

A Discussion of the Possible Causes of Couple's Conflict ..................... 74

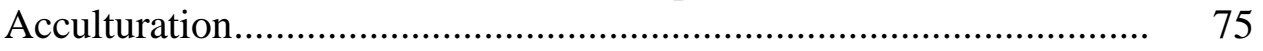

Economic and Money Issues .................................................. $\quad 77$

Educational Challenges Facing International Students and Their

Spouses

78

Sex and Infidelity ................................................................. 80

Poor Quality Time....................................................................... 83

Lack of Communication ............................................................. 84

Sociocultural and Psychosocial Factors ............................................ 86

Levels of Couple's Conflict: From Mild to Severe ................................ 88

Unresolved Conflicts ....................................................................... 89

The Impact of Couples' Religiosity and Spirituality on Conflict............ 92

Summaries of Findings from Some Studies That Have Used the

Conflict Tactics Scale

The Marriage License as a Hitting License: A Comparison of

Assaults in Dating, Cohabiting, and Married Couples

Perceptions and Experiences of Intimate Partner Violence among

Hispanic College Students

Acculturation, Partner Violence, and Psychological Distress in

Refugee Women from Somalia

Intimate Partner Violence among Adolescents in South Africa and Tanzania

The Level of Parental Conflict and Children's Behavioral

Reactions to Divorce.

102

Summaries of Findings from Some Studies That Have Used the

Attitudes Towards Women Scale

Attitudes toward Women among College Students in Urban

India 
Definitions of Dating Violence among African American College

Students: Their Relationships with Gender Role Beliefs

Sex-Role Attitudes and Some Selected Background Characteristics

of Women in Nontraditional Careers, Women in Traditional

Careers, and the Homemakers in Malaysia

Rehabilitation Counseling Master's Students: Beliefs and

Attitudes about Domestic Violence Toward Women

Conclusion

3. METHODOLOGY

Introduction

Research Design

Population and Sample

112

Hypotheses and Objectives

Variables and Their Definitions....

114

Negotiation

115

Psychological Aggression

Psychological Aggression Scale Items: Minor

116

Psychological Aggression Scale Items: Severe

116

Physical Attack

Physical Attack Scale Items: Minor.

117

Physical Attack Scale Items: Severe....................................... 117

Injury

118

Injury Scale Items: Minor .................................................... 118

Injury Scale Items: Severe ................................................. 118

Sexual Coercion ....................................................................... 119

Sexual Coercion Scale Items: Minor ........................................ 119

Sexual Coercion Scale Items: Severe ....................................... 120

Instrumentations.......................................................................... 120

Conflict Tactics Scale ............................................................... 120

Attitudes Towards Women Scale............................................... 120

Immigration Questionnaire ................................................... 121

Reliability and Validity of the CTS2 Instrument .................................. 121

Reliability and Validity of the AWS Instrument ................................. 122

Procedures for Data Collection ............................................................ 123

Data Analysis ................................................................................ 124

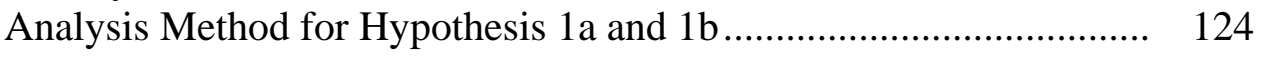

Analysis Method for Hypothesis 2a and 2b................................. 124

Multiple Choice Immigration Questionnaire Observation ................. 124

4. RESULTS

Introduction

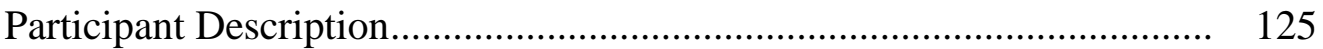

Observed Variables Description ....................................................... 128 
Hypotheses Testing and Description of Objective..................................... 131

Immigration and Acculturation Questionnaire ........................................ 135

Time Related Issues .................................................................. 136

Social Support Related Issues: Extended Family Issues...................... 138

Culture Related Issues.................................................................... 139

Job Related Issues ....................................................................... 140

Parenting Related Issues .................................................................. 141

Achieving American Dreams and Goals............................................ 142

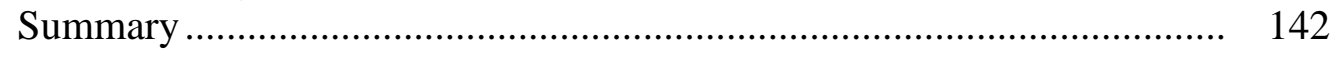

5. SUMMARY, DISCUSSION OF RESULTS, CONCLUSIONS AND RECOMMENDATIONS ............................................................ 144

Introduction and Summary of Study .................................................... 144

Statement of the Problem..................................................................... 147

Purpose of the Study ........................................................................ 148

Research Hypothesis and Objective....................................................... 148

Significance of the Study ....................................................................... 149

Summary of the Literature Review ..................................................... $\quad 150$

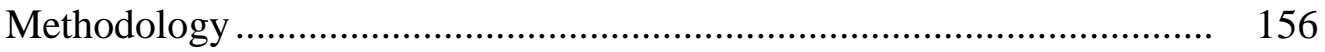

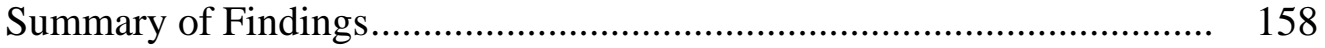

Discussion of the Findings................................................................... 160

Discussion of Hypothesis 1a and 1b Testing Results ........................ 161

Discussion of Hypothesis 2a and 2b Testing Results ........................ 164

Discussion of Immigration/Acculturation Questionnaire

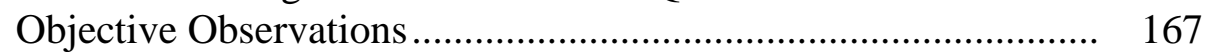

Theoretical Implications ....................................................................... $\quad 170$

Practical Implications...................................................................... 173

Future Implications ............................................................................ 174

Strengths and Weaknesses of the Study................................................. 175

Recommendations .......................................................................... 178

Recommendations for Future Research ........................................... 178

Recommendations for Future Practice................................................ 181

Appendix

A. PROJECTED SEQUENCE OF EVENTS …………................................... 186

B. LETTER TO PASTORS AND GROUP LEADERS …................................... 188

C. CTS2 QUESTIONNAIRE ……………………..................................... 190

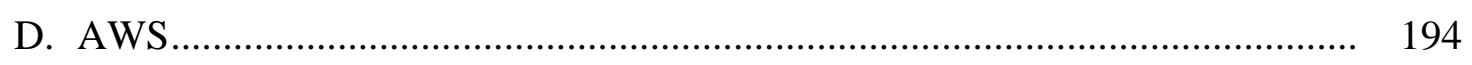

E. IMMIGRATION QUESTIONNAIRE ......................................................... 201 


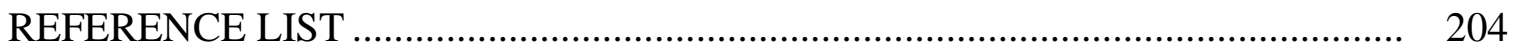

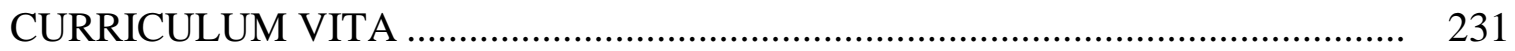




\section{LIST OF TABLES}

1. Dependent and Independent Variable of CTS2 .......................................... 114

2. Frequencies and Percentages of Demographic Characteristics of

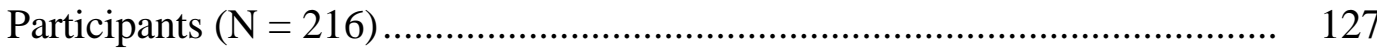

3. Observed Variables Mean and Standard Deviations - African American and African Immigrant.

4. Observed Variables Mean and Standard Deviations - African American and African Immigrant (self)

5. Observed Variables Mean and Standard Deviations - CTS2 Subscale Variables (partner)

6. Adjusted and Unadjusted Group Means for Psychological Aggression Self, and Sexual Coercion Self

7. Adjusted and Unadjusted Group Means for Psychological Aggression Partner, and Sexual Coercion Partner

8. Correlation Analysis between AWS and CTS Total Scores

9. Frequencies and Percentages of Immigrant Questionnaire Responses 


\section{LIST OF ABBREVIATIONS}

$\begin{array}{ll}\text { AWS } & \text { Attitudes Towards Women Scale } \\ \text { CTS2 } & \text { Conflict Tactics Scale } \\ \text { IPV } & \text { Intimate Partner Violence } \\ \text { SPSS } & \text { Statistical Package for the Social Sciences }\end{array}$




\section{ACKNOWLEDGMENTS}

I acknowledge God the Father, Jesus Christ the Son, and the Holy Spirit, for being with me on this long journey. It has been 10 years and 7 months since this trip began. The road was very rough, and the end uncertain, but the Trinity saw me through it all. Glory! Glory!! Hallelujah!!! Amen!!!!

I extend my unreserved appreciation to the chairman of my dissertation committee, Dr. David Sedlacek, for being a loving father to me throughout the journey; thank you and God bless you real good, Sir. My wholehearted gratitude goes to my indefatigable methodologist, Dr. Tevni Grajales; thank you for your cooperation and understanding, Sir. Dr. Boubakar Sanou, the third member of my committee, you were very proactive in responding to me anytime I needed you for guidance; you are indeed highly valued, Sir.

In addition, I express my appreciation to Dr. Perry Downs, Professor Emeritus, my External Examiner, for his wise counsel during the defense. Words are not enough for me to thank and appreciate Dr. Alina Baltazar, my Fourth Reader, for her guidance, Dr. Alayne Thorpe, Dean of the School of Graduate Studies, for gracing the occasion, and Dr. Jasmine Fraser, Convener, Dissertation Defense, for her moral and spiritual supports all through the journey.

I again need to thank you, my wife Oluwasayo Osuntade, for all the sacrifices you made in your life; a loud applause to this supportive woman!!! My children, Martins 
Osuntade, Chelliot Osuntade, and Julianah Osuntade, have been very understanding since we arrived at the United States; God's blessings will be upon you as you plan for your future in the mighty name of Jesus Christ our Lord. Amen. Much resounding applause to my one and only brother, Isaac Osuntade, for your magnanimity towards my wife, our children, and me; God will visit you in a mighty way and give you your heart desires in Christ's name. Amen. My special gratitude is given to my father-in-law and mother-inlaw for being so concerned that I finish this degree. They were always "pestering" me to finish on time. Thank you, Sir and Ma. God will give you more healthy years in Christ's name. Amen.

I say “thank you very much” to Dr. Kathleen Beagles Coneff for her unflinching support. My special dedicated thanks go to Dr. Abiodun Olalere, Dr. Kingsley Chigbu, Dr. Mrs. Ibidun Ukegbu, Dr. Oladapo Oke, Dr. Mrs. Yetunde Oke, Pastor Oludare Olatunji, Pastor Dipo Dada, Brett Kellerdstet, Mrs. Bukky Balogun, Elder Gboyega Adeoye, Elder Taiwo Ayeni, Mrs. Victoria Ayeni, Pastor Dapo Oriola, Mr. Sunday Ola, Mrs. Sola Ola, Elder Samuel Adepoju, and Elder Sandeep Meesarapu, for your full moral and spiritual supports. I appreciate you all. I pray that God will visit all of you with the goodness and mercy of heaven in the Mighty name of Jesus Christ our Lord. Amen.

Last, but not least, I am using this medium to show my appreciation to all the members of Living Springs Seventh-day Adventist Church, Irving, Texas—men and women, old and young, for believing so much in me. Thanks for your generous investments in my wife, our children, and me. God used you to establish us in the United States. Thank you so much. We do not have enough words to show our gratitude. Long live the Living Springs families! Long live the Living Springs Church!! AMEN!!!!!!! 


\section{CHAPTER 1}

\section{INTRODUCTION}

This research was an exploratory comparative analysis of conflict in African immigrant and African American marriages. There is a point of convergence between African immigrants and African Americans through the historical affinity that they share. It has been argued by some African-centered scholars that "...African cultural retention in African and African American marriage and family structure and functioning...” (Dixon, 2017, p. 2) cannot be underestimated. It is very well in order to do an exploratory study of African immigrants and African American marriages together because there is a transfer of African culture from Africa which was

...brought to bear on the business of everyday life in African America, however long the separation from the homeland might have been. The forms of worship, family organization, music, food, and language developed by African Americans in slavery can all be seen to bear the signs of African traditional culture, as can the architecture, art, and handcrafts they left behind (Library of Congress, n.d., para. 5).

In essence, it can be opined that "...to understand African American marriages and families, it is important to first understand African marriages and families" (Dixon, 2017, p. 2). Putting this assertion into proper perspective, Allen and Olson (2001) mentioned that "there is a convincing evidence that ethnicity and culture play critical roles in shaping the relational experiences of African Americans" (p. 303); therefore, in the handling of conduct of marital and family relationships of African Americans and in their effort to devise more proactive ways of clinical care and cure for African American 
marriage and family problems, practitioners “...must be keenly aware of the role that race, class, culture, and socioeconomic conditions and factors play in the lives of African American families" (Rockymore, 2006, p. 7). Hence, relating the word "Afrocentric" to the marital similarities between African Americans and Africans, Stewart (2004) has hypothesized that there are "...cultural connections between African Americans and their African roots. It is those long-held traditions, behaviors, and values that make Afrocentric interventions relevant and appropriate for use with African Americans today” (p. 221). Thus, in their studies, Allen and Olson (2001), suggested that there are three Afrocentric characteristics - extended families, equalitarian relationships, and religious orientationwhich have considerable influence on African American marriage and family (p. 303). Further comparing African American and African marriages and families, Ruggles (1994) has argued that to assess "the origins of the current pattern of African American..." marriage and family composition, “...economic explanations cannot be ruled out," but more than that, "the cultural explanations appear just as persuasive as the economic ones. The experience of slavery and African traditions were probably just as important" (p. 148). As a result, three of the forces that "...account for the forms and manifestation of African American family life as it exists in the contemporary United States [are] “... (1) integration into family life of cultural practices adapted from West Africa; (2) structural adaptations to slavery, especially the disruptions of family ties and the overall lack of control over life; and (3) past and current discrimination and economic inequality" (Barbarin \& McCandies, 2020, para. 2). In view of all the above, understanding African American marriage and family may, therefore, be analogous to understanding African marriage and family. 
It should be noted that the institution of marriage and family is especially important to a peaceful and productive society. The internal dynamics of marriage and family relationships, to an exceptionally large extent, affect the parties involved either positively or negatively. All relationship underpinnings which are laid in the home become an asset or a liability that these parties carry as baggage to bear upon society. Two things are important to note here: First, the effects that couples' relationships have on children, and second, the prevailing attitudes toward women within marriage and family interaction.

Regarding the children, what happens in their parents' relationship affects the formative years of the children, and this multiplies the effects on society. This is confirmed by Futris, Mallette, Schramm, Ahsan, and O'Connor (2016) when they stated that “...conflict between parents does not go unnoticed by children. In fact, parental conflict can impact children's social, emotional and physical well-being" (p. 3). In view of this, more attention should be directed to the care and nurture of this institution in order to ensure that the children who are trained from it become excellent citizens that will contribute to the peace and stability of society.

Regarding females, the prevailing attitude toward women among African immigrants and African Americans is such that sees women as subservient to men. This is the reason why the Attitudes Towards Women Scale (AWS), has been introduced in order to find out whether the way women are treated in the home and society aggravates or mitigates couple conflict, especially to the point of domestic violence. For instance, a reversal in the female role "...particularly in the economic arena, is one of the postimmigration consequences of the acculturation process, which, as exemplified in studies 
of immigrant women in the African community, places immigrant women at an economic advantage over the men" (Kalunta-Crumpton, 2015, p. 2). The resulting effect of this situation is that

...because immigrant women not only access the labor market but may also earn more income than their husbands or may become the sole breadwinner, IPV [Intimate Partner Violence] is triggered or exacerbated as a result of the men's loss of their culturally-ascribed social status, authority and decision-making power previously enjoyed in their country of origin (Kalunta-Crumpton, 2015, p. 2).

Invariably, what is seen about the situation of African immigrants is that their “...gender-based patriarchal culture, when transposed onto a less gender-based patriarchal society, might interact with the patriarchal culture of the new society in a turbulent relationship" (Kalunta-Crumpton, 2015, p. 3).

In essence, some African nations' cultural view of women "...continues to promote patriarchy in many ways and this perpetuates the subordination of women" (Ngubane, 2010, p. 1). For example, in South Africa, serious abuse perpetrated against women is abetted by "...culture and tradition of male dominance. Because women are still refused rights and are seen as inferior to men, they are more likely to be mistreated at the workplace, in the community and at a personal level" (Ngubane, 2010, p.1). Women are apparently seen as being the underdog and are "...viewed as the property of men, first of their fathers and then, when they get married, of their husbands" (Ngubane, 2010, p. $1)$.

In the situation of African Americans, women are not only victims of gender stereotype, but “...black women [also] experience various forms of oppression simultaneously, as a complex interaction of race, gender, and class" (Roberts, 1993, p. 2). 
Jordan (2015) further confirmed the deplorable situation of an average African American

woman:

The most permissible form of violence in communities of color is that against women of color, by men of color (or by white men) with whom the women of color are in relationships. African American women (women of color) live in the dangerous intersection of gender and race. As dual minorities, these women are most likely to live in extreme poverty, in segregated areas, and in poor housing. They are frequently exposed to violence in the home and on the street, in addition to experiencing a series of health problems and social stresses (pp. 15, 16).

Coupled with the problems of gender stereotype and racial issues confronting African American women is the pathway that some African American men are following in recent times; they seem to be abdicating their manly roles as leaders of their homes and families. Because of this, some African American women have no choice but to brace up to the challenges of holding the home together and training the children without the presence of African American men. To buttress this, Malveaux (2008) posited that ....since the 1980s, women head more than 40 percent of African-American families. The majority of African-American children grow up in households headed by women. Part of the reason why African-American households are so often headed by AfricanAmerican women are economic and structural-African-American men are more likely to be unemployed or incarcerated, and are often unwilling or unable to make long-term family commitments based on their economic status. African-American women have had no choice but shoulder the burden of family leadership in the African-American community (para. 9).

According to Duffin (2020), there has been a slight increase in the number of Black families with single mothers in the United States of America since the 1980s; "in 2019, there were about 4.15 million Black families in the United States with a single mother. This is an increase from 1990 levels, when there were about 3.4 million Black families with a single mother" (para. 2).

The conflicting issues characterizing marriage and family dynamics, as well as all the players involved, suggest that there is a dramatic departure from the ideal; marriage 
and family institution should facilitate and enhance peace, joy, and the general welfare of society as originally designed by God and not contribute to chaos and crises in the society. When marriages are consummated between men and women, conflict is natural and inevitable. "All families are assumed to experience frequent conflict. Further, the occurrence of conflict is neither good nor bad; rather, the response to conflict is what determines the long-term vitality and resilience of relationships" (Sillars, Canary, \& Tafoya, 2014, p. 3).

Charny (1980) explained this by saying that "what really becomes important in family life is not the ability to stay out of trouble but to get out of trouble, that is, the ability to process conflicts and dilemmas and unfairness constructively" (p. 43). However, if couples are not in competition with each other, they will engage in cooperation to resolve their conflicts; this is amplified in the words of Deutsch (1973) where he mentioned that "cooperation breeds cooperation, while competition breeds competition" (p. 367). Islami (2017) has also mentioned that,

....in marriages where there is conflict, there are typical examples of interaction, which result in high proportion of negative communicative acts that affect the quality of marital relationships such as: loss of confidence, the emergence of frustration, feelings of anxiety, discomfort, leading to escalation of marital conflicts.

Communication as a variable has a large impact on the resolution of marital conflicts (p. 69).

Negative communication can increase conflicts. Good communication can positively impact marital conflicts. Cooperation, selflessness, compromise, collaboration, negotiation, as well as accommodating each other's needs will help to reduce marital tensions. 


\section{Background to the Study}

African immigrant couple conflict can be looked at from the perspective of issues

confronting immigrants. By and large, it becomes apparent that in America,

...when families undergo the trauma of migration, its effects may be felt in every area of family functioning, especially in the marital dyad. More often than not, the resources available to husband and wife sink, in terms of education, income, property, self-esteem, autonomy, prestige, and all the various ties that comprise marital life (Ben-David \& Lavee, 1994, p. 134).

In another vein, even though African American couples do not experience immigration stressors like African immigrants couples do, Bryant (2010), has identified stressors such as "economic adversity, financial strain, low-income employment, duties/obligations to extended family, presence of children, and racial discrimination/minority status" (para. 8) as stressors contributing to marital tension among African Americans. This is aptly corroborated by Al'Uqdah, Maxwell, and Hill (2016) when they mentioned that

the issue of Intimate Partner Violence [IPV] in the African American community is large and complex. Intimate Partner Violence [IPV] is not attributable to one singular cause but is a product of multiple factors. These factors include: residing in disadvantage neighborhoods, unemployment, low SES, experiences of racism, and the social, political, and historical remnants of racism that have resulted in a process of projective identification within the African American community. Slavery is directly responsible for the social, political, and historical remnants of racism that mediates the impact of environmental risk factors (e.g. disadvantage neighborhoods) and individual risk factors (e.g. Low SES and unemployment) contributing to IPV in the African American community (p. 880).

In addition, marital roles are important to the smooth running of couples' relationships. Due to one reason or the other, it may sometimes be cumbersome for couples to play their roles effectively and to the satisfaction of their partners. When these roles, expectations, and hopes have to take place in a cultural context other than that of the original culture of the couple, more caution is needed. 
The major focus of this dissertation was to do an exploratory analysis of couple conflict among African immigrant couples and African American couples; hence, it is important to define what couple conflict is. Tolorunleke (2014) has explained that couple conflict is

...the state of tension or stress between marital partners as the couple tries to carry out their marital roles. Carrying out these marital roles in a new cultural milieu can be very challenging. Ordinarily, the fact that two people agree or plan to live together as husband and wife calls for different expectations and hopes. Some of these hopes might be fulfilled while others remain unfulfilled (p. 22).

From all the aforementioned, it can be said that issues such as immigration, racism, past historical experiences, ethnicity, and culture, as well as acculturation and socioeconomic status, may cause conflict in a couple's marital relationship; by recognizing these problems, it is possible to move closer to understanding the experiences of African immigrant couples and African American couples. For African immigrant couples to succeed within the North American culture, they need to recognize the cultural values of the new country where they find themselves. A good understanding of the culture of the new country they now live in may help the immigrant couples to navigate the difficult terrains of some aspects of the new country's culture, which may be hostile to having an experience of a great and successful marital relationship. On the other hand, immigrant couples may also be able to learn things from the cultural values of the new culture that could promote marital stability.

Put differently, the ability of immigrant couples to be able to cope in a new culture will go a long way in helping them deal with marital conflicts. For instance, African immigrant couples who are coming from a communal cultural set up may learn that one of the cultural contents of the United States, that is, individualism, may be 
detrimental to their marital relationship, especially within the context of social support which is needed in marital conflict mediation as it exists in Africa. As Arthur (2000) has explained,

the immigrant families replicate African kinship structures that are central to their survival in the United States. They tend to cluster in particular neighborhoods for collective security in dealing with the problems of daily living. Bonds are fostered, friendships renewed, and goals and values reaffirmed (p. 112).

On the other hand, since in most parts of Africa, "marriages are not egalitarian, as husbands have more power" (Ngazimbi, 2009, p. 15), African couples may learn that the cultural principle of patriarchal domination, as obtainable in most of the African cultural context, may not be applicable in America, and hence, learn in their marital relationship that the principle of egalitarianism, as obtainable within the American cultural milieu, may engender marital peace. For instance, Arthur (2000) affirmed that when African couples arrive in America,

...the women redefine their roles to assert a measure of autonomy and independence from their husbands. The dominance of husbands and brothers is considerably diminished; the majority of the women no longer allow their husbands to claim the rights of dominance that the patriarchal system confers on males in Africa (p. 112).

For African American couples, there must be a conscious recognition that their past history, which serves as a facilitator in reference to their present struggles in society, must not be allowed to brew marital conflicts. There should be renewed interest that will create opportunities "to highlight how African American couples can address unique challenges while simultaneously sharing strategies that have worked through generations to support healthy African American marriages" (Bent-Goodley, 2014, para. 12).

It is interesting to note that "Black Africans are among the fastest-growing groups of US immigrants" (Capps, McCabe, \& Fix, 2012, p. 1); thus, "contemporary migration 
from sub-Saharan Africa to the United States, which is a relatively recent phenomenon, has risen steadily over the past several decades" (Zong \& Batalova, 2017, para. 1). Generally speaking, the new life of immigrants in America exposes them to a new reality that they have to adjust themselves to "...changes in regards to family arrangements, the division of labor, and gender roles within families. While family roles are renegotiated in the United States, immigrant parents strive to retain their specific cultural understandings, symbols, and meanings of their homeland" (Podgorski \& Rumer, 2009, p. 12). For instance, Kibria (1993) observed that the "Vietnamese American women worked hard to incorporate the new realities of their lives into the ideological confines of the traditional family system... (p. 109). This poses arduous challenges as “...they walked an ideological tightrope-struggling to take advantage of their new resources but also to protect the structure and sanctity of the traditional family system" (Kibria, 1993, p. 109).

Amidst the tensions, immigrants should be cognizant of the fact that their ultimate goal as immigrant couples, coming into a new cultural context, should be for husbands and wives to fulfill their marital roles in a way to bring about marital satisfaction for one another; therefore, it is pertinent that immigrant couples have open minds to embrace new cultural realities, and at the same time, be mindful of what can adversely affect their marital relationships. For example, one of the cultural realities of African immigrants in a new culture is the absence of kinships; therefore,

the absence of immigrants' close kin in the new setting creates the need to improvise new arrangements, a reason why "fictive kin" are common in immigrant communities and why men sometimes find themselves filling in as helpmates to their wives in childcare and other household tasks (Foner, 1997, para. 9).

One of the hardest realities that may be faced by African immigrants is "immigrant women gaining authority in the household and increased leverage in relations with their 
spouses now that they have greater opportunities for wage employment and contribute a larger share of the family income in the United States" (Foner, 1997, para. 9). Foner also said that by and large, apart from the "...cultural or sociodemographic features of the immigrant group, external forces in the new environment shape immigrant family lives as they provide new opportunities and constraints as well as new sets of values, beliefs, and standards...” (para. 9). All these may be used to the advantage of engendering marital satisfaction.

\section{Statement of the Problem}

There has been a high level of marital conflict in immigrant families from patriarchal cultures. There are negative attitudes toward women that contribute to couple conflict. In the same vein, African American couples experience conflicts that militate against the stability of their marriages. With regard to couple conflict, a better understanding of the challenges facing African immigrant couples and the impact of the African heritage on African American couples are germane to this study.

\section{Purpose of the Study}

The purpose of this research was to identify which of the CTS2 subscales would be highest and lowest among African American and African immigrant couples with AWS serving as a covariate. Whether scores on the AWS interacted with the relationship between groups and scores on the CTS2 was also explored. The study further examined the impact of acculturation and immigration on African immigrants' ethnic groups. It was hoped that examination of these variables would contribute significantly to better strategies for family life education and marital counseling among African immigrants and 
African American families in North America.

\section{Rationale for the Study}

Before I came to the United States of America in 2005, I was completely oblivious to the intensity of couple conflict. I did not get involved in incessant mediations of couple conflict in my ministry back in my country; this is not to confirm that conflicts were not present among couples in Nigeria. I think it may be a big issue that may not be recognized as such because of the way couples are taught to relate to conflict or cultural norms that regulate spouses' expression of their feelings in conflicting situations. For instance, Halim, Steven, Reich, Badi, and Messersmith (2018) found in their research that "Tanzanian women may not disclose victimization fearing blame, shame, divorce, abandonment, and loss of the custody of children...” (p. 4). McCleary-Sills, Namy, Nyoni, and Rweyemamu (2016) further explained that “. . . at the core of this is a sense that women are at fault for any violence they experience because they have somehow provoked their partners into beating them" (p. 229). In addition, Halim et al. (2018) posited that "women fear that Intimate Partner Violence [IPV] signals to society that women have failed in their role as a wife and mother, bringing shame to women and their families. Women fear additional negative repercussions of reporting Intimate Partner Violence [IPV], including divorce, abandonment, loss of custody of children, loss of support, and violence escalation" (p. 4). It is, therefore, a possibility that such sociocultural issues as identified above hindered reporting of marital problems back in Africa.

On my arrival in the United States in 2005, I became overwhelmed by having to mediate between African couples who had very serious conflicts. Some of these conflicts 
led to domestic violence, abuse, separation, and divorce. As the years rolled by, I became aware of more conflicts among African immigrant couples in North America that needed intervention. This still persists to the present time. As mentioned above, couple conflict back in Africa was not as pronounced within the context of Africa where I came from, but among African immigrant couples who come here, it seems to be a normal thing. The reason for this may be associated with the assumption that "...these marital problems are the results of cultural dissonance due to the immigrant couples' exposure to a new cultural set up" (Musyoka, 2014, p. 1). Every other problem that comes up may be linked to this. This is the first issue that informed my decision to carry out this research on African immigrant couples.

The reason why African American couples have been added to this study is because of the experiences I had with them. I worked with African Americans for eleven years and I saw the struggles they passed through to keep their marriages; this was especially true with more of the women than the men. I had discussions with some of them who wanted very desperately to trace their roots back to Africa. This is the second issue that informed my decision to add African American couples to this study.

\section{Significance of the Study}

There is a need to build on existing information and further develop a knowledge and an understanding of both African immigrant families and other minority immigrant families. It is also important to examine the challenges that may incite conflicts among African American couples in comparison to African immigrant couples. Because the health of marriages and families is very central to the health of society, information from this research may help to increase the knowledge that can be garnered and used to 
reshape frameworks, theories, and research methods in the study of marriage and family relationships, especially in curtailing couple conflict before they escalate into uncontrollable violence. This study may be a useful source of information for the various categories of marriage and family resource professionals who are involved in helping to form policy and implement decision-making on the marital and family needs of these two groups of people.

\section{Conceptual Framework}

The conceptual framework of this study was based on two theories: conflict theory and catharsis theory. After World War II, the proponents of conflict theory “...drew on Max Weber and (to a lesser extent) Karl Marx to construct their arguments, giving differing emphases to economic conflict (Marx) and conflict about power (Weber)" (Overview: Conflict Theory, 2018, para. 1). Through observing the world and human relationships, economic conflict and power struggles, Karl Max and Max Weber suggested that conflict has become an inevitable part of human existence. "Conflict theorists emphasized the importance of interests over norms and values, and the ways in which the pursuit of interests generated various types of conflict as normal aspects of social life, rather than abnormal or dysfunctional occurrences" (Overview: Conflict theory, 2018, para. 1).

To further buttress this point, Rubin, Pruitt, and Kim (1994) described conflict as “...perceived divergence of interest, or a belief that the parties' current aspirations cannot be achieved simultaneously" (p. 5). The situation described by this definition is normal in society. There will never be a time when all people will coherently reach a point of convergence. Due to this fact, 
...conflicts really are inevitable. However, they should not in all cases be regarded as dysfunctional, or as a kind of social pathology. Conflicts are of many different types, some functional, some dysfunctional. Some conflicts are harmful, but, in some cases, conflicts may improve society and social relations on a long-term basis (Björkqvist, 2009, pp. 26-27).

In another vein, "Sigmund Freud was the first to use catharsis theory in psychological therapy. The theory states that expressing or getting out one's aggression and anger should reduce the feeling of aggression" (Olsen, 2018, para. 4). The word "catharsis" (katharsis, Greek) literally translated, means “...a cleansing or purging” (Bushman \& Phillips, 2002, para. 1). Catharsis theory, which can also be called "hydraulic models" or "ventilation theories" as explained by Straus (1974),

...assumes that all of us have built into our nature a greater or lesser tendency toward aggression which cannot be bottled up. According to these theories, if we attempt to repress this deep biologically based motivation, it will only result in a more destructive explosion of the innate aggressive drive at some later time. Hence, it is important to let it out. It is better to have a series of minor explosions than to let them accumulate into the equivalent of thermonuclear bomb (p. 14).

Couple conflict is the main concern of this study, and hence, it is assumed that conflicts cannot be avoided in close relationships such as couples' relationships. According to Fincham, Bradbury, and Grych (2014), “all close relationships involve some underlying conflict of interest insofar as partners do not share all the same goals and even goals that are shared are not likely to be identical in every respect" (p. 175). Inasmuch as conflict is ubiquitous to human relationships, what this study, together with one of the instruments used, the Conflict Tactics Scale (CTS2), seeks to focus on is how couples respond to conflicts when they arise. Couples' responses to conflicts will determine the outcome of conflicts. This concept supports catharsis theory which suggests that it is healthy for couples not to bottle up how they feel when conflicts arise; rather, they should let it out and be relieved. How couples let out their feelings is also 
very central to what comes up after letting out those feelings. This is aptly summarized in the words of Segal and Smith (2018):

The key is not to avoid conflict but to learn how to resolve it in a healthy way. When conflict is mismanaged, it can cause great harm to a relationship, but when handled in a respectful, positive way, conflict provides an opportunity to strengthen the bond between two people. Whatever the cause of disagreements and disputes, by learning these skills for conflict resolution, you can keep your personal and professional relationships strong and growing (para. 1).

The CTS2 instrument has five subscales, which are negotiation, psychological aggression, physical assault, injury, and sexual coercion. Using the CTS2, this study sought to measure the frequency of conflicts in relation to these five subscales. "Couple conflict is an important antecedent of domestic violence, ineffective parenting, and marital dissolution... Not all couple conflict is damaging; constructive conflict and negotiation is beneficial for relationships" (Booth, Crouter, \& Clements, 2009, p. viii). Thus, based on conflict and catharsis theories, it is apparent that it is not the existence of couples' conflicts that should be a major concern,

...but how they are expressed and resolved...Some couples handle differences and conflicts constructively, by either negotiating and agreement or agreeing to differ...With other couples, differences remain unresolved and act as continual irritants, the conflicts recycle and escalate, and eventually lead to an atmosphere of constant tension... This may cause one or other partner to periodically explode with hostile anger, or to increasingly withdraw from the relationship. Both responses are very destructive to the future of the relationship and may threaten the continuance of the marriage and lead to divorce (Ooms, 2009, p. 227).

Thomas-Kilmann conflict modes (Figure 1) corroborated the fact that an individual's response and behavior during conflict is very fundamental to the result of that particular conflict. It "describes an individual's behavior along two dimensions: (a) assertiveness, the extent to which the person attempts to satisfy his own concerns, and (b) cooperativeness, the extent to which the person attempts to satisfy the other person's 
concerns" (Finepoints, 2015, para. 5). Understanding these conflict modes encourages couples not to take the route of assertiveness when conflict arises; rather, they are encouraged to take the route of cooperativeness. Cooperativeness in handling couple conflict will breed compromise, collaboration, and accommodation, as opposed to assertiveness, which will breed avoiding and competition. By and large, the ThomasKilmann conflict modes concept is supported by the CTS2, one of the instruments which this study uses: namely, that negotiation in couple conflict may become a catalyst to peace and harmony through the use of cooperativeness.

Conflict is inevitable in couple's relationship; the skill to manage it should be acquired so that society will not be plundered into chaos and crises due to restlessness in marriages and family circles. When marriage and family relationships are not violenceinfested, it will have a direct harmonious effect on the community.

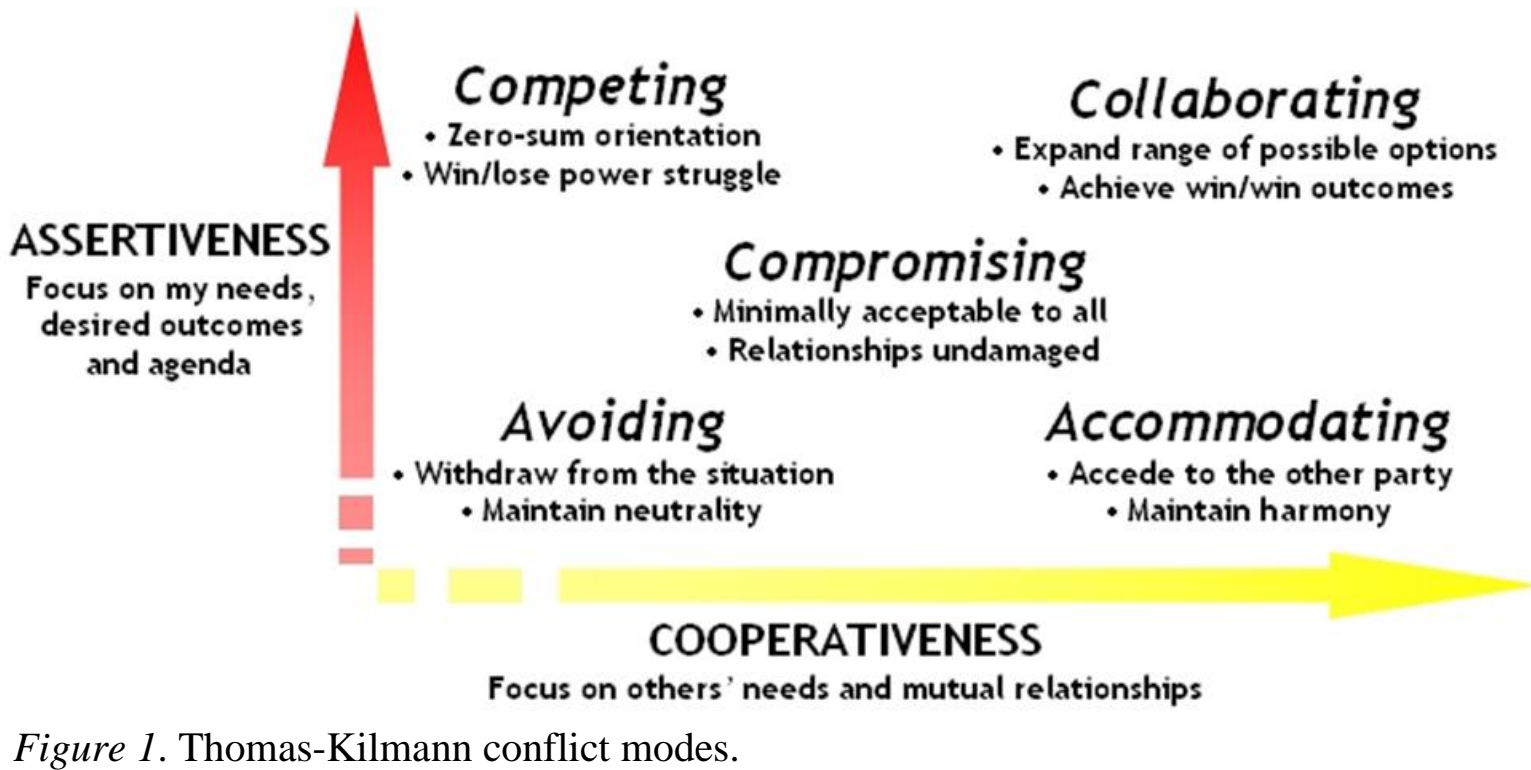




\section{Brief Developmental History of Conflict Tactics Scale (CTS2) and Attitudes Towards Women Scale (AWS)}

At this juncture, it is important to give a brief developmental history of the CTS2 and AWS.

\section{Conflict Tactics Scales}

It was developed by Murray Straus in 1979. They are "designed to measure the use of reasoning, verbal aggression, and violence within the family" (p. 75). This scale is popularly used in family conflict research. There have been many different versions of the CTS used in various studies “....involving more than 70,000 participants from diverse cultural backgrounds" (Straus, Hamby, Boney-McCoy, \& and Sugarman, 1996, p. 284).

\section{Attitudes Toward Women Scale}

It was developed in 1972 by Spence and Helmreich. The AWS, which is subtitled “"An Objective Instrument to Measure Attitudes Toward the Rights and Roles of Women in Contemporary Society,' appeared at a time when the influence of the women's movement in encouraging psychological research relevant to gender was becoming visible” (Spence \& Hahn, 1997, p. 17).

\section{Research Questions}

This study seeks to answer the following research questions:

1. Which of the CTS2 subscales will be highest and lowest among African American and African immigrant marriages?

2. Do scores on the AWS interact with the relationship between groups and scores on the CTS2? 
3. How do participants in the African immigrant group respond when asked, in a separate multiple-choice questionnaire, how they think their marriage has been affected by immigration stress and acculturation, and what they think specifically caused those problems?

\section{Limitations}

I found out while trying to apply the study, that, because of the sensitivity of the instruments, very few people responded to the survey. Out of about 1,117 samples who received the SurveyMonkey generated link containing the questionnaires, only 216 respondents-118 of the African immigrants' ethnic group and 98 of the African American ethnic group-responded to the survey.

The resultant effects of the sensitivity of the instruments were reluctance and refusal of the respondents in filling out the questionnaires, as well as the enormity of time and travel expenses I needed in looking for respondents. Various church and group leaders consulted promised to help administer the survey to their members, but most members of these churches and groups finally declined or delayed in responding to the survey. It took about 10 months of travelling back and forth before I was able to secure the 216 responses for this study.

\section{Delimitations}

The sample was delimited to married heterosexual couples in the African American ethnic group and the African immigrant ethnic group in an acculturation process who were living in North America. 


\section{Definition of Terms}

CTS2. The Conflict Tactics Scale is an instrument used to "...measure both the extent to which partners in a dating, cohabiting, or marital relationship engage in psychological and physical attacks on each other and also their use of reasoning or negotiation to deal with conflicts" (Straus, Hamby, Boney-McCoy, \& Sugarman, 2018, para. 8). When it was first constructed by Straus Murray in 1979, it was called CTS; however, it was revised and renamed CTS2 in 1996 to "... improve the original version [that was] criticized for measuring acts out of context" (Straus et al., 2018, para. 2). The CTS2 has five sub-variable components which are defined below:

Negotiation. This is defined as "....actions taken to settle a disagreement through discussions" (Straus et al., 1996, p. 289).

Psychological aggression. It is defined as “...the use of verbal and nonverbal acts which symbolically hurt the other, or the use of threat to hurt the other" (Straus, 1979, p. 77).

Physical assault. It may include “.... a range of behaviors from slapping, pushing or shoving to severe acts such as being beaten, burned, or choked (Black et al., 2011, p. $37)$.

Sexual coercion. This is a “...behavior that is intended to compel the partner to engage in unwanted sexual activity" (Straus et al., 1996, p. 290).

Injury. This is “...partner-inflicted physical injury, as indicated by bone or tissue damage, a need for medical attention, or pain continuing for a day or more" (Straus et al., 1996, p. 290). 
AWS. The Attitudes Toward Women Scale is considered to be “...the most widely used instrument to assess attitudes about women's right and roles in society. It was developed in 1972 as a 55-item, self-reported instrument and was subsequently reduced to 25, 21, and 15 items" (Jaruseviciene et al., 2014, p. 2).

Conflict. This word can be used in a sociological context. It views society as a place of friction and unhealthy competition. There are obviously winners and losers who will always emerge from this brawl, and this normally results in “...disastrous and tragic consequences for the losers... People are tortured, mutilated, and incinerated as a consequence of social conflict; they are also shunned, humiliated, exploited, and otherwise systematically shortchanged by the social structures they take part in" (Simon, 2016, para. 3).

Marriage. "Marriage was divinely established in Eden and affirmed by Jesus to be a lifelong union between a man and a woman in loving companionship" (Seventh-day Adventist Church, 2020, para. 1). This definition is in consonance with Gen 2:24 which establishes that "a man shall leave his father and mother and be joined to his wife, and they shall become one flesh" (NKJV).

Ethnicity. Glazer, Greeley, Patterson, and Moynihan (1974) have described ethnicity as "... a form of group alliance, it denotes a kind of personal identification involving a set of symbols or traits which serve as the basis for this identification (p. 11).

Catharsis. This word (katharsis, Greek) literally translated, means “...a cleansing or purging” (Bushman \& Phillips, 2002, para. 1). 


\section{CHAPTER 2}

\section{LITERATURE REVIEW}

\section{Introduction}

\section{African Immigrants}

There are 54 sovereign countries in Africa today that are recognized by the United Nations. There are also over 1000 official languages spoken across the African continent (Moafrika Tours, 2020, para. 1). A look at this huge diversity may make one query the broadness of studying African immigrants who live in North America and who have come from this largely diversified continent. However, ethnographic studies of subSaharan African societal culture seem to suggest a high degree of homogeneity in the cultural dimensions among cultures in this very diverse continent, particularly from where the respondents of this study migrated. For instance, "in the United States of America (USA), research suggests that African Americans, Caribbean Blacks and African immigrants have communalist value orientations" (Burholt, Dobbs, \& Victor, 2017 , p. 4). This is very true because collectivist cultures originated from Africa and the Caribbean, and these cultures may be described as communalist (Burholt et al., 2017, p. 4).

To corroborate this point further, evidence of this cultural homogeneity is drawn from the findings of the GLOBE Sub-Saharan Africa cluster consisting of Namibia, 
Zambia, Zimbabwe, Nigeria, and South Africa (these countries were the Black sample),

where researchers found that

The societies belonging to this cluster reflect high scores of the societal cultural practices on the dimensions of In-Group Collectivism and Power Distance (i.e., the degree to which the community accepts and endorses authority, power differentials, status privileges, and social inequality). They were also found to be low on Gender Egalitarianism dimension (in these cultures, women generally have lower status at work and in the culture). Overall, these societies maintain close family ties and individuals' express pride and loyalty in organizations and family. Members of these societies do not expect power to be distributed evenly among citizens, nor do they have gender equity. (GLOBE, 2020, Sub-Saharan Africa section, para. 1)

The distinct similarities among the sub-Saharan African cultures in the three dimensions of in-group collectivism, power distance, and gender egalitarianism suggest a high degree of similarities in these cultures, especially as these dimensions have a direct impact on family relationships. This evidence supports the inferences that may account for similarities in family experiences among these immigrant groups in North America. In view of the apparent similarities among sub-Saharan cultures, it may be safe to submit that studying the marriages of African immigrants' population in North America may not be too broad; as a matter of fact, this may engender convenience in the data analysis and interpretation of findings of this study.

African immigrants come to the United States from what may be defined as the five regions of Africa: Eastern, Western, Northern, Southern, and Central Africa. They all bring with them their different cultural heritages (Nyamwange, 2014, p. 43). Some of these Africans come to study, some come to visit, while some come to conduct business. However, in recent times, not all Africans who come to North America want to go back home: many prefer to stay here for a variety of reasons.

Some of these Africans come with their family members; others come as singles 
with the intention of going back to Africa at a later time to bring their spouses. In other cases, singles may decide to select their spouses from among a wide variety of different nationals, races, and cultures in the United States. Some of them may also marry someone here in the United States who comes from their home country and cultural backgrounds (Swaray Law Office, 2010, para. 1).

According to Capps et al. (2012), "Black African immigrants represent one of the fastest-growing segments of the U.S. immigrant population, increasing by about 200 percent during the 1980s and 1990s and by 100 percent during the 2000s" (p. 1). They mentioned that "black Africans are much more likely than other groups to have entered the United States as refugees or gained asylum after coming to the country" (p. 6). Why is the United States becoming a place of attraction to Africans? This is obvious for two reasons: first because of war, and second, to seek better living conditions (Solomon, 2017, paras. 1, 11).

African immigrants do not find things easy coming to a new culture; they “...encounter many stressors as they begin to adapt to American life ... Africans, like other immigrants, experience a deep sense of loss of their culture" (Kamya, 2005, p. 103). For example, what is opined about many Kenyan immigrant couples is generally true of other African immigrants, and it is that

many Kenyan couples immigrating to the United States appear to be overwhelmed as they grapple with marital and family issues often occasioned by the new environment. Having been isolated from their Kenyan cultural environment, the immigrant couples lack the marital checks and balances that made their marriages work before they immigrated and apparently fail to maintain their traditional ways as the host culture impacts their lifestyles and worldviews. After living in the United States for a number of years, hence, many Kenyan immigrant couples eventually succumb to the influence of American culture in positive and negative ways (Musyoka, 2014, p. 2). 


\section{African Americans}

African Americans have a history that is characterized by servitude. Putting this in a proper perspective, “the overwhelming majority of today's African American population traces its ancestry to the slave trade from Africa" (U.S. Department of Health and Human Services, 2001, para. 4). In view of this, therefore, it can be posited that it is this “...historical adversity, which included slavery, sharecropping, and race-based exclusion from health, educational, social, and economic resources [that has translated] into the socioeconomic disparities experienced by African Americans today" (Office of the Surgeon General (US) et al., 2001, para. 31). In order to reinforce the current influence of this historical adversity on African Americans, Halloran (2019) explained that "the impact of slavery was a significant trauma to African American people, which was carried forward through successive generations, providing an explanation of their current anxiety-related conditions, poor health, and maladaptive behaviors" (p. 45). In essence, with the current socioeconomic and political contexts of America, it is apparent that African Americans are still not at par with some other population groups. Even though the U.S. Senate, Joint Economic Committee (2020) opined that "over the past half-century, Black Americans have made substantial social and economic progress, gaining political rights that long had been denied to them...However, very deep social and economic inequities persist” (pp. 1, 27). And this cannot be divorced from the impacts of their long historical antecedents of slavery.

African Americans are "one of the largest of the many ethnic groups in the United States. African Americans are mainly of African ancestry" (Lynch, 2018, para. 1). The 
first set of Africans arrived in the new world, that is, the present-day United States, in 1619. That took place

...when a handful of captives were sold by the captain of a Dutch man-of-war to settlers at Jamestown. Others were brought in increasing numbers to fill the desire for labor in a country where land was plentiful and labor scarce. By the end of the 17th century, approximately 1,300,000 Africans had landed in the New World. From 1701 to 1810 the number reached 6,000,000, with another 1,800,000 arriving after 1810 (Drewry, 2018, para. 2).

The African American history contributes to the way their worldview has been shaped; it also adversely affects the way they live and relate in the society. This is because the "cultural psychology of African Americans is critically affected by their systematic dehumanization over centuries; [therefore,] "the motivational goal of African American behavior and perception could be described as re-humanization and self-esteem protection and maintenance" (Jones \& Campbell, 2011, p. 7). According to Iheduru (2006), the fact that these cultural, racial, and religious values inherited by African Americans from Africa “... still find expressions in the lifestyles of diasporic Africans in the United States, Cuba, Brazil, the Caribbean, and Latin America...” (p. 218) suggests that the African American worldview may be linked to their past experiences.

Apparently, this history also has a retrogressive effect on the marriage and family life of this group of people. For instance, Williams (2010) has suggested that "...slavery not only inhibited family formation but made stable, secure family life difficult if not impossible" (para. 2). Thus, the present general condition of African American marriages and families cannot be dissociated from the past historical issues that accumulated over time as a result of the historical and contemporary experiences of this group of people. In exploring the "...uniqueness of African American couples and families both from a historic and contemporary systems perspective" (Kelly, Maynigo, Wesley, \& Durham, 
2013, p. 264), it can be safely concluded that the “...historical and present day ecological systems such as structural racism that impact African Americans, and African Americans' strengths..." (Kelly et al., 2013, p. 264) may constitute some of the factors affecting their marriage and family dynamics and how long the marriage and family bonds endure.

It is assumed that conflicts do not arise without any reason; hence, for African American couples, the historical experiences of their background(s) in America, coupled with “...contemporary stereotypes and myths may inhibit African Americans from having healthy..." (Dixon, 2017, p. 168) marital relationships, which may in turn engender couples' conflicts.

Dixon (2017) painted a very comprehensive and graphic picture of African American experiences and how these experiences have affected and are still affecting their communal relationships, as well as their interpersonal marriage and family relationships. This, to a great extent, has made their story very distinctive when compared with other people groups living in the USA:

Although African Americans share similarities in their relationships, marriages, and families with other ethnicities comprising American families, they have sociohistorical and cultural experiences that make theirs different. They experienced 250 years of slavery, torture, terrorization, segregation, and institutional racism. Because of these different socio-historical experiences, some factors may linger in their reality that affect how they interact in relationships, which subsequently affects the formation or non-formation of marriages and families and whether they last. There is also current racial discrimination that may not be as blatant as it was in the past but still permeates throughout U.S. society in various forms in subtle ways whether intentional or unintentional. In addition are culturally specific factors unique to African Americans that stem from their African heritage. These socio-historical and cultural factors place African Americans' relationships, marriages, and families in a unique position in U.S. society and they are affected in different ways (p. xi). 


\section{Africans and African Americans Cultural Affinities}

It is important to state here that the historical affinities between these two ethnic groups cannot be overemphasized since they share the same historical roots, it should be expected that their perception of marriage and family relationships may have some resemblance even though the African Americans have been long departed from the African cultural milieu. The cultural affinity between Africans and African Americans has provided a concrete background for African Americans' history. For instance, Iheduru (2006) opined that “...lacking this proud ethnic and national origin history, African Americans have been rootless and drifting as they were shorn of the solid anchors of personal and group identity on which to hitch the aspirations and accomplishments that would, in turn, sustain their history" (p. 217). This affinity is further revealed when

...many African Americans, descendants of forced migrants, look to Africa to know about their past and develop a transnational consciousness to their ancestral home. African Americans have a rich history of engagement with Africa that is evident in their collective memory (Pendaz, 2010, pp. 31-33).

Finally, in order to strengthen the evidence of the Africans and African Americans Cultural Affinities, "scientists from the consumer genetics company 23andMe have published the largest DNA study to date of people with African ancestry in the Americas” (Kenneally, 2020, New York Times, headlines). The researchers “... analyzed genotype array data from 50,281 research participants, which-combined with historical shipping documents-illustrate that the current genetic landscape of the Americas is largely concordant with expectations derived from documentation of slave voyages" (Micheletti et al., 2020, p. 265). The result of the research showed that "overall, genetic evidence of Atlantic African ancestry across the Americas is consistent with historical 
documents of the transatlantic shipping of enslaved Africans" (Micheletti et al., 2020, pp. 270-271). In view of all the aforementioned, the historical affinity between Africans and African Americans is incontrovertible.

In addition, there is a theoretical concept that explains a resemblance of African American marriage and family to that of the Africans. This is referred to as the ““...Africanity” model. The underlying tenets of this model are that African traits were retained and are manifested in black styles of kinship patterns, marriage, sexuality, and child rearing" (Hudgins, Holmes, \& Locke, 1990, p. 2). The affinity between African American and African marriage and family set-up is reinforced by the Africanity approach to the study of the Black family; it

...suggests that among the African patterns that were transplanted and transformed by Afro-American slaves were consanguineal kin groupings ("kin networks"), husbandwife relations, sibling bonds, socialization practices, patterns of exogamy, marriage rules and rituals, naming practices, relationships between alternate generations (i.e., grandparents and grandchildren), patterns of respect and deference, and the extension of kinship terminology to elders throughout the community (Sudarkasa, 1980, p. 37).

There may appear to be a disconnect between the Africans and African Americans as a result of some obvious factors. As a matter of fact, research reveals that "in spite of their common ancestry, Africans and African Americans remain separated by myths, misperceptions, and negative stereotypes" (Traoreé, 2003, pp. 243-254). However, the factors that separate them may not be as powerful as the common root that bond them together. With the common heritage that African Americans share with the African continent, it is safe to conclude that "the current family formation of many black Americans is the culmination of vestiges of a pre-slavery West African heritage, the system of chattel slavery, social class, and acculturation into Euro American culture" (McAdoo, Younge, \& Getahun, 2007, p. 95). 


\section{Literature Review: Areas of Coverage}

This review of related literature explored the following areas of study as they relate to family, marriage, couple's relationship, couple's conflict, and immigration experiences:

1. Theological foundations of marriage

2. An overview of conflict and catharsis theories

3. A brief exploration of what conflict is: Biblical and contemporary insights

4. Support system for Africans' and African Americans' marriages and families

5. Cohabitation, divorce and decline in marriage among African Americans and African immigrants

6. A discussion of the possible causes of couples' conflicts

7. Levels of couples' conflicts: from mild to severe

8. Whether religiosity and spirituality levels of couples mitigate or aggravate conflicts

9. Findings from some studies that have used the CTS2

10. Findings from some studies that have used the AWS

11. Conclusion

\section{Theological Foundations of Marriage}

Before expounding on the theological foundation of marriage, it is important to give a biblical definition of marriage. God's original blueprint of marriage is found in Gen 2:24 where God joined Adam to Eve; that is, the union of one man and one woman. Genesis 2:24 established that "... a man shall leave his father and his mother and hold fast to his wife, and they shall become one flesh" (ESV). In Mal 2:14, marriage is described 
as a covenant. In essence, since marriage was established by God, it is a covenant between Him (God), the husband, and his wife.

According to Hammer (2011), the family was God's idea. It was the first institution He ever created, and it is a gift with which humanity has been blessed. Since God is the Architect of marriage, it has been confirmed that "from the beginning of time, the marriage relationship has been central to God's revelation of Himself as a God of community and a God of redemption" (p. 107). In giving the institution of marriage to humanity as a gift, God demonstrated His interest in establishing a community of people who will share, interact, and help one another in a way that will show forth the glory of God. It becomes apparent, then, what God meant when He observed the following: “...It is not good for the man to be alone; I will make him a helper suitable for him" (Gen $2: 18)$.

At this point, it is good to put emphasis on the fact that marriage was specifically instituted by God for relationships. A genuine display of love, with the maintenance of cordial relationship among humanity, is a central theme in the Bible beginning in Genesis and culminating in Revelation. God designed man and woman for relationships with Him and other fellow human beings. Hammer (2011, p. 106) reiterated that the Bible in its entirety educates us on how to maintain relationships with God and with our fellow human beings. This shared relationship was enunciated by Paul when he said: "As it is, there are many parts, but one body. The eye cannot say to the hand, 'I don't need you!' And the head cannot say to the feet, 'I don't need you!' (1 Cor 12:20-21). We are indeed created for relationships! Garland (2012) summed it up in this way:

The goodness of God's creation, when it comes to people, is found in the potential and need for our relationship with one another. It is "not good" for us to be alone. 
God created in us a need for intimate relationships, a need that draws us to leave the persons from whose bodies we have come-our parents-to form a new "body" with a new partner (Genesis 2:23-24). Being family means sharing the same ribs; the same flesh... (p. 92).

God's plan in creating male and female in a complementary relationship achieves the purpose of interdependence and cooperative interaction among people. The idea of relationships in a communal society points to the establishment of a strong bond among humanity; this idea is facilitated when members of a community coexist together mutually and are always willing to be genuinely concerned about the welfare of others within a communal society. This peaceful co-existence has to begin from the various families that constitute society. The idea of relationships here is not to exclude or ignore non-familial relationships; rather, God's intention is that the depth of bonding in familial relationships equips family members to develop empowering relationships with one another and with those in the wider human community (Balswick \& Balswick, 2014, pp. $8,21)$.

Each family constitutes the basic building block of the society. As long as a family is groomed in such a way as to become others-centered, the people who are raised in such a family will go out into the community to network with others who belong to different families, thereby making society a place where everyone selflessly seeks to look after the welfare of the others. The intention of God, accordingly, is to create pockets of Christian families all over the world, which will attract others who are outside this big family into God's family as a result of genuine and sincere love being displayed to one another by members within (John 13:34-35). The world will become a better place to live in if, inside all the families of the world, the members being reared there become selfless, 
not only to family members within, but also to others outside the circle of their immediate family (Garland, 2012, pp. 102-103).

The emphasis in the Bible about marriage relationships is that "for Adam no suitable helper was found" (Gen 2:20b). When God described Adam as being alone and that there was no suitable helper for him, it was because there was obviously no human community for him to interact with (Nwaomah, 2012, p. 17). According to Coogan, Brettler, Newsom, \& Perkins (2001), “Adam presumably realized that a companion appropriate or suitable for him was absent, and that the need for a suitable companion as a wife was apparent" (p. 14). After Eve was created for Adam by God, they enjoyed a season of marital peace before the impostor came to intrude upon their peaceful coexistence; since then, they started living a life full of conflicts; this has been extended to generations after them.

A brief exegetical study of Gen 3:16 is important at this point because the position and the role of women in the home and in society is controversial especially in the wake of the development of the feminism movement around the world. In looking critically at Gen 3:16, I believe that it is both a divine prescription for the consequences of sin and a divine description of what the fallen world would look like after sin. It is important first to consider this sentence, "And thy desire shall be to thy husband," as a divine prescription which suggests that in spite of the entrance of sin, the woman's desire would still be for her husband in other to perpetuate the needed intimacy between husband and wife so that God's purpose for marriage will still be fulfilled. For instance, Brown, Driver, and Briggs (2007) exegeted the Hebrew word for "desire" as used in Gen 3:16, Song 7:10, and Gen 4:7 in this way: “'teshuqah' means 'longing': a longing of woman 
for man in Genesis 3:16; a longing of man for woman in Song of Solomon 7:10; and, figuratively, a longing of a beast (representing sin) to devour Cain in Genesis 4:7” (p. 1003). Since the word "desire" is "'Teshuqah' derived from a stem 'shuq' which means 'attract, impel, of desire, affection' (p. 1003), the context of Gen 3:16 can be interpreted to mean that the word "desire is not a curse to dominate the husband, but it is a blessing of intimacy the woman will continue to have toward her husband, even though sin has entered the world" (Peterson, 2013, p. 13). This point was commented on more fully by Busenitz (1986):

The "desire factor" is not a part of the judgment but an explanation of conditions and relationships as they will exist after the Fall. Even though the intimacy between the first man and his wife was abrogated, even though the unity with man would bring woman to the threshold of death itself in the process of childbirth, yet woman would still possess a strong desire to be with man. The broken intimacy and the pain in childbearing would not be allowed to nullify the yearning of woman for man and the fulfillment of God's command to populate the earth (pp. 207-208).

The second part of Gen 3:16, which says: "And he shall rule over thee" is descriptive of what took place after Adam and Eve fell into sin, and it was a part of the curse that God placed on the woman. Concisely put, "Eve was an equal of Adam's before the Fall, but in some mysterious manner made unequal or inferior to him after the Fall" (Younker, 2020, p. 45). The idea of patriarchy was not part of the relationship of Adam to Eve before the fall; and so, Younker (2020) suggested ...that Genesis 3:16's "rule over" was not designed to return Eve to any inferior role she occupied after her sin but to place her for the first time under a curse of subjection, one that included some sort of inferiority, which would require a blessing to survive - a loving desire for her husband. Furthermore, White's intriguing final comment that the race has been placed on a second probation may indicate that there is a better solution to seek in their second trial beyond hierarchical superiority and inferiority, a pathway beyond these distinctions on the way toward the Edenic ideal of a more truly harmonious and cooperative marriage that helps sanctify both marriage partners (pp. 53-54). 
Atkinson (1990) opined that "this is not a divine prescription of what should be, but a description in the fallen world of what we will be" (p. 94). It is, therefore, evident that what the result of sin brought is a contention for superiority in marital relationships. Perry (2019) mentioned in his exegesis that "the man will be tempted to pursue a tyrannical role in ruling harshly over his wife. In turn, the woman will be tempted to pursue a headship over the man rather than that which helps the man" (p. 18).

Unfortunately, this passage has been held on to in some cultural context, over a long period of time, to justify patriarchy. Mowczko (2015) explained that

there is ample evidence that, due to the prevalence of patriarchy, men have ruled their wives. God's prophetic description that "he will rule over you" has been played out in countless marriages throughout millennia across the globe. Over the centuries, many Christians have even assumed that Genesis 3:16 gave men permission to rule and control their wives, yet there is no divine mandate here (para. 18).

On a final note, regarding this issue, the cultural context of putting females in subjection among the Jews as we read in the Bible does not justify patriarchy. God did not mean it that way before the fall. It was the entrance of sin that brought about the present aversive stratification between males and females. Groothuis (1997) submitted that

we should not believe that the ancient Hebrew language was an expression of patriarchal culture. We cannot conclude, simply because the Bible was written under divine inspiration, that the languages in which the Bible was written were themselves created under divine inspiration. These languages were as male centered as the cultures they reflected and by which they were created. The fact that certain words in a language can be used to refer either to a male human or to humans in general reflects cultural concepts of gender; it says nothing about God's view of gender ( $p$. 24).

From the foregoing, it becomes undeniable that the original position of Eve as a suitable helper to Adam became altered to that of the position of subservience as a result of the entrance of sin. This accounts for the reason why, in so many cultures of the world 
today, the attitude toward women is going farther away from egalitarianism. From the biblical point of view, the bone was taken from the side of Adam, not from the head and not from the foot; that is why the woman cannot dominate the man, and neither can the man turn the wife into a property or an inferior object. Henry (n.d.), commenting on Gen $2: 21,22$, confirmed that "the woman was made of a rib out of the side of Adam; not made out of his head to rule over him, nor out of his feet to be trampled upon by him, but out of his side to be equal with him, under his arm to be protected, and near his heart to be beloved" (para. 1). Thus, she was created equal to man to stand by his side.

It should be noted that based on the Jewish culture of how women were regarded, בעל the (ba'al: husband) connotes the hierarchical relationship of master and owner. However, from the theological insight of Hos 2:16, "God indicates that someday soon, the relationship between God and Israel will operate on the 'ish' paradigm - the paradigm of mutual respect rather than the paradigm of domination and hierarchy" (Scheinberg, 2013, para. 9). The two Hebrew words “' ish' and 'ishah,' meaning 'man' and 'woman,' are etymologically egalitarian words, unlike the Hebrew word 'ba'al,' which establishes a hierarchical relationship between husband and wife" (Scheinberg, 2013, para. 3). The Hebrew emphasis, "tikre'i ishi, ve-lo tikre'i li od ba'ali" (Scheinberg, 2013, para. 8), meaning “[It will happen soon that] you will call me 'ishi,' 'my husband,' and you will no longer call me 'ba'ali,' 'my master' (Hos 2:16 [Heb. v. 18])” (Scheinberg, 2013, para. 8), drives home the point that if God could deal with us as a Friend and not as a Master, husbands and men should also do the same in the way they relate with women.

In the same vein, White (2007) established that the relationship between Adam 
and Eve was like that of equals. She postulated that Eve was not "to be trampled under his feet as an inferior, but to stand by his side as an equal, loved and protected by him.

She was his second self, showing the close union that should exist in this relationship" (p.

13). In her further analysis, White (1952) explained that

when husbands require the complete subjection of their wives, declaring that women have no voice or will in the family, but must render entire submission, they place their wives in a position contrary to the Scripture. In interpreting the Scripture in this way, they do violence to the design of the marriage institution. This interpretation is made simply that they may exercise arbitrary rule, which is not their prerogative. If he is a coarse, rough, boisterous, egotistical, harsh, and overbearing man, let him never utter the word that the husband is the head of the wife, and that she must submit to him in everything; for he is not the Lord, he is not the husband in the true significance of the term.... Neither the husband nor the wife should attempt to exercise over the other an arbitrary control. Do not try to compel each other to yield to your wishes. You cannot do this and retain each other's love (pp. 116-118).

The issue of submission, as a general misconceived part of the marital relationship among cultures of the world, is a major cause of conflict in marriages (Omorogbe, Obetoh, \& Odion, 2010, p. 58). The usual pattern that manifests itself in relationships where submission is a major cause of conflict can be identified with two models of marital submission as opined by Tracy (2008): The first model has been tagged as "Unqualified Submission; Unqualified Male Authority" (p. 8). This model "asserts that husbands have essentially unlimited authority. Hence, wives are obligated to give virtually unqualified submission. In this model male/female differences are accentuated, and equality is at best de-emphasized" (Tracy, 2008, p. 8). The second model is tagged as “Single Qualification Submission: All Encompassing Male Authority” (Tracy, 2008, p. 10). The emphasis here is that God put in place an inflexible familial arrangement where "the husband is the God ordained leader for the home. His authority is great (he has the final authority and is to be obeyed) and it is extensive (it extends to every domain of 
life)" (Tracy, 2008, p. 10). There are, however, two basic variations from the first model: (a) emphasis on "spiritual equality between the sexes" and (b) "the husband's authority is plainly qualified...” which “...boils down to a single principle—a wife is always to submit to her husband unless he commands her to do something that clearly violates Scripture" (Tracy, 2008, p. 11). According to Sedlacek and Sedlacek (2016), "to submit does not mean to be a doormat, passively 'taking' whatever abuse another wishes to dish out. It is an active, strong, voluntary act of the will to place oneself under another for the good of all concerned" (pp. 80-85).

In general, the ideal marriage relationship has been tainted by different cultural biases of humanity across the length and breadth of the world. This is vividly manifested in patriarchy and male dominant cultures. For instance, "in some cultures, submission implies total, unquestioning obedience of children, regardless of age, to their parents, and wives to their husbands. Anything short of full, immediate obedience could result in physical punishment for either children or women" (Sedlacek \& Sedlacek, 2016, p. 8085). The result we see in a culture where the submission of women to men is taken out of the biblical context is " ... a degree of commodifying women, commodifying their sexuality, and commodifying their availability, so she's just something there for him" (Morgan, 2018, p. 71). Thus, it should be emphasized that women's submission to men was "descriptive" of life after Eve's sin, but not "prescriptive" of the way God intended male/female's relationship to be from the beginning (Morgan, 2018, p. 70).

A very good biblical example of submission done wrongly is shown in the way Adam readily agreed to Eve's request to eat the forbidden fruit. God said: "Because you listened to the voice of your wife" (Gen 3:17), a series of endless conflict would follow. 
Adam had the option of listening to Eve, his wife, in order to avoid conflict. However, in doing that, a series of woes followed which plunged our world deeper into the raging controversy between good and bad that the world is in right now. The immediate consequences of this action to Adam and Eve were very grievous, parts of which were losing the beautiful Edenic home that would have been theirs forever and ever; the loss of their beloved son, Abel; as well as the infiltration of woes, chaos, crises, and conflicts into their hitherto harmonious marital relationship. Köstenberger and Jones (2010) affirmed that "the consequences of the fall extend to the man and the woman alike, affecting their respective primary spheres" (p. 27). The human families and the whole world are all directly reaping the consequences of their sin today. This incident indeed served as the beginning of human conflict in the world.

In addition, different scholars have aired different opinions in regards to whether or not Adam was physically present with his wife when the snake spoke to her. Because God created marriage in order to fill the vacuum of loneliness, the argument being made here is to establish how couples living apart can adversely affect their relationship. Living apart can actually create a wedge which may cause misunderstanding and conflict in marital relationships. Since it has been established above that God created marriage and family to build relationships, it is important that we take a look at this issue.

There are two views on whether Adam was present or absent at the scene of the temptation. John Calvin held the view that Adam was absent at the scene. He believed that it is in no way reasonable to believe that Adam was at the scene of the temptation, just looking on without engaging in any act of intervention to stop his wife from eating the fruit. Calvin and King (2010) suggested: 
It might be that he [Adam] soon joined her, and that, even before the woman tasted the fruit of the tree, she related the conversation held with the serpent, and entangled him with the same fallacies by which she herself had been deceived (pp. 151-152).

Wesley (1765) supported John Calvin when he, in turn, asserted that Adam "was not with her when she was tempted; surely if he had, he would have interposed to prevent the sin; but he came to her when she had eaten, and was prevailed with by her to eat likewise" (p. 1). Leupold (1942), on the other hand, speculated that "when the temptation began, Adam was not with Eve but had only joined her at this time" (pp. 152-153). To support this proposition, the Seventh-day Adventist Bible Commentary reiterates that the expression

“...with her" (in Genesis 3:6) does not imply that he had been with her all the time, standing mute at the scene of temptation. Instead, she gave him of the fruit upon rejoining him that he might eat it "with her" and thus share its presumed benefits (Nichol, 1978, p. 231).

In another vein, theologians who hold the second view believe that Adam was physically present at the scene of the temptation. For example, Hughes (2004) exclaimed: "Here is a shocker: Adam was apparently privy to the conversation between Eve and the snake!" (p. 70). Walton (2001) also rhetorically inquired, "Where was Adam through all of this?" (p. 206). He insisted that "the text tells us, but for some reason we have been reluctant to accept what the text says: Adam was there with Eve" (p. 206).

This study will take the position of the first view which suggested that Adam was absent at the scene because of two reasons advanced by de Souza (2015). The text reads: "She also gave to her husband with her, and he ate" (p. 2). First, the prepositional phrase in Gen 3:6, "with her," which is immah in Hebrew, does not mean that Adam was with her on that day, because a similar phrase was also used by Adam in Gen 3:12: "The woman whom you gave to be with me (immadi), she gave me of the tree, and I ate" 
(p. 2). According to de Souza (2015), both statements suggested an intimacy that existed between Adam and Eve as a result of the "one flesh" marital relationship that both of them were incorporated into; it does not suggest the "spatial location of Adam in the scene” (pp. 2-3). Second, de Souza (2015) argued that “...twice in the story, the narrator introduces the speech of the serpent with quotation formulas that portrays Eve as the sole audience: 'And he [the serpent] said to the woman' (Gen 3:1) and 'then the serpent said to the woman' (Gen 3:4)" (pp. 2-3).

The conclusion here is that from the foregoing arguments, White (1890) unambiguously affirmed that Eve was all by herself at the scene of the temptation; she opined that Adam was not present (pp. 53-54). "Adam and Eve were supposed to stay together in the Garden in order to mutually strengthen each other and resist temptation. The disruption of that togetherness paved the way for the entrance of sin into the world" (de Souza, 2015, p. 3), and hence, for the entrance of conflict and violence, as well. As much as possible, it is highly encouraged that husbands and wives live together physically; they should also always align with each other emotionally, affectively, and spiritually (de Souza, 2015, p. 3). Couples living apart from each other may drive in a wedge in between them that may become detrimental to their marital relationships; this may, in turn, create scenarios that may lead to insinuations that spark up marital conflicts.

Furthermore, let us note that even though there has been a departure from the original blueprints laid down by God for marriage and family, God still wants couples to stay together as one indivisible entity. In addition, "the Old Testament creation accounts show that monogamy is the form of marriage willed by God from the beginning, and that 
it is not simply a cultural institution dependent upon the customs and conditions of a particular society...” (Blum, 1989, pp. 276-277; Bromiley, 1980, p. 3; White, 1958, p. 46). Man does not have the right to change the layout of marriage. Notwithstanding that over the centuries it has gone through different modifications as a result of sociocultural, economic, religious, and spiritual biases of people, the institution of marriage should still maintain its originality as established in Genesis (Carlson, 2013, para. 4).

The following pronouncements established strong emotional, spiritual, physical, social, and sexual bonds between husband and wife as ordained by God Himself. It is stated that "therefore shall a man leave his father and his mother and shall cleave unto his wife: and they shall be one flesh. And they were both naked, the man and his wife, and were not ashamed" (Gen 2:24-25). White (1952) called this "the blending of two lives into one" (p. 102).

Nwaomah (2012) explained further that

...the Hebrew word "to leave" (azab) means "to cut loose," and the word for "cleaving" (dabaq) is translated from a root word that means, "to stick to, to fasten, to join, to hold onto." As a noun, the word can be used for brazing and soldering (Isaiah 41:7). The strength of this bond demonstrates the nature of the bond of marriage and the family, which also conveys the strength of the bond between God and His people. Marriage and family involve leaving behind the former primary relationships to form one flesh (p. 22).

In marriage, partners not only provide for and complement each other, but also stick together in a way that no separation is encouraged in any way. The life couples live when they get married is lived to serve God's interest, and each partner lives to serve the interest of the other partner. They are so committed to this relationship that each one is willing to die for the other and both husband and wife are ready to sacrifice all that they have for God who brought them together as a couple (Nwaomah, 2012, p. 23). 
In contrast to couples' conflict prevalent in today's marriage and family relations, the Old and New Testaments agree that marriage is ordained by God to create a harmonious community for humanity through the genuine love that is supposed to be in existence between every couple in the world. When genuine and unconditional love exists in the marital relationship of every couple, hatred is removed from their offspring who go out to constitute society. Although conflicts may ensue in marriage and family relations, such conflicts will not be the type that will lead to unresolvable bitterness, acute violence, and/or abuse.

There are three individuals whose contributions to marriage in the New Testament are noteworthy: Jesus Christ, Peter, and Paul. John recorded that Jesus Christ attended the marriage ceremony in Cana and performed His first miracle there (John 2:1-11). This, to a large extent, is very significant in showing Jesus Christ's full backing of the institution of marriage which God started at creation. Jesus taught the people that marriage should be pure and holy and that it is a symbol of the heavenly family here on earth (White, 1999, p. 230).

Jesus concluded that under the marriage law, divorce was not condoned. However, Jesus gave an exception to why divorce was permitted when the Pharisees retorted: "Why then did Moses command that a man give his wife a certificate of divorce and send her away?" (Matt 19:7). Jesus said to them,

...because your hearts were hard and stubborn, Moses permitted you to divorce your wives; but from the beginning it has not been this way. I say to you, whoever divorces his wife, except for sexual immorality, and marries another woman commits adultery (Matt 19:8-9).

Every aberration, including divorce, which man has introduced to the institution of marriage and family was, apparently, not condoned by Jesus Christ. Chapman (1994) 
posited that sanity would be restored back to the institution of marriage when human beings went back to the original blueprint of marriage as established by God through His marriage law which Jesus Himself upheld when He came to the world (para. 20). If this is done, marital conflicts will be reduced. These conflicts multiply daily, and they lead to heartaches and unhappiness in different forms; these include relationship vices such as separation, emotional trauma, domestic violence, and sometimes, divorce. All these marital evils occur because of man's deviation from God's marriage law.

Peter and Paul both wrote about the wife submitting to her husband and the husband loving his wife genuinely. Husbands are encouraged to provide quality Christian leadership for the household. Peter admonished husbands to treat their wives like weaker vessels so that their prayers can be answered (1 Pet 3:7). It can be deduced from this text that a husband who relates to his wife as if the woman is fragile and should not be broken is reckoned with by God as a strong and spiritually regenerated man. Such a husband will receive answers to his prayers and abundant favors from God. More often than not, what some men count as strength is the ability to show that they are the boss in their home. Such men may not hesitate to resort to the act of bullying their wives. Peter's opinion is that the husband should serve as the head; he should be able to protect his wife, provide for her, and be a savior to her when in danger; he, as the husband, should not constitute a danger to his wife. The fact that Peter referred to women as weaker vessels does not make them inferior to their husbands; wives are also very pivotal to the existence of their husbands. For instance, Solomon confirmed that "an excellent wife is the crown of her husband, but she who causes shame is like rottenness in his bones" (Prov 12:4). This means that the wife, though a weaker vessel, is an indispensable part of the husband. This 
point establishes that the husband and the wife are partners in progress - the husband as first among equals and the wife as second among equals. The husband is king because of the wife who is a crown on his head.

White (1999) expressed her concern about husbands who would not submit themselves to the headship of Jesus Christ, but would expect their wives to submit to them as the head:

The Lord Jesus has not been correctly represented in His relation to the church by many husbands in their relation to their wives, for they do not keep the way of the Lord. They declare that their wives must be subject to them in everything. But it was not the design of God that the husband should have control, as head of the house, when he himself does not submit to Christ. He must be under the rule of Christ that he may represent the relation of Christ to the church. If he is a coarse, rough, boisterous, egotistical, harsh, and overbearing man, let him never utter the word that the husband is the head of the wife, and that she must submit to him in everything; for he is not the Lord, he is not the husband in the true significance of the term . . There is One who stands higher than the husband to the wife; it is her Redeemer, and her submission to her husband is to be rendered as God has directed - 'as it is fit in the Lord.' When husbands require the complete subjection of their wives, declaring that women have no voice or will in the family, but must render entire submission, they place their wives in a position contrary to the Scripture. In interpreting the Scripture in this way, they do violence to the design of the marriage institution. This interpretation is made simply that they may exercise arbitrary rule (pp. 115-118).

Every man is ultimately responsible to God for what his home becomes. The man has been given the responsibility to lead, but the husband, too, must look unto Jesus as his own leader so that he can emulate Christ's method of leadership. In writing to the Corinthians, the Apostle Paul reiterated that "...the head of every man is Christ, and the head of the woman is the man, and the head of Christ is God" (1 Cor 11:3). This statement establishes how family order should be viewed.

In addition, according to Eph 5:21, Paul enjoined that Christians should submit to one another in the fear of God. Every Christian relationship, including the marital relationship, should be characterized by mutual submission. Even though Paul mentioned 
in Eph 5: 23 that the husband is the head of the wife, it is instructive to note that this headship is in the context of Christ's being the head of the Church with Jesus displaying servant-like characteristics; thus, mutual submission in a Christian marriage should be done in the fear of God where the wife will submit to her husband and the husband will, in turn, sacrifice everything he has for the wife. Fowler (2005) put this in a clearer perspective below:

The verse is connected to the clause in Ephesians 5:18: "Be filled with the Spirit" (NKJV). Christian submission must not be equated with servility but rather with a proper attitude of humility and consideration to each other. Admittedly, such an attitude is not part of the natural self but a result of being "filled" with the Spirit, as was the case with fellowship and worship, singing and praising, and continual thanksgiving (Eph. 5:19, 20). Viewed thus, submission does not carry the meaning we normally attribute to it. The biblical view of submission in no way teaches a dictatorial, authoritarian, unjust stance in social relationships where one exercises power and the other crawls in helplessness. Submission in human relationships is never absolute and unquestioned. As its border, it has the will of God. Submission "in the fear of God" (Eph. 5:21) demands respect on the part of wife and dignity and honor on the part of husband. This is even more crucial in an age such as ours, during which spousal and child abuse abound. No child of God should become or should be treated as a doormat (p. 126).

From the above, it can be safely concluded that issues such as headship of the man, the man loving his wife, wives submitting to their husbands, and husbands and wives submitting to each other will pose no threats to either of the couple as long as it is done under the influence of the Holy Spirit. All these issues have become problematic because of the entrance of sins. According to Perry (2019), "the consequences of the actions of Adam and Eve in the Garden of Eden that day had repercussions on family life..." (specifically, that of parenting and the dynamics of the marriage union itself; p. 24).

Furthermore, looking intently at the New Testament teaching on submission and love, both Paul and Peter explained the roles of husband and wife in the marriage 
relationship. Husbands are clearly encouraged to love their wives as Christ loved the church and gave Himself for her. Wives are called to submit to their husbands as the church submits to the leadership of Christ. Both of these postures require that couples have an authentic vulnerability before each other and before God.

Hammer (2011) opined that the New Testament teachings of Paul and Peter on marital submission are in the "...context of communal relationships that have some sense of reciprocal submission— — husbands and wives, children and parents, slaves and master" (p. 113). Every reference made about submission within the marital relationship is a reflection of the submission of Jesus to the Father. It is the "believer's responsibility to submit first to Christ, and then the outworking of submitting to one another" (Hammer, 2011, p. 113). The godly husband is to provide vision and leadership in line with biblical teaching on leadership with the attitudes which were in Christ Jesus, that is, humility, self-sacrifice, and servant leadership attitudes.

In the Bible, conflicts, in general, and couple conflicts, specifically, are engendered by several factors; some of these include lack of submission, lack of adequate display of love, lack of humility, selfishness, ego, and a contentious spirit. Others may be unwillingness to follow God's relationship commandments, pride and arrogance, as well as the use of the tongue. Thus, the Apostle Peter gave practical solutions to couples' conflict and societal conflict in general. He counseled:

Finally, all of you be like-minded [united in spirit], sympathetic, brotherly, kindhearted [courteous and compassionate toward each other as members of one household], and humble in spirit; and never return evil for evil or insult for insult [avoid scolding, berating, and any kind of abuse], but on the contrary, give a blessing [pray for one another's well-being, contentment, and protection]; for you have been called for this very purpose, that you might inherit a blessing [from God that brings well-being, happiness, and protection]. For, "the one who wants to enjoy life and see good days [good - whether apparent or not], Must keep his tongue free from evil and 
his lips from speaking guile (treachery, deceit)" He must turn away from wickedness and do what is right. He must search for peace [with God, with self, with others] and pursue it eagerly [actively — not merely desiring it]. "For the eyes of the Lord are [looking favorably] upon the righteous (the upright), and His ears are attentive to their prayer (eager to answer), but the face of the Lord is against those who practice evil" (1 Pet 3:8-12).

In conclusion, the theology of marriage and family promotes the institution as a vehicle of harmonious relationships where unity, joy, and peace are present. That is not to say that conflict will be absent from there, but it does mean that conflicts are tackled as couples put the interests of each other above their own interests. The institution is a place where those produced in it go out into the world to make an impact on the lives of other people. Through this institution, God seeks to portray the agape love relationship that exists between Jesus Christ who is the husband and the church who is the bride. Homes should be a miniature heaven on earth. The husbands, the wives, and the children are to live amicably together in anticipation of the marriage supper of the Lamb and the Church at the second coming of Jesus Christ. In view of this, the institution of marriage and family must not be conceived of as an arena of unresolvable conflicts, riots, and domestic violence.

\section{An Overview of Conflict and Catharsis Theories}

Conflict arises in society as a result of conflicting interests and the inability of people to get what will satisfy them due to limited resources available to cater to human needs. While some have the means to satisfy their needs, others who do not may see those who have means as constituting an impediment to the fulfilment of their own needs. As a result, conflict becomes inevitable because there will always be clashes among human beings over their needs, wants, desires and interests. Thus, 
conflict theory examines any social phenomenon through the lens that there is a natural human instinct towards conflict. It is an unavoidable aspect of human nature and helps explain why things are. For example, conflict theory can be used to look at wars, violence, revolutions, and other forms of injustice and discrimination by explaining that there is a natural disparity in a society that causes these problems (Corporate Finance Institute, 2018, paras. 2- 3).

From the works of Karl Marx, there are three basic premises of conflict theory. The first premise is that conflict is inevitable among human beings. The second premise is that conflict arises as a result of human beings competing with one another over limited resources available in the world. The third premise is that there are inequalities in the world which have given rise to two classes of people competing over these limited resources; the first class consists of the bourgeoisie who own the means of production and are also capitalists. They are the advantaged. The second class consists of the proletariat; people in this class are the working class and they are the poor people; they are the disadvantaged (Crossman, 2019, paras. 1-2).

The conflict theory as propounded by Karl Marx is very consistent with what the Bible teaches. First, according to the Bible, conflict became inevitable within humanity because the originator of conflict came into this world in the Garden of Eden. Since then, the world has been plunged deeper and deeper into conflict. Second, the Bible records several stories of human beings in competition with one another. A typical example of this is found in the birth of Esau and Jacob, where, right from the womb, the children struggled together within their mother (Gen 25:22). Third, this story later exemplified inequality between these two children when the Bible stated that "one people shall be stronger than the other, and the older shall serve the younger" (Gen 25:23). In essence, "from family feuds to labor strikes and international warfare, human conflict is an everpresent and universal social problem and the methods to manage it are a challenge for 
everyone, from average citizens to policymakers and social theorists" (Bartos \& Wehr, 2002, para. 1).

Conflict is an inherent part of human relations; therefore, it can be safely concluded that couples and their marriage relationships are not exempt from conflict. Farrington and Chertok (1993) suggested that the most “...satisfying versions of family conflict theory [are] explicitly macrostructural in nature" because all the structural variations of family conflict are explored in dealing with underlying potential family problems (p. 370). Thus, pragmatic approaches should be employed to tackle all areas of apparent family conflict that are fast becoming an epidemic in society. "Sociological views on today's families generally fall into the functional, conflict, and social interactionist" (University of Minnesota, 2010, para. 1). One of the major assumptions of this theoretical perspective of conflict theory about family is that "...the family contributes to social inequality by reinforcing economic inequality and by reinforcing patriarchy. The family can also be a source of conflict, including physical violence and emotional cruelty, for its own members" (University of Minnesota, 2010, para. 3). This prevalent condition about family should be reversed. Ideally, families should be characterized by fairness, peace, and amiableness.

As mentioned above, conflict is inexorable in human interaction. However, by and large, growth and development may accompany conflicts if they are well managed. What is important to be mindful of is how the conflict is handled and how it eventually ends. "The primary goal should be for family members to learn how to manage the conflict so that it doesn't escalate and alienate others and lead to estranged relationships" (Ray, 2015, para. 4). This brings us to a brief discussion of catharsis theory. 
Catharsis theory is based on the notion that "if you express your feelings you will purge yourself of your troubles" (Tolboll, 2014, p. 1). To explain more, according to this theory, “...engaging in an aggressive act in response to frustration should lead to both (a) tension reduction and (b) aggressive drive reduction" (Verona \& Sullivan, 2008, p. 331). Catharsis theory suggests that expressing feelings can help those engaged in conflict not to have their feelings aggravated to the point of misbehaving. However, according to Tolboll (2014),

...the problem is that cathartic psychotherapies are neglecting the importance of thoughts. Feelings are the body's reaction on the mind (the thoughts). Feelings arise where the mind and the body meet...Rational thinking (critical thinking, which uses logic and argumentation) assist people to find ways to talk with others, to change situations, and to identify socially useful and mature means to reduce angerproducing interactions and situations (pp. 1, 16).

Human beings should guide against conflict's degenerating into aggravated domestic or society violence. One of the major ways of handling conflict is by putting the concept of catharsis theory into functional use. However, the use of this theory has to be combined with other factors such as rational, critical, and logical thinking, as mentioned above, before it can be restorative. As mentioned earlier, even though catharsis theory postulates that "holding one's emotions in leads to feeling 'bottled up,' while letting them out leads to relief..., the expression of anger, whether verbal or physical, does not automatically reduce anger...” (Kellermann, 1992, pp. 79-80). Kellermann (1992) argued that catharsis theory, in the modern dispensation, cannot produce any desirable result by itself. He summed it up by opining that

...interpersonal, behavioral, and/or cognitive factors were crucially related to whether catharsis was anger reducing or not. Pure ventilation, without the acquisition of skills for the future, was of no curative value. Catharsis alone was never enough to bring about a psychotherapeutic cure. Giving expression to what one has heretofore kept in, 
in the right environment, can become an important new experience which leads to therapeutic growth (pp. 80-82).

Catharsis theory should be described in the light of both emotional and cognitive experiences (Powell, n.d., para. 24). If done this way, catharsis theory can become an effective way of curbing conflict from becoming abusive. Powell (n.d.), referring to Scheff (2001), has pointed out that cathartic experiences in clients will be productive in reducing aggressive incidents if psychologists, engaging their clients in therapy, balance “...the past distress and feeling of safety and support in the present. The repeated somatic-emotional discharge of grief, fear, and anger with appropriate distancing and support are necessary components for success" (para. 24). Powell (n.d.) concluded that in order to make cathartic techniques veritable and potent, researchers should research and interpret catharsis theory

... within the context of other important components of a therapeutic process, such as safe and trusting relationship between client and therapist, building a client's ego strength, creating a safe and supportive environment in the client's present life (making behavioral changes), finding meaning of the past experiences, and others. The complexity of phenomenon of catharsis involves experiencing repressed emotional traumas within safe and supportive environment, involving emotional discharge, as well as appropriate cognitive processing and insight (paras. 25, 27).

Looking closely at literature on couple conflict and conflict, in general, it may be opined that conflict can be a way of bonding a husband and a wife together more intimately if conflicts that ensue between them are handled on time and in a good way. The objective is to ensure that these conflicts do not degenerate into outrageous violence. Approaching conflicts in the right direction and tackling them with the right tools and in a conducive environment would help in ameliorating conflicts that could lead to domestic violence which has the capability of separating husband and wife. 


\section{A Brief Exploration of What Conflict is All About: \\ Biblical and Contemporary Insights}

\section{Biblical Insights}

Let us begin by emphatically mentioning that the selfishness of humanity is one of the major sources of conflict. Selfishness is orchestrated by the failure to love fellow human beings. The essence of sin is a break in relationship with God and thus, sin is framed as a relational barrier spawned by selfishness in human lives. This is also a failure of man to show love to God and love to fellow human beings. Because of this situation, conflict has become an integral part of the world. Conflict, which resulted in war, actually started in heaven. John the Revelator announced that

war broke out in heaven: Michael and his angels fought with the dragon; and the dragon and his angels fought, but they did not prevail, nor was a place found for them in heaven any longer. So, the great dragon was cast out, that serpent of old, called the Devil and Satan, who deceives the whole world; he was cast to the earth, and his angels were cast out with him (Rev 12:7-9).

Thus, the ravaging intensity of the conflict which began in heaven was transferred to the world that had just been created by God in the Garden of Eden. John the Revelator continued his announcement by warning the inhabitants to beware: “...But woe to the earth and the sea, because the devil has gone down to you! He is filled with fury because he knows that his time is short" (Rev 12:12). The following words of Peter amplified this pronouncement: "Be alert and of sober mind. Your enemy the devil prowls around like a roaring lion looking for someone to devour" (1 Pet 5:8). Right from the Garden of Eden, the progenitor of conflicts desired to proliferate and entrench conflicts in society through marriage relationships and families; this is undoubtedly becoming more vigorous because it is from the institution of marriage and family that conflicts are transferred into the community. 
Elucidating more on the relationship between family and community, Bowen's

family systems theory drives home the point that the family and the community are interreliant; one cannot be separated from the other:

Instead of seeing individuals as an emotional unit of his own, or as a separate entity, and the individual as the basic unit of treatment, Bowen deemed that individual functioning should be understood in the context of his relationships, that each person's emotional functioning is closely interconnected with each other, with reciprocal impact on each other (International Social Service, Family Institute, 2015, p. 1).

God designed that the family should serve as a feeder of human beings for the society. Because of this, family dynamics cannot be divorced from interaction with society. That is why God commanded Adam and Eve to "be fruitful and increase in number; fill the earth and subdue it. Rule over the fish in the sea and the birds in the sky and over every living creature that moves on the ground" (Gen 1:28). Thus, the Bowen family systems theory does “....acknowledge the familial systemic nature, the societal systemic nature, and the multigenerational nature of psychological development while not neglecting the role of the individual in the process (Flaskas, 2010; Skowron and Friedlander, 1998; Skowron et al., 2009)" (Cochran, 2011, p. 25). This accounts for why marriage and family institution cannot be trivialized in the development and maintenance of societal values.

In another vein, since family and society interact with each other, it is pertinent to mention that Köstenberger (n.d.) has postulated that the institution of marriage and family is not immune from the cosmic conflict (p. 16) that goes on in the world. There is a serious attack on the institution of marriage and family because it is the basic unit and the building block of the society; if the institution stabilizes very well, society will experience peace; hence, destabilizing the institution of marriage and family is the 
primary objective of evil forces. It becomes apparent that “...spiritual warfare

surrounding marriage and the family is a reality, and awareness of this conflict as well as skill in engaging in it is imperative" (Köstenberger, n.d., p. 16).

Doss (1999), referring to John \& Millie Youngberg (1994), explained that "the great controversy motif places Christian beliefs in a cosmic perspective. Adventist family ministry is distinctive because it sees family life issues as playing a role in the cosmic struggle between good and evil” (p. 7). Doss (1999) further underscored that

this thumbnail sketch of the great controversy shows the priority God places on the most intimate of human relationships as He works out His plan of redemption. First, $\mathrm{He}$ intends to restore the relationship between humans and Himself and then, $\mathrm{He}$ intends to restore loving relationships between humans. Marriage, the primary human relationship, heads the list of relationships to be restored by the gospel. Adventist family ministry aims to facilitate loving family relationships as the vital starting point to loving relationships with all of humankind. As Ellen White said: 'The strongest argument in favor of the gospel is a loving and lovable Christian.' Having good relationships is vital both for personal salvation and for evangelism (p. 19).

In addition, Hutchison (2011) stated that "we are all damaged goods, needing healing and redemption. One of the most important factors to remember is that we daily live in 'enemy territory,' and our adversary, Satan, delights in disrupting the marriage relationship" (paras. 3, 5). Our enemy introduced crises and conflicts and openly denied that God's words were true. When the great controversy started in heaven, it became festered and the next point of call for the accuser was the newly wedded couple in the Garden of Eden. Since that time, marriage and family have been under severe attack. John alluded to the fact that the accuser of the brethren came as a thief to steal the joy of marriage and family, he came to kill married couples and their children, and he is working tirelessly to destroy all the families that God has established. However, Jesus' mission was to come and give life to all the dead marriages so that every crushed couple 
and their children can be remolded into God's original state. Thus, they will be revived back into abundant life (John 10:10).

\section{Contemporary Insights}

The institution of marriage and family is no longer valued as much as it was some years ago. At the present time, the importance of this institution as a catalyst to society's peace has been undermined.

The contemporary culture is in a deep crisis regarding marriage and family today. While the crisis has important political, social, and economic ramifications, in the ultimate analysis only a spiritual return to the biblical foundations will address the root issue of the current crisis (Köstenberger, 2016, p. 6).

Conflict arises when one spouse pursues a goal or talks about pursing that goal, and in so doing, interferes with the goals the partner holds. These incompatibilities definitely affect the indexes of marital functioning adversely (Gere \& Schimmack, 2011, pp. 38, 39). The inability to let go of the goal being pursued is characterized by selfishness and self-esteem, and this triggers different ill-feelings that may eventually lead to conflicts which may be mild or severe.

The widely influential social learning concept of marriage holds that couples' being at variance with each other and not working towards early resolution may make conflict more intense. This suggests that "couples' aversive and ineffectual responses to conflict" (Koerner \& Jacobson, 1994, p. 208) may deepen conflict. For example, "when conflicts arise, one or both partners may respond aversively by nagging, complaining, distancing, or becoming violent until the other gives in, creating a coercive cycle that each partner contributes to and maintains" (Koerner \& Jacobson, 1994, p. 208). The cycle of violence may be broken by one or both partners if the theory of catharsis is 
functionally put into practice and accompanied by positive intellectual processing and insight as stated by the conceptual framework of this study.

Outside the family, violent behavior has become an ever-present aspect of the contemporary scene. In the last couple of decades, we see a series of events, violent in the extreme, that have made it pertinent to look closer at the general problem of man's inhuman and violent treatment of his fellow man. Freud, through observation, case study, and speculation, came to ascribe sexuality and aggressiveness as basic characteristics of man's nature (Smith, 2008, para. 3). As a result of this display of aggression, the problem of conflict and violence has been on the increase, and African immigrants as well as African Americans are not exempted. For instance, in the United States, research shows there are more than “ $\ldots 16,000$ homicides and 1.6 million nonfatal assault injuries requiring treatment in emergency departments. More than 12 million adults experience intimate partner violence annually and more than 10 million children younger than 18 years, experience some form of maltreatment" (Sumner et al., 2015, p. 2). In a recent statistic in the United States, “...the number of violent incidents increased from 5.2 million in 2017 to 6.0 million in 2018 . The offender was of the same race or ethnicity as the victim in $70 \%$ of violent incidents involving black victims" (Morgan \& Oudekerk, 2019, p. 1). It is worthwhile to mention that

exposure to violence increases vulnerability to a broad range of mental and physical health problems over the life course; for example, meta-analyses indicate that exposure to physical abuse in childhood is associated with a 54\% increased odds of depressive disorder, a 78\% increased odds of sexually transmitted illness or risky sexual behavior, and a 32\% increased odds of obesity (Sumner et al., 2015, p. 2).

According to Fagan (1995), "empirical evidence shows that too many young men and women from broken families tend to have a much weaker sense of connection with 
their neighborhood and are prone to exploit its members to satisfy their unmet needs or desires" (para. 5). Thus, it can be assumed that some individuals who perpetrate one crime or the other may come from dysfunctional family backgrounds-environments not conducive to the healthy nurturing and growth of children (para. 5). "Policymakers at last are coming to recognize the connection between the breakdown of American families and various social problems" (Fagan, 1995, para. 1).

Couple conflict, one way or the other, will have adverse effects on the couples who regularly engage in high levels of malignant conflict. As highlighted above, children are affected because it is the foundation of their lives that is being put in jeopardy. Domestic violence is fast becoming an epidemic in our contemporary world and it should be of a serious concern. To sum it up, the general contemporary picture of the modern family is graphically portrayed in the following explanation by Straus, Gelles, and Steinmetz (2006):

Americans run the greatest risk of assault, physical injury, and even murder in their own homes by members of their own families. Across the country this is borne out by official crime statistics. Tales of battered babies and beaten wives are widespread enough to be identified as "child abuse" and "wife abuse." And the estimated 2 million women and children battered and beaten by family members each year are only the tip of the iceberg identified as "violence between family members." Brothers and sisters beat, stab, and shoot each other. There are husbands who are struck and beaten by their wives, and even grandparents are battered by their own children. Violence in one generation affects and encourages violence in another generation. In many families, perhaps a majority of violent families, violence is not even considered taboo or wrong. Rather, it is an accepted and integral part of the way the family functions. Child abuse reporting laws, research, and efforts of the feminist movement, have brought on a new awareness of the high level of aggression in the modern family (p. 4).

Looking at the above portrayal regarding the situation of the institution of marriage and family, it is pertinent to suggest that marriage and family experts should endeavor to beam more searchlights on the institution. Without tackling couple conflict 
on time and allowing it to aggravate into violence and aggression, homes may become more and more a training ground for violent children. "Our task is to accurately present the facts of early life in a way that raises awareness and leads to dialogue and change. People everywhere need to be involved in discussions of how early life affects all of us" (Bezruchka, 2015, p. 219).

Frederick Douglass postulated that "it is easier to build strong children than to repair broken men" (Bezruchka, 2015, p. 205). The statement of Frederick Douglass is ...consistent with overwhelming evidence that spending directed at early life averts spending for disease conditions in later life. High-quality, comprehensive, intensive interventions that stimulate the early childhood environment have been found to not only improve cognitive skills, but also substantially boost adult health. When communities are aware of the importance of early life on adult outcomes, they can act to improve those circumstances (Bezruchka, 2015, pp. 217-218).

Thus, we should not ignore the dangers that dysfunctional marriages and families can pose by focusing our attention only on violence in the streets; otherwise, it will just be like scraping the surface of a problem and leaving the root cause unattended to.

\section{Support System for Africans' and African Americans' Marriages and Families}

Human beings are created to live in communities where people help and support one another. It is especially important that marriages and families have supports that will become catalysts to building up the institution; reducing or eradicating conflict among couples is especially pivotal to this. "The connections that couples develop with their family, peers, and community offer a source of meaning, purpose, and support that influence the health and vitality of their couple relationship" (Futris et al., 2016, p. 3). 
Support System for Africans’ Marriages and Families

The support system for Africans' marriages and families is embedded in the cultural context of the Africans. This is deeply rooted in “"...living together' and the sense of "community of brothers and sisters"” (Mafumbate, 2019, p. 8). This communal living is reinforced in "...the expression of the extended family system in Africa. This arrangement guaranteed social security for the poor, old, widowed, and orphaned which is one of the most admired values in the traditional African socioeconomic arrangement" (Mafumbate, 2019, p. 8). This heritage is still being upheld among African immigrants in North America under national and regional organizations, nongovernmental organizations, as well as African indigenous churches so as to help keep African immigrants' marriages and families together, and also ensure that their welfare is well taken care of.

\section{Non-Governmental Organizations}

Such non-governmental organizations that are seeking to provide help to African immigrants in the United States have been broadly categorized into four types by Kassa (2013); these include but are not limited to “...multiracial service providers (MSPs), African-focused service providers (ASPs), ethnic specific associations (ESAs), and multiracial advocacy organizations (MAOs)" (pp. 35-36). Kassa (2013) opined that “organizations serving African immigrants use a variety of strategies to engage African immigrants in civic life and advocate on their behalf, including domestic policy advocacy, international policy advocacy, constituent education, and grassroots policy campaigns" (p. 71).

Furthermore, there is another specific body especially tailored towards the needs 
of African immigrants called "African Immigrant and Refugee Foundation." This nongovernmental organization “... was established in the year 2000 by Dr. Wanjiru Kamau “...to assist Africans who come to the United States by supporting their various needs cultural, linguistic, employment, mental health, and their desire to fit in" (African Immigrant and Refugee Foundation, 2021, para. 2). It is a not-for-profit 501(c)(3) organization which “... achieves this mission through multicultural group and individual counseling, survival skills training, African cultural awareness education, cultural competence training for caregivers and the African population itself, referrals and consultation" (African Immigrant and Refugee Foundation, 2021, para 3).

Some of the other support systems for the African immigrants' marriages and families, which are intricately linked to “...their strong interpersonal networks and tradition of "mutual aid"” (Kassa, 2013, p. 120) and “...identity and connection to cultural heritage" (p. 123) are discussed below.

\section{Kinship Connection}

The web of relationship goes beyond the connubial members. The hands of fellowship from a nuclear family are extended to members of the extended families, the clan, lineage, and sometimes the village. The wheel of relationship is lubricated through help and assistance rendered to one another within the circle of the extended family. The kinship connection or the extended family bond is as strong as the nuclear family bond. (Kutsoati \& Morck, 2012, p. 2).

Some terms are used to symbolize or depict this close family fraternity. For example, in South Africa, the word "ubuntu" signifies “...human respect, dignity, trust, equality, togetherness, mutual responsibilities, and mutual assistance.” An ubuntu 
community is built on strong and caring families and neighborhood." In Kenya, the word "harambee" symbolizes "togetherness, mutual responsibilities and mutual assistance, pulling resources together to build family and community." In Rwanda, the statement, "urukwavu rukaze rwonka abana" literally means “... an old hare suckles from the young"; this expresses "...the cultural concept of intergenerational support" (Marzi, 1994, pp. 3-7). In Nigeria among the Yorubas, "alajobi" is a word used to address the strong bond that exists among members of an extended family; this means that the binding robe that holds the extended family together cannot be broken by any circumstance.

More often than not, ties and support for the institution of marriage and family within the African culture, as well as couple conflict intervention, control, and alleviation, are based on the activities of the groups of people that are discussed below.

\section{Elders' Council}

There is the old adage in most parts of Africa which literally means that "when elderly people are present in a complicated situation, they bring their wisdom to proffer solutions to such a situation.” Africans also believe that white hair is wisdom. Elderly people are well respected; it is believed within the African tradition that elderly people, as a result of several years of living, have the experience to resolve issues amicably within the community, among families, and between erring couples. In view of this, the council of elders is considered to be a bridge of reconciliation within the community (Kariuki, n.d., p. 1).

Aubel (2010) confirmed the above by underscoring the idea that was brought up by Mandela in regards to the importance of elders within the African context. In 2007, 
Mandela, in a bid to reduce some of the problems confronting Africa specifically and the whole world generally, constituted a council of elders which included a few renowned world leaders. Mandela was no doubt influenced by the traditional role of elders in African cultural settings (Aubel, 2010, pp. 42-43). In the opinion of Ampim (2003), elders' roles in the community cannot be overemphasized; he counseled that every black community should endeavor to utilize the long time-acquired knowledge, wisdom, and understanding of these elders in matters such as “...family or marriage disputes, community-wide issues, naming of buildings and community centers, and directing resources to supporting important projects..." (paras. 11, 19). By and large, elders mean a lot in stabilizing marriage and family, especially in the reduction of marital conflicts among couples. Elders are in the forefront of guiding and counseling couples from the time they start dating until the time the marriage is consummated and the family is well stabilized. Invariably, it can be concluded that "the institution of elders is one of the crucial institutions for conflict resolution in most African societies" (Kariuki, n.d., p. 1).

\section{Women's Groups}

Women relate with each other in a way of advising and encouraging one another as they face challenges of matrimonial homes. They form groups and associations among themselves which are basically geared towards strengthening one another's relationships through counsels and words of encouragement. Because other people's lives are formed through and in them, women's groups are considered to be life-givers; hence, they are expected to be life preservers as well (Edmonds, 2008, para. 5). Life is produced through marriage consummation, while life is nurtured and grown through the family; thus, 
women are regarded as the livewire and the custodian of marriage and the family institution.

More importantly, “women in different pre-colonial African societies had traditional peacemaking and peace-building roles as they were involved in mediating and preventing conflict within and between societies" (Isike \& Uzodike, 2011, para. 18). It has been argued that "women offer unique, substantive, and measurable contributions to securing and keeping peace. Evidence shows that security efforts are more successful and sustainable when women contribute to prevention and early warning, peacemaking, and post-conflict resolution and rebuilding" (Bigio \& Vogelstein, 2016, p. 3). This is because "research suggests that women can improve the efficacy of conflict prevention and early warning strategies. Women's central roles in many families and communities afford them a unique vantage point to recognize unusual patterns of behavior and signs of impending conflict” (Bigio \& Vogelstein, 2016, p. 3).

Another area where women's group functions is the nurture they provide to upcoming young women. Young girls learn from older women how to do house chores as they aspire to become responsible women in the future. Women who are seen as very successful housewives and mothers are encouraged to bring young girls of marriageable age into their homes as understudies so that they can learn the act of becoming good housewives and mothers; they also learn how to take care of their prospective husbands, children, and homes, as well as how to develop the skill of conflict management. It is after these older women have trained the younger women that the latter become qualified to assume the roles of a wife and a mother (Jonasi, 2007, paras. 6, 13; Suda, 1996, p. 73). 


\section{Peer Groups}

The role of peers in socialization among Africans may be seen in the areas of “...empathy, caring, social responsibility, negotiation, persuasion, cooperation, compromise, emotional control, conflict resolution, and more. Peers also provide social and emotional support and are socialization agents who model and mold others' behaviors and beliefs and solidify their own" (Emmy, n.d., p. 1). Thus, the newly wedded husband and wife do not give up their friendships with their peers. Both of them still maintain such relationships for the purposes of socialization, cooperation, advice, help, and encouragement. For instance, Serpell (2011) referred to the word

"Kugwirizana ndi anzache" in Chi-Chewa language, which means "to cooperate with one's peers.' It is a highly valued dimension of behavior in many societies around the world, especially in Africa. The goals and objectives of peer groups is to work together in harmony towards a shared goal; it is the dynamic relationship that enables individuals to pool their efforts for the benefit of a group (p. 196).

Thus, it can be affirmed that "peers are a pervasive aspect of our social lives that impact us from childhood to old age" (Reitz, Zimmermann, Hutteman, Specht, \& Neyer, 2014, p. 22). Peer group friendship for the newly wedded husband and wife is a catalyst to help in facilitating and enhancing marital goals without allowing marital conflicts to degenerate into public nuisance. For instance, peer groups may be in the position of advising their friends on what to do when difficult issues arise in their marital relationships.

\section{Churches}

African indigenous churches in America play a supportive role in helping African marriages and families overcome marital problems and challenges. The churches also see it as their primary duty to see to the full settlement of couples and families who arrive 
newly to the United States. For instance, the "Ethiopian Coptic Church now plays an important role in the adjustment of Ethiopian immigrants to American society. The Nigerian, Ghanaian, Sierra Leonean, and Liberian Christian churches are also playing similar roles in their communities" (Nyang, 2013, para. 15). African immigrants are daily besieged by problems, and so with the constant reality of

...daily stress and pain, many African immigrants, including those with limited financial and emotional means, are drawn to these churches. The churches are socializing agencies that respond to the material and spiritual needs of [the newly arrived members, helping to solve] immigration, legal and other problems (Nyang, 2013, para. 17).

Oyebade (2016) buttressed the role of churches as a medium of help for African immigrants. He explained that

African immigrants, as they face the challenges of integration, have created their own social, cultural, and religious institutions to meet their needs. Of the many civic institutions established by African immigrants, the church appears to be the most vibrant; it is significant for the level at which it is patronized by the community. Recent immigrants from Nigeria, Ethiopia, South Sudan, Ghana, Kenya, Liberia, Uganda, and other African countries have established indigenous churches to serve their respective communities. More people in the African-born community are drawn to these churches than to any other social and cultural institutions they have established. Parishioners, whether regular members or occasional attendees, seek benefits that transcend the fulfillment of spiritual needs; the churches also serve as an important avenue to foster social and cultural identity. In short, the African immigrant church has served as a multi-purpose institution for the immigrants (chap. 3).

It is important to mention here that even though some African immigrants come to the United States without wanting to associate with churches, yet churches still focus on newly arrived African immigrants in order to offer help on a continuous basis to them. "The churches offer the social climate in which members are able to interact with each other. The worship communities serve as oases of peace and tranquility in a sea of confusion and chaos" (Kwakye-Nuako, 2006, p. 131).

Africans generally have a culture rooted in communal living; hence, as the 
newcomers are being integrated into the community of these Christian churches, the churches are also consistently providing "...a web of support to help people cope with the uncertainties in their new environments" (Kwakye-Nuako, 2006, p. 131).

The churches also continue working on the marriage and family relationships of African immigrants so as to ensure that there are no problems that will lead to chronic conflict which may bring about domestic violence. The churches see to it that the types of support provided are basically targeted to stabilize marriages and families and so that they might be conducive to the healthy growth and nourishment of the children. For instance, some of the aids and supports provided to African immigrants include but are not limited to premarital counseling programs to help eligible bachelors and spinsters among them choose correct emotional support for those passing through one type of distress or another, and parenting classes to educate parents on ways to raise children in the new culture in which they find themselves (Kwakye-Nuako, 2006, p. 133).

Pastors, elders, men, and women in these churches do not stand aloof to watch couple's conflict degenerate into domestic violence. Even though issues of family violence still happen, churches strive to minimalize divorces by educating couples to love, cherish, and respect each other. There are support groups formed in these churches who, through various programs that they organize, help to strengthen the home and to provide the climate for children to mature into responsible adults (Kwakye-Nuako, 2006, pp. 133-134). In summary, the role of Christian spirituality in curtailing conflicts among couples and stabilizing homes, whether back in Africa or here in the United States, cannot be overemphasized. 


\section{Support System for African Americans' \\ Marriages and Families}

The African American support system and communal care arrangements for marriages and families can be said to have originated from their connection with African historical and cultural antecedents and heritages (Sudarkasa, 1998, p. 92). It is obvious that "African American families are at a critical crossroad - the Black family is in worse shape now than at any other point in American history" (National Black Church Initiative, 2018, para. 2). A spiral down this pathway “...has proven to lead to violence, poverty, moral depravity, and failure..." generally for African American families (National Black Church Initiative, 2018, para. 2). In view of this, support systems have been developed to help African American couples in conflict resolve the conflict and establish strong social networks designed to lubricate the wheels of progress, peace, and harmony for the institution of marriage and family in the African American community. The following support systems have proven to be very beneficial.

\section{Kinship Connection}

Kinship is synonymous with the concept of extended family relationship. Through the kinship network, marriages and families in the African American circle enjoy reciprocated support and an informal exchange of care from members of the extended family. This type of support may include help “...to families facing a variety of life crises including death, illness, unemployment, child rearing problems, and catastrophic events such as automobile accidents, fires, floods, and storms. Similarly, they encircle children at risk to provide nurturance, guidance, stimulation, and safety" (Mills, Usher, \& McFadden, 1999, p. 28). It has been opined that kinship produces a “...pattern of strong 
family bonds among African Americans" (Briscoe, 2000, p. 102); hence, it can be assumed that kinship may lead to de-escalation of conflicts in marriages and families in African Americans as a result of this kinship bond.

In addition, a kinship network may assist in engendering peaceful conflict resolution and coexistence in marriage relationships and family dynamics because of the fear by members of the family not to lose the benefits associated with this system. Boundaries are set up to curtail relationship excesses that may lead to domestic violence. Jewell (2003) explained this in detail:

The mutual aid network reinforced values, beliefs and behaviors governing social interaction between husbands, wives and children. African American family members received positive or negative sanctions, depending on their willingness to exhibit prescribed behaviors. Nonconformity to established norms could result in the withholding of goods and services, or some other forms of social sanctioning. With the ultimate goal being the maintenance of African American two-parent families, it is little wonder that husbands and wives confronted with family or marital problems sought and utilized strategies for problem resolution that seldom included separation or divorce (p. 45).

\section{Churches}

Traditionally, the African American church has served as an essential religious, social, and public organization among Black communities. "Research findings have indicated that formal religion (i.e., the Black church) is a primary contributor to values that create supportive and responsive family relationships (Brody, Stoneman, Flor, \& McCrary, 1994, pp. 878-888). Brody et al. (1994) went on to postulate that “...this support system is based in the formal religious structure that helps African American families cope with life and social stressors, such as economic and racial inequalities. Many churches provide for basic needs, such as, food, shelter, and clothing" (pp. 878888). 
Furthermore, African American Churches or so-called Black Churches are undoubtedly committed to the well-being of African American marriage relationships and families. They try to put in place different mechanisms that will ensure that cohesion and peace exist in African American marriages and families. Churches are aware that a lot of damage has been done to African Americans as a result of their slavery background, which has also given rise to their circumstances in this contemporary society. In view of this, Black churches have resolved to put programs together that are geared towards the reconstruction of the past and the betterment of the present for African Americans. For instance,

The National Black Church Initiative, a coalition of 34,000 churches, is committed to strengthening the African American family by repairing the damage created by unmarried parents, weak moral standards, and years of neglecting to address this truly pressing societal issue (National Black Church Initiative, 2018, para 1).

They believe very strongly that "the family unit is an essential component in the fabric of American life and the success of the Black community depends on the Church's vigorous defense of the traditional family" (National Black Church Initiative, 2018, para. 1).

An apt summary of the support that the coalition of churches is providing in order to create a consciousness required for African American families to break off from their inhumane past is enunciated below:

The central essence of NBCI's Family Strengthening Circles is to create a structured environment of education, learning, and training. The core issue of the African American family, we believe, is to provide sufficient and adequate educational training modalities on how to implement a successful, Christian family-based model. The model should help our families deal with any evils that are destroying the family i.e. marital strife, sexual, economic, and spiritual issues (National Black Church Initiative, 2018, para. 26). 


\section{Cohabitation, Divorce, and Decline in Marriage among}

African Americans and African Immigrants

A brief examination of cohabitation, divorce, and decline in marriage in the USA, in general, and among African American and African immigrant ethnic groups, specifically, may be necessary at this juncture. This is important, because, just like these three situations are prevalent in North America and are rampant among African Americans, it may also be that they are present among African immigrants. The possibility of the presence of cohabitation, divorce, and retreat from marriage among immigrants may be because

... as immigration increases in the United States, attention has focused on how new arrivals and their offspring fare across multiple social outcomes. One of the key questions surrounding the adaptation or assimilation of immigrants is the extent to which their family formation patterns will change in accordance to the dominant patterns in the receiving society. (Brown, Van Hook, \& Glick, 2008, p. 531)

Generally, among immigrants, "family formation processes have a significant bearing on adult living arrangements" (National Academies of Sciences, Engineering, and Medicine, 2015, p. 365). The prevailing situation is that

integration presents a number of union status options to immigrants. Among them is the retreat from marriage along with an increased emphasis on nonmarital cohabiting relationships. As immigrants adopt new social norms, they may also increasingly view divorce and separation as normatively acceptable alternatives to a bad marriage (Qian 2013; Glick 2010). Declines in marriage and increases in union dissolution increase the likelihood that immigrants would live alone or in other nonfamily households. (National Academies of Sciences, Engineering, and Medicine, 2015, p. 365)

\section{Cohabitation}

Cohabitation means that two people who are romantically involved choose to live together without making the formal commitment of marriage (Gilles, 2016, para. 2). According to Pew Research, "cohabitation rates are more consistent across racial and 
ethnic groups - $8 \%$ of whites and Hispanics and 7\% of blacks are cohabiting, as are 3\% of Asians" (Horowitz, Graf, \& Livingstone, 2019, para. 7). Whereas the percentage of first-generation black immigrants cohabiting is $5.5 \%$, the percentage of secondgeneration black immigrants cohabiting is $6.8 \%$, while the percentage of third-generation black immigrants cohabiting is $9.4 \%$ (National Academies of Sciences, Engineering, and Medicine, 2015, p. 367). It follows then, that “....with each successive generation, immigrant populations have adapted to their new environments by assuming patterns of family structure — size and composition—-that resemble those of their native-born counterparts and the majority white population" (National Academies of Sciences, Engineering, and Medicine, 2015, p. 370). The CDC (as cited in Legaljobs) has come up with some statistics to show that by and large, cohabitation may have its own downsides on the couples who practice it, especially as it relates to the advantage that legal marriage has on cohabitation:

There is a $20 \%$ chance of a first marriage resulting in divorce within five years. In comparison, couples who cohabit for five years have a $49 \%$ chance of separating. Similarly, married couples have a $33 \%$ chance of divorce within 10 years, whilst cohabiting couples have a $62 \%$ chance of splitting up in this timeframe. These statistics indicate that married couples are likely to remain together longer than couples who choose to cohabit but do not marry. (Vuleta, 2021, Item no. 25)

\section{Divorce}

Researchers used to put the statistic of divorce rate in America as 50\% of marriages ending in divorce. That is no more the case. The divorce rate in American society seems to be decreasing (Luscombe, 2018, para. 1), and the marriage rate seems to be decreasing, as well. For instance, according to the $S M U$ [Southern Methodist University] Daily Campus. (“How frequently,” 2020), “...today, some 39 percent of 
marriages in the United States are ending in divorce. This data comes from the most recent census data" (para. 3). In addition, "recent news from Census data is that for every 1,000 unmarried adults in 2019, only 33 got married" (Wang, 2020, para. 5).

African American and African immigrant ethnic groups are not immune to this situation because they also live right in the middle of it. From the research conducted by Bowling Green State University, of all the racial-ethnic groups studied, African American "... black women were the only group that had a higher divorce rate than marriage rate, with nearly 31 divorces per 1,000 married women aged 15 and older" (Schweizer, 2019, para. 3).

Concerning the situation with African immigrants, it has been opined that "...migration increases divorce risk when women migrate without their husbands, or when both partners migrate simultaneously" (Caarls \& Mazzucato, 2015, p. 142). The explanation given is that from the perspective of sociodemographic studies, the stresses associated with moving from Africa to their place of destination, as well as with immigration and acculturation, can contribute to an increase in the possibility of marital tension in the immigrant couple's marriage, which can in turn culminate in divorce (Caarls \& Mazzucato, 2015, p. 127). Thus, “...compared to their countries of origin, divorce among African families in the United States is very high. The average span of an African married couple in the United States is, unfortunately, only about seven years" (Swaray Law Office, 2010, para. 2). It follows, then, that with the rates of both divorce and marriage dropping generally in the United States of America,

we expect to see the marriage divide deepen and poor and working-class Americans increasingly disconnected from the institution of marriage. The impact of this disconnection on our family lives can be destructive, which makes it an issue that 
policymakers, community leaders, and scholars should continue to pay attention to. (Wang, 2020, para. 8)

\section{Decline in Marriage}

There is another growing concern about fewer people wanting to get married and more single parents with children born out of wedlock. For instance, according to the 2010 census, "more than 70\% of black women are unmarried" (Stewart, 2020, para. 1).

To lend more credence to this assertion, Caucutt, Guner, and Rauh (2019), reported that "in 2006, 67\% of white women between ages 25 and 54 were married, while only $34 \%$ of black women were - a gap of 33 percentage points" (para. 1). Furthermore, in regards to single parenting "in 2019, there were about 4.15 million Black families in the United States with a single mother. This is an increase from 1990 levels, when there were about 3.4 million Black families with a single mother" (Statista, 2021, para. 1). With the incidences of single parenting among the blacks, "Black children are more likely than white and Hispanic children to live with a single parent and more likely to live with no parents" (Wherry \& Finegold, 2004, p. 3). In order to curb this endemic single parenting and fatherless situation, an all-inclusive method to marriage promotion is needed to expand the range of allowable activities to include responsible fatherhood programs, job training, and elimination of marriage disincentives in the list of allowable activities from which state officials can choose. Such an approach would give the states more flexibility to develop programs that best match the characteristics of their own diverse populations. (Wherry \& Finegold, 2004, p. 6)

\section{A Discussion of the Possible Causes of Couple's Conflict}

A closer look at the prevalence of couple conflict portrays the reality that conflict between people who love each other can escalate to a critical extent where perpetual, indeterminable pains and heartaches will be manifested. The important factor is not that 
such people have differences, but how constructively or harmfully they are able to resolve their differences. Rather than withdrawing from and avoiding the conflict, couples should be intentional about using such conflict as a way to build, strengthen, and deepen their relationships. As discussed below, marital or couple conflicts among African immigrant couples may be caused by acculturation and immigration issues, economic and money matters, educational challenges confronting international students and their spouses, sex and infidelity, poor quality time spent together, lack of communication, as well as sociocultural and psychosocial factors.

\section{Acculturation}

Acculturation has been described as covering " ...all the changes that arise following 'contact' between individuals and groups of different cultural backgrounds"' (Sam \& Berry, 2006, p. 11). According to these authors, "the groups or individuals commonly identified as undergoing acculturation include immigrants, refugees, asylum seekers, sojourners, ethnocultural groups and indigenous peoples" (p. 15). It is explained that acculturation requires adaptations which “...occur through developmental and socialization processes in the home and broader community" (Dalla, Defrain, Johnson, \& Abbott, 2009, p. 11). As demonstrated by research, Abbott and Gupta (2009) explained that

American culture can have a powerful effect upon the marriage and family life of new immigrants (Kalita, 2003; Trask and Hamon, 2007). The American media, the secular social norms such as; egalitarianism, individualism, humanism, and American political values such as democracy, freedom of speech, and multiculturalism, may all combine together to influence various aspects of marital interaction. Aspects of marital relationship that may be affected include; increasing or decreasing sexual interaction, parenting patterns and behaviors, challenges to authoritarian discipline, and less family time as well as less leisure activity time (Ingodsby and Smith, 2005). Thus, new immigrants face a challenge when they are overwhelmed by the demands 
of American culture: How much assimilation will they embrace or permit and how much will they retain of the values and behaviors of their homeland culture (Min, 2005; Parrillo, 2005; Petievich, 1999) (pp. 93-94).

Couples who come to another culture to live temporarily or permanently, whether to work or to go to school, are most likely going to face culture shock and adaptation problems. The demand of their marital relationship is one thing to contend with, while the stress of coping with the new culture they find themselves in is another challenge altogether. Couples who find themselves in such situations need to be skillful enough to marry these two issues together so that serious marital conflicts do not ensue through this process.

From the above, it becomes apparent that African immigrants living in North America, as time goes on, may become Americanized in the way they conceive family lives through acculturation. and therefore, face the challenges confronting the ideal family life set up. Thus, the

families of new arrivals may increasingly reflect the unprecedented shifts in marriage and family life in the United States and other rich countries over the past several decades, which include the "retreat from marriage," more childbearing outside marriage, higher rates of nonmarital cohabitation, and increasing divorce and remarriage (Landale, Oropesa, and Bradatan, 2006; Sassler, 2010). Household or family extension among some immigrant populations also has slowly given way to the nuclear family system and the rise in nonfamily households (including cohabitation and living alone) (Waters \& Pineau, 2015, p. 371).

From the angle of African American couples, problems confronting them in their marriages and family relationships are obviously not acculturation. Dixon (2009) opined that

factors contributing to the marriage status of African Americans include structural, cultural, individual, and interactive factors. Structural factors include the disparity in sex ratios between African American males and females and employment instability among African American males. Cultural factors include changing cultural trends such as marriage not being a perquisite for sex, the independence of women, the shift 
from familism to individualism, cohabitation as an increasing option, and the promotion of the values of materialism and patriarchy through popular culture (p. 29).

\section{Economic and Money Issues}

There has been considerable research about the leading causes of marital conflict and stress; most of these studies have identified money or material things as one of the leading causes of marital violence. For instance, Holland (2015) said, without mincing words, that "finances are the leading cause of stress in a relationship" (para. 1). In addition, a study by Jeffrey Dew of Utah State University found that husbands and wives who quarrel about financial issues "once a week are $30 \%$ more likely to end up divorced than those who disagree over money only a few times a month. Fighting about money was the only disagreement that was highly correlated with divorce in the study" (Heath, 2013, paras. 6-7).

Most men and women in the world today have been sold out to pleasurable things such as food and drinks, posh cars, big and elegant buildings, adventurous traveling, attending and organizing feasts and parties, to mention a few. The reality is that the purchasing power of money is what is required by these men and women to have full access to these pleasurable things of life; hence, they want to remove anything from their path that will block them from having full access to money, including their spouses, if they see them as impediments. This is the reason why, “...consequently, financial disagreements may be more likely to predict negative conflict responses than other types of disagreements. Thus, we hypothesized that financial disagreements will be the strongest predictors of negative conflict tactics" (Dew \& Dakin, 2011, p. 26). Because of this, in comparison to other types of marital disagreement, financial disagreements may 
be more problematic for couples. Misunderstandings about how money should be administered can be a constant source of conflict among couples (Dew \& Dakin, 2011, pp. 23, 26). More often than not, “...it is the working out of financial interdependence in marriage that is often so difficult" (Strong, DeVault, \& Cohen, 2008, p. 268).

In view of the sensitivity of money and material issues in marital relationships, it should be well noted that "achieving marital harmony around money may require special attention, energy, and awareness of underlying pitfalls and challenges. Particular attention should be paid to money issues" (Papp, Cummings, \& Goeke-Morey, 2009, p. 12). Couples are encouraged to heed the counsel given by Paul that men and women should be careful about greediness and the uncontrolled desire to get rich because those who desire to be rich fall into temptation and a snare, and into many foolish and harmful lusts which drown men in destruction and perdition. For the love of money is a root of all kinds of evil, for which some have strayed from the faith in their greediness and pierced themselves through with many sorrows (1 Tim 6:9-10).

It is better to live in a modest house with peace and calmness, eating a dry morsel of food than to live in a sprawling and magnificent house that is filled with feastings, food, drink and abundant money with riotous living (Prov 17:1). Of course, what is very true in a couple's relationships as regards money and material possessions is that the possession of money in a marital relationship does not necessarily determine peace and happiness for the couple; it is the selfless and loving acts of the couple toward each other and to God that predicate genuine and lasting peace and happiness.

\section{Educational Challenges Facing International Students and Their Spouses}

Several factors can cause domestic violence in a family and between couples. Challenges of higher education, where either of the partners enrolls for classes, can be 
very encumbering on the family. Because the family finances are divided among the payment of tuition, buying books, and taking care of other school expenses, members feel financially stressed. Things may become more difficult for international students who have come with their families and who may not have access to loans, grants, financial aid, and scholarships as American citizens or permanent residents have. The resulting effect of this is that other members of the family will start to feel the strain and the pain being brought upon the family. Schnabel (2012) opined that “...to compound the situation, previous support groups can be lost when a family uproots themselves, leaving their family and friends to move to a community in which they may be relatively isolated" (pp. 46-47).

In addition, Anim (2013) explained the other area of educational challenges which can cause conflict among couples. This has to do with the awareness that educational attainment by females has created for the wives. The attainment of education becomes an enlightenment factor that opens the eyes of women who think that they have been perpetually relegated to a second-class position in the home and society. He advanced that

Western education and its consequent "emancipation" of women may have also affected marital distress in a society where male dominance is taken for granted. An educated wife may seek to exert "equal-status" authority in the marriage, and may challenge her husband's final decisions pertaining to the home. Some highly educated couples find it difficult agreeing who controls affairs in the marriage: the husband, wife, or both? Many educated women answer that it is both, for in marriage both should share the same authority or exercise equal-status rights and power. These ideas may make some wives behave in traditionally unacceptable ways in their relationships, and this may spark a lot of friction, communication problems, marital dissatisfaction and distress (p. 162).

For example, Ladepo (2014) mentioned with a few examples that there has been an epidemic of Nigerian men killing their nurse wives in the United States (para. 1). Most 
of these killings happen when a man goes back home to marry a Nigerian village girl and brings her to the United States to educate her as a nurse. The girl becomes educated as a full-fledged nurse, becomes aware of her rights and privileges as an educated woman, and then starts to free herself from the oppression of the husband who still wants her to behave and relate like a typical Nigerian village girl. The end result is usually domestic violence which has led to the murder of several of these women. For instance, Ladepo (2014) wrote about the experience of Moses and Grace Egharevba of Dallas, Texas. This story is just one of many that are similar:

In Dallas, Moses Egharevba, 45, did not even bother to get a gun. The husband of Grace Egharevba, 35, bludgeoned her to death with a sledge hammer while their seven-year-old daughter watched and screamed for peace. Mrs. Egharevba's "sin" was that she became an RN and started to make more money than her husband. This led to her "financial liberation" from a supposedly tight-fisted husband who had not only brought her from Nigeria but had also funded her nursing school education (para. 3).

\section{Sex and Infidelity}

God gave humanity the gift of sex; however, humanity has engaged in extraneous activities to profane this gift. Because of the entrance of sin, sex has been taken out of its spiritual context and now the picture that is painted of sex is that it is basically for recreation outside of marriage. It is sad to note that within the cultural, social, economic, and religious domains, the gift of sex has been trivialized and has been made a cheap thing that can be done at will (Balswick \& Balswick, 2014, p. 214). Modern American society actually goes a step further in that the issue of sexual immorality has become very prevalent among the rank and file of human beings. Hill (2008) painted a graphic picture of the situation: 
A surge of popular books dealing with sex, romance, attraction, and relationships within the last several decades drives home how interested many people are in the topic. Likewise, rental of erotic videos currently makes up a huge portion of all video rentals. Sex-related issues are a frequent focus on TV and radio talk shows, reality shows, soap operas, and movies. Moreover, in recent times, among the most profitable internet web sites are those that offer erotic images, stories, services and products (pp. 5-6).

With the multiplication of sexual activities outside the marriage institution, there seems to be building up a high level of promiscuity that has turned the society into a seemingly sexually permissive place. This sexual misdemeanor has extended to marriages, with infidelity becoming a common occurrence among married couples. As a result, conflicts may erupt that lead to a series of domestic violent acts due to the unfaithfulness of married couples to one another.

Sexual opportunities abound more when people regularly go without their partners to club houses, recreation centers, fitness centers, parties, and work trips which demand that the individual sometimes has to stay away for days and weeks. Nowadays, sexual opportunities present themselves in schools and churches; in the neighborhood; on the streets; and in villages, small towns, and big cities. In fact, if a married man or a married woman does not close his or her eyes to all the sexual temptations around, it is easy to fall prey to the temptation. Hence, Treas and Giesen (2004) concluded that within the social context, opportunities may abound whereby a spouse looks for a place to socialize outside the company of his/her mate (p. 50). Since infidelity predicts lower marital satisfaction and divorce (Shackelford \& Buss, 2000, p. 918), it can be opined that infidelity may lead to a couple's conflicts, aggression, domestic violence, and finally, to separation and divorce if it is not handled well and on time.

Looking at another perspective of problems associated with sex and infidelity, 
there is a dichotomy of the sociocultural view about marital rape between Africans and

African Americans.

Historically, marital or intimate partner rape was not considered a crime. In many countries, including the United States, rape was traditionally defined as forced sexual conduct with someone other than one's wife. As a matter of law, rape could not occur within a marital relationship; the wife's consent to the sexual conduct was presumed. In recent years, however, there has been marked progress in removing such marital exemptions from rape statutes. As of 2011, at least 52 countries have explicitly made marital rape a criminal offense, and according to a 2006 report from the UN Secretary-General, at least 104 countries criminalize marital rape - if not under explicit marital rape statutes, then under general rape laws. Yet, despite the trend on the books, legal systems in many countries continue to reflect the belief that rape within a marriage is not rape (Engel, 2020, paras. 9-10).

Thus, while African Americans will view marital rape as an offense punishable under the law, African immigrants, because of their cultural orientation, may view marital rape as normal. One of the cultural practices is the payment of the bride-price, which is “... sometimes seen as a way of validating a man's right to 'own' his wife so that wives are sometimes viewed as the property of their husbands" (Kamau, Nyaundi, \& Serwanga, 2013, p. 8). Therefore, it was not surprising to hear in the debate on the passing of the Sexual Offences Act that one Member of Parliament used the practice of bride price payment to negate arguments for the possibility of marital rape:

"I have paid dowry for my wife and we are formally married. I cannot rape her by any chance. You can see the damage that western indoctrination has done to us. I cannot rape my wife! I don't think there is one man who can rape his wife...you can rape someone else." (Kenya National Assembly Official Record (Hansard), Second Reading of the Sexual Offences Bill, April 27) (Kamau et al., 2013, p. 10).

Rape of women is a pandemic that has not been completely cleared off from the African sociocultural environment. For example, "according to the World Bank Research on Women, Business and Law, only 14 countries in Africa have legislation in place that specifically criminalizes marital rape" (Chakamba, 2016, para, 5). 
In addition, just as in the case of marital aggression, the incidences of sexual coercion may be underreported due to cultural stigmas and stereotypes associated with it. Since not all cases are reported to the respective authorities, proportions of as high as “...67\%-84\% of cases of sexual violence may go unreported due to the sensitivity of the issue, thereby making it difficult to gather exact figures and true sense of the problem" (Kalra \& Bhugra, 2013, para. 7).

\section{Poor Quality Time}

Relationships have to be intentionally worked upon with quality time being devoted to it before it can thrive. The marriage relationship is even more technical; thus, more time is required in working on it. Most married couples do not see their relationships as taking priority over other areas of their lives.

In the busyness of life, love isn't self-sufficient. Your marriage must be constantly fed and nurtured by spending regular time together. In marriage, opportunities to enjoy each other's company should not be few and far between. On the contrary, they have to be part of the fabric of a couple's life. That means making together-time a priority. And that requires intentionality (Focus on the Family, 2018, paras. 1, 4).

Furthermore, couples who do not spend time together to interact and communicate are working towards killing their marital relationship. Distance can lead to a deep relational gorge which can bring about emotional damages to either of the couples. Disaffection, stonewalling, and hatred can set in. "As resentment and disconnect begin to infiltrate marriages, feelings of loneliness emerge and couples perceive that they have suffered a great loss" (Rolwing, 2012, para. 10).

As much as possible, it is suggested that "couples remain curious about each other, similar to the time when they first began dating, and ask questions in an effort to better understand and communicate with their spouse" (Rolwing, 2012, para. 11). There 
may be some fundamental reasons why couples do not have enough time to bond together. One major reason is the various demands and stresses that couples are exposed to. "When couples are chronically exposed to external stressors, the foundation of their intimate relationship may slowly erode over time" (Milek, 2015, p. 16), thus affecting the time spent together. Consequently, “...in stressful periods..., they have less opportunities to participate in joint leisure or share thoughts and innermost feelings" (Milek, 2015, p. 17). Conflicts may constantly infiltrate marital relationships if one partner feels that the other partner is not making him or her a priority, especially when it comes to quality of time devoted to a partner.

\section{Lack of Communication}

For a relationship to have healthy growth, there must be constant and effective positive communication between the individuals who are in that relationship. Communication occupies an important place in marriage. "When couples have communication problems, they often fear that their marriages are seriously flawed, one of the most common complaints of couples seeking therapy is about their communication problems (Burleson \& Denton, 1997)" (Strong \& Cohen, 2013, p. 237). Communication is a lubricant to relationship; if not used to a sufficient degree, it may cause a relationship to halt. "Studies suggest that poor communication skills precede the onset of marital problems (Gottman, 1994; Markman, 1981; Markman et al., 1987). Even family violence has been seen by some as the consequence of deficiencies in the ability to communicate (Burleson \& Denton, 1997)" (Strong \& Cohen, 2017, p. 251).

Communication happens one way or the other in any relationship; it may be a type of communication that aggravates conflict or one that douses tension build-up. 
Communication patterns that are flavored with genuine and sincere love can become an instrument that will reduce conflict and promote universal peace. Thus, as much as possible, couples should endeavor to learn the appropriate communication skills needed that will facilitate the reduction of conflict in their relationship. This is important because "effective communication between partners is widely considered to be an essential part of successful romantic relationship functioning, and dissatisfaction with communication is the most common reason couples seek therapy" (Crenshaw, Christensen, Baucom, Epstein, \& Baucom, 2017, p. 913). When couples speak soothing words to each other, the tense atmosphere will automatically become relaxed. As much as possible, negative thoughts and words that can tear down the other partner should not be said. Paul counseled, "Finally, brothers and sisters, whatever is true, whatever is noble, whatever is right, whatever is pure, whatever is lovely, whatever is admirable — if anything is excellent or praiseworthy—-think about such things" (Phil 4:8). In the same vein, Solomon established the fact that "a soft answer turns away wrath, but a harsh word stirs up anger" (Prov 15:1).

Referring to Gottman's four basic noxious behaviors that may possibly create a communication crevasse between couples, Pleaner (2017) alluded to the fact that if these behaviors happen very frequently in a relationship, they may breed isolation, loneliness, and disunity, which, in turn, may cause constant relationship frictions between couples. Criticism is one of the four noxious communication behaviors which "entails complaining with blaming or attacking or criticizing or harshness" (Pleaner, 2017, para. 13). Defensiveness is another one. This involves justifying "oneself and making the other party take the blame" (para. 19). 
Contempt includes a wide variety of attitudes such as "facial expressions - rolling one's eyes, sighing in resignation, body language which pushes one's partner away-to an 'I'd never sink so low as to do something like that—what kind of person are you?"' There are usually derogatory behaviors that accompany contempt such as "despising, loathing and devaluing one's partner." The last harmful communication identified by Gottman is stonewalling. This behavior is characterized with "shutting down, withdrawing associated with high physiological arousal and efforts to self-soothe with thoughts like 'I can't believe she's saying this!' Typically, women are more likely to criticize than men and men are more likely to stonewall and withdraw" (Pleaner, 2017, paras. 13-19).

\section{Sociocultural and Psychosocial Factors}

Other psychosocial factors have been identified as sources of conflict between partners. For instance, "there is considerable empirical evidence that alcohol use often precedes or accompanies acts of marital aggression (Leonard, 1993). Furthermore, a number of studies indicate that alcohol and drug use are associated with levels of IPV severity" (Cunradi, Caetano, \& Schafer, 2002, p. 493). Added to this is the fact that when marital problems get complicated, either or both of the partners may resort to drinking, smoking, drug use, gambling, and a number of other social misdemeanors that could actually bring total ruin to their relationships.

Looking at the general sociocultural situation of the African Americans, it has been argued that since "many violent African American males are from single parent households or unwed households" (Alvin, 2007, p. 35), it has increased, to a large extent, "...the risk for the presence of a number of other such as absence of discipline, economic 
and social deprivation, and insufficient positive exposure" (Alvin, 2007, p. 35). Some fallouts of this situation for the average African American may include aggression and violence in all their forms as possible responses to this unpleasant situation "The stereotypes of African American males as aggressive and violent have persisted to the point that the victims of the stereotype have assumed their ascribed position" (Alvin, 2007, pp. 35-36).

In another vein, one major issue that may continue to perpetuate but hide the true picture of marital conflict from the sociocultural perspective of the Africans is the impact that racial loyalty has upon African women. For instance, underreporting of sexual coercion, physical and psychological aggressions, as well as injury sustained due to racial loyalty may prolong the lifespan of such crimes. Sable, Danis, Mauzy, and Gallagher (2006) identified three notable barriers to reporting: “(a) shame, guilt, embarrassment, not wanting friends and family to know; (b) concerns about confidentiality; and (c) fear of not being believed" (p. 157).

This situation is further compounded with the sociocultural belief that African wives can be disciplined if they misbehave, thereby ruling out the concept of men's aggression on their wives. Marital aggression is thus more entrenched and accepted in most parts of sub-Saharan Africa than in some other sociocultural contexts. The prevalence of acts of physical and psychological aggressions such as wife beating, scolding, verbal abuse, discipline, and wifely transgressions may therefore be justified by men and women within African sociocultural contexts. For example, “...about half of women interviewed in Zambia in 2001 and 2002 said husbands had a right to beat wives who argue with them, burn the dinner, go out without the husband's permission, neglect 
the children or refuse sex" (Lafraniere, 2005, para. 11).

\section{Levels of Couple's Conflict: From Mild to Severe}

The intensity of a couple's conflict can increase if not handled very well.

Conflicts can progress from a minor war of words to slapping and beating, and finally, to even more serious domestic violence (Feld \& Straus, 1989, pp. 141-142). “...Even though the bulk of the assaults that occur in couples' conflict in marriage are minor, they could continue indefinitely and escalate into more severe assaults. A number of studies report such a pattern (Giles-Sims, 1983; Pagelow, 1981; Walker, 1979)" (Feld \& Straus, 1989, p. 142). The intention of the perpetrator of conflict or domestic violence is to satisfy a particular goal or objective. The victimized individual is seen as a barrier to achieving such a goal or objective. Hence, the perpetrator wants to do whatever he or she thinks possible in order to remove the object of obstruction.

There are four reasons advanced by Feld and Straus (1989) as to why minor conflicts can graduate into serious violent attitudes in time:

First, the presence of minor violence may indicate that violence is permissible or tolerable and therefore severe violence is more likely to occur. Second, although the motivation toward violence varies from time to time and situation to situation, the presence of any violence at one time indicates a greater likelihood of violencemotivating factors (e.g., stress, power struggles) at other times; some of those factors could motivate severe as well as minor assaults. Third, violence could be an effective way for a husband to achieve his ends; consequently, he might be motivated to continue its use and even escalate its level when minor violence is no longer effective. Finally, assaults of any level by one partner increase the likelihood of violent response by the other partner, which in turn may provoke response from the first partner, and so on. Such interchanges could continue over a long time, and sometimes escalate (p. 147).

In the case of couple conflict, it has been found out that "couples with a high level of conflict engage in more verbal aggression (Straus \& Hotaling, 1980)" (Straus \& 
Sweet, 1992, p. 350). Verbal aggression can be mitigated if conflicts are attended to in a timely fashion. However, it may escalate into physical aggression if not handled relatively quickly. Verbal aggression may be characterized by “...name calling or nasty remarks (active, verbal), slamming a door or smashing something (active, nonverbal), and stony silence or sulking (passive, nonverbal)" (Straus \& Sweet, 1992, p. 347).

Physical aggression may be accompanied by beating and inflicting injury or severe damage on the partner. Conflict may take the turn of just ordinarily grabbing a partner and shaking him or her "...to such incidents as hitting and kicking ..., torture . . ., burning ..., stabbing ..., and shooting. The most frequent type of violence involved pouncing on someone, grabbing them forcefully or causing them to fall ... Clearly, we are not dealing with 'kid stuff'” (Straus \& Hotaling, 1980, pp. 55-56). Verbal and physical aggressions, which lead to aggravated domestic violence, do not start in one day; they are most likely the results of accumulated conflicts that have been neglected or not seriously confronted over time. Some of these may have even started when the couples began dating and courting or at the earliest part of marriage. This, indeed, is a serious matter that needs more attention. The world will only experience peace and harmony if love replaces violence in homes. This remains a valid point which resonates with what Mother Teresa said:

If you want to bring happiness to the whole world, go home and love your family." Rather than trying to change the entire world, Mother Teresa suggested that we spend more time loving our spouses and children, which will transmit joy in our wider communities (Ewing, n.d., paras. 1-2).

\section{Unresolved Conflicts}

There comes a point in some families and between couples when unresolved 
conflicts make living together no longer workable. When a husband or wife or both become disillusioned, believe that the marriage no longer offers security or that it is impossible to get one's basic needs met, the marriage is on its way to dissolution. According to Squires (2012), conflict is not always resolved. There are times when positions are too strong and

...independent to change that no agreement can be met (Floyd, 2009). A conflict will then be pushed to the background of the relationship, unresolved. Research shows that different types and styles of conflict revolve around unresolved conflict. Avoiding, stonewalling, serial arguments, perpetual arguments, and intractable arguments all play a role in circumstances surrounding unresolved conflict. Avoiding a conflict can leave it unresolved...; there are many instances where conflict exacerbates, when parties try to make it disappear (Floyd, 2009) (pp. 6-7).

Unresolved conflicts graduate from petty things that could have been taken care of, to huge issues that could completely destroy the marital relationships. Unresolved conflicts may lead to domestic violence, separation, or divorce. It may sometimes lead to the death of one of the partners. According to Tucker and Tucker (2017), "nowadays, the studies of many researchers indicate that the most important factor when it comes to explaining the high rate of divorce is the inability to manage disagreements" (p. 108). Some couples try to resume working on their conflicts after a lot of issues have been swept under the carpet and they have become unbearable (Scot, Rhoades, Stanley, Allen, \& Marman, 2013, p. 13).

It is important to note that some of the factors associated with couple conflict are mostly manmade and addictive in nature. A few of these factors happen as a result of sociocultural issues. For instance, some men and women who are either separated or divorced

...cite unresolved issues such as alcoholism, drug abuse, marital infidelity, sexual incompatibility, and conflicts about gender roles as relationship factors leading to 
their (separation) and divorces. They also often cite external events-problems with in-laws or the effects of jobs (Strong et al., 2008, p. 499).

A cultural factor that often leads to conflict among some African couples is the problem of patriarchal domination, especially when they come to live in the United States. Some African men "grow up with an inflated, hyper-masculine view of manhood and are therefore more prone to violence" (United Nations, 1996, p. 108).

Putting all the above together, there needs to be some effective mechanisms put in place by marriage and family resource persons to intervene fairly early in couple conflicts. Couples should also be intentional about timely conflict settlement. Tucker and Tucker (2017) have, at the same time, warned and counseled couples that

if you allow unresolved issues to stack up between the two of you, those issues will separate you. They may or may not separate you through divorce or legal separation, but they will cause the two of you to live separate lives. You may continue to live in the same house but have no real intimacy. It is far better to commit to resolving issues on a timely basis. Don't allow things to stack up. Deal with issues one at a time (p. 106).

The news is replete with unresolved conflicts leading to abuse and domestic violence which have, in turn, resulted in the murder of either member of the couple or even of children. Before unresolved conflict leads to murder, it is advisable to leave such a relationship; instead of allowing unresolved conflict to degenerate into death, watch for signs that could bring permanent damage to the parties in a relationship and leave before it happens. Icheoku (2008) counseled:

There are other more acceptable options available for getting out of a hellish marriage including just getting up and leaving; mutual separation or the penultimate divorce instead of committing the mother of all crimes - taking the life of another! Nothing is worth it (para. 34).

Violence and abuse are becoming more rampant among couples as a result of malignant conflicts that have become indeterminable; this is having a direct effect on 
families and society. The adverse effects of this cannot be overemphasized. "Violence holds victims, families, friends, and neighborhoods hostage. It rips communities apart or prevents them from coming together" (Los Angeles Police Department, 2018, para. 2). Marriage and family professionals should stand up to do something drastic and positive in curtailing this endemic act “...because a healthier, safer community benefits each of us. Because failing to act costs lives and resources. Because our children should not have to raise their children amid violence" (Los Angeles Police Department, 2018, para. 1).

\section{The Impact of Couples' Religiosity and Spirituality on Conflict}

Religiosity and spirituality are two different concepts. The Association of Religious Data Archives (Johnstone, 2016) theorized that religiosity is an individual's level of religious commitment. It is most commonly measured through a self-report of various practices such as frequency of attendance at religious services, frequency of prayer and its intensity, reading of sacred texts such as the Bible, how much money a person gives to his/her place of worship in terms of tithes and offerings, and how frequent these contributions are made (para. 1).

In another vein, spirituality, according to Christina Puchalski, Managing Director of the George Washington Institute for Spirituality and Health, is “...the aspect of humanity that refers to the way individuals seek and express meaning and purpose and the way they experience their connectedness to the moment, to self, to others, to nature, and to the significant or sacred" (Research Connections, 2016, para. 3). Since

"spirituality is about seeking a meaningful connection with something bigger than oneself and which can result in positive emotions, such as peace, awe, contentment, gratitude, and acceptance" (Research Connections, 2016, para. 8), then we can safely assume that 
cultivating a spiritually positive state of mind can enhance a good relationship connection between husbands and wives.

A distinction between religiosity and spirituality helps to see how couples' relationships can be affected positively or negatively. However, "this is an unfortunate distinction, now so defined that one must accept the ideas in order to communicate. But the distinction is really a false dichotomy, because true religion is very much about justice and compassion" (John Matthews, personal communication, 2018). Be that as it may, Shapiro (2012) distinguished between religiosity and spirituality when he explained that "religion is often about loyalty to institutions, clergy, and rules. Spirituality is about loyalty to justice and compassion. Religion talks about God. Spirituality helps to make us godly" (para. 2). He went on to opine that "spiritual practice often calls upon us to surrender ourselves, our will and our comforts to others. Spirituality helps us to build ourselves and others up and not to tear them down" (para. 6). The goal and objective of a spiritually inclined person is to make others comfortable. He or she strives to make the world a better place to live in for all he or she meets and relates with on a daily basis. Such a person becomes selfless, considerate, peaceful, and loving to all peoples with different backgrounds.

Tucker and Tucker (2017) have also mentioned the importance of spirituality in marriage and the role it plays in marital stability, marital satisfaction, and in the resolution of conflicts:

It is difficult to overstate the importance of the spiritual component of marriage. For centuries, preachers have touted the value of spirituality in the marriage relationship. "The family who prays together stays together..." In multiple studies, relationship researchers come to the same conclusions: Couples who possess and practice faith in God have stronger marriages. One study states that, "the deeper the religious experience the greater the marital satisfaction." Religion offers couples guidelines to 
resolve conflict. Greater religiousness is tied to more constructive conflict resolution strategies (pp. 80-81).

In addition, according to University of Wisconsin researcher Bumpass (2000), "persons who attend church at least weekly are about 40 percent less likely to have their relationship break up than are those who do not" (p. 8).

This was aptly buttressed by Lambert and Dollahite (2006) when they found that "couples often expressed that their religious involvement has helped them to develop conflict deterring virtues” (p. 446). Dudley and Kosinski (1990), in discussing the effects of religiosity on marriage, also posited that "religious participation helped couples more often think of the needs of others, be more loving and forgiving, treat each other with respect, and resolve conflict"' (p. 82).

In agreement with the above, the American Psychological Association (2014) has ascertained in their research that "praying for partners, spiritual intimacy, attending services with parents may improve quality of life" (para. 1) among couples and in the family generally. The American Psychological Association (2014) elucidated more on the benefits of spirituality on couples' relationship:

The more spiritual intimacy couples say they share, the better they handle their top three topics of conflict, according to this study. Additionally, couples who viewed their marriage as sacred had more positive marital interactions. Couples' ratings of their spiritual intimacy were based on how often they revealed their spiritual beliefs, questions and doubts to each other, and listened supportively to each other's spiritual disclosures. It didn't matter whether the spouses were blue-collar employees with high school educations or wealthy professionals with advanced college degrees - the results were the same (para. 15).

\section{Summaries of Findings from Some Studies That Have Used the Conflict Tactics Scale}

The CTS was developed by Murray Straus. It is the most widely used instrument 
in measuring intimate partner violence in couples (Criminal Justice, n.d., para. 1; Jory, 2006, p. 88).

Between the first study using the CTS (Straus 1973) and 2005, about 600 research papers and at least ten books reporting results based on the CTS were published. Between 1995 and 2005, four to six articles reporting results obtained using the CTS were published every month (Criminal Justice, n.d., para. 39).

This section will take a brief look at the summaries of findings from five studies that have used the CTS2.

The Marriage License as a Hitting License: A Comparison of Assaults in Dating, Cohabiting, and Married Couples

This research was conducted by Stets and Straus in 1989 and stated: "The marriage license as a hitting license" was coined by Gelles and Straus at the beginning of the 1970s "in response to the discovery that the assault rate among married couples was many times greater than the assault rate between strangers" (Stets \& Straus, 1989, p. 33). This is a comparative analytical study of physical violence among 526 dating couples, 237 cohabiting couples and 5,005 married couples. It should be noted here that some patriarchal domination cultures such as those of the Africans still condone the chastisement of a wife in order to bring her back on course if she is misbehaving. However, it does not have to be like that; this perception, though it is changing gradually, is still pervasive in some parts of the world. Such a cultural belief of male superiority has been found by research to be one of the reasons why some African immigrant couples are having conflicts (Malley-Morrison \& Hines, 2004, p. 200).

As was mentioned earlier, conflict does not have to resort to physical violence, coercion, or injury if handled well and on time. According to this study, even though "...there is an inherently high level of conflict in marriage and cohabiting, nevertheless, 
conflict does not necessarily lead to violence. There are other modes of resolving conflicts..." (Stets \& Straus, 1989, p. 48) that can curb violence among couples. It is sad to note, however, that cohabiting, dating, and married couples all experience physical violence in their relationships.

There were 237 cohabiting couples in this study. It was found that assault is more predominant among cohabiting couples. In addition, after controls for age, education, and occupational statuses were introduced, this study still revealed that there is more severity of violence among them than among dating and married couples (Stets \& Straus, 1989, p. 46). One of the reasons advanced by this study is that cohabiting couples may be distant from kinship connection, which may invariably help in intervening in couples' conflicts before they aggravate into violence. Another reason is that of “...issues of autonomy and control..." (Stets \& Straus, 1989, p. 47), which may lead to these cohabiting couples' wanting to keep their individuality. As a result, there may be constant friction over rights, duties, and obligations that may lead to violence. The other reason why violence is greater among cohabiting couples is because of lack of investment and commitment to the relationship. Cohabiting relationships are based on mutual agreement between two people; hence, there are no legally binding documents to back up such a cohabiting relationship. In view of this, cohabiting partners may behave in certain ways that may engender violence because there is no investment and commitment involved as in the case of legally married couples.

There were 526 dating couples involved in this study. It was found that there is less violence among dating couples. The reason given for this is that "dating couples are less involved in a relationship, and thus the conflict-generating characteristics do not 
apply as strongly in their case as they do among cohabiting and married couples" (Gelles \& Straus, 1989, p. 48). However, Stets and Straus (1989) opined that as a dating relationship matures over time and gets more serious, the level of conflict and violence may increase to the same level as that of cohabiting or married couples (p. 48).

The study found that violence is less severe among married couples than among cohabiting and dating couples. This is because the "...greater risk of assault typically occurs when individuals live together but are not married" (Stets \& Straus, 1989, p. 47). Married couples are tied to the kinship connection which, by and large, turns out to be a support system for married couples. Because of the influence of the kinship connection as embedded in the extended family system, conflicts among couples are less violent, and negotiation and compromise may be more prevalent in helping to curtail conflict from graduating into violence. The point that negotiation should be used as a means of conflict reduction before conflict graduates into physical assault, psychological aggression, sexual coercion, or injury, is germane, not only to this research study, but also to the CTS2 instrument that will be used for data collection.

\section{Perceptions and Experiences of Intimate Partner Violence among Hispanic College Students}

This study was carried out by Vera (2014). Since only a "few studies have examined the impact of IPV among the Hispanic college student (HCS) population or explored how HCSs perceive and experience IPV" (Vera, 2014, p. vi), this study, with the use of the CTS2, will be very useful in adding to the literature. With a sample of 120 Hispanic college student between the ages of 18 to 25 , "this mixed methods study was designed to explore the perceptions and experiences of IPV focusing on levels of 
victimization and perpetration in relation to gender role attitudes and beliefs, exposure to parental IPV, acculturation, and religiosity" (Vera, 2014, p. vi). I have decided to review this study because it is alarming to see a high rate of dating college students who engage in intimate partner violence. As a matter of fact, "researchers and practitioners are alarmed by the high proportion of college students who consider some degree of physical violence in dating relationships 'acceptable or normal in some circumstances'” (Vera, 2014, p. 7). The question at this point is that if such a magnitude of violence characterizes the dating relationships of college students, what will their future marriage relationships look like in terms of conflict and violence? If the dating relationship is considered to be a foundation for future marriages, then it is safe to conclude that dysfunctional dating relationships may eventually lead to dysfunctional marital relationships.

The recurrent decimal in the literature review of the study on these Hispanic college students has to do with gender roles. Vera (2014), citing Kasturirangan and Williams (2003) and Vandello, Cohen, Grandon, and Franiuk (2009), mentioned that "the acceptance of traditional gender roles leads to the acceptance of domestic violence and the willingness of abused Latinas to remain in abusive relationships" (p. 18). The traditional Latin gender-role ideology espoused "the culture of machismo," which in turn "promotes male dominance and privilege. Marianismo is based on the premise that women model themselves after the Virgin Mary, a paradigm of self-sacrifice" (Vera, 2014, p. 21). Apart from the gender issue, other factors similar to the situations of African immigrant couples and African American couples such as “...acculturation, education, socioeconomic status (SES), country of origin, and religious beliefs as well as individual differences in attitudes, beliefs, and experiences must all be considered in 
understanding the issue of IPV" (Vera, 2014, p. 19).

A summary of the findings in this study suggests that these Hispanic college students face problems in their dating relationships that have led to intimate partner violence at one time or the other. This is aptly summarized below:

The participants were asked if they had experienced problems while in a relationship. More than half responded affirmatively. The most prevalent types of problems that affected a majority of those who reported relationship problems were communication $(77.9 \%)$ and jealousy or lack of trust (57.4\%). Other problems reported by at least $10 \%$ of the participants were family problems, financial problems, infidelity, and abuse (Vera, 2014, p. 104).

In addition, further findings by Vera revealed that only a very small percentage of those who took part in the study perceived themselves as being the object of violence. Neither did they see themselves as the aggressors: "Out of 120 young adult women and men, only $5 \%$ perceived themselves to be victims or survivors of IPV. The proportion that saw themselves as past or present perpetrators of IPV was even smaller, at $4.2 \%$ " (p. 108). This may be due to the way some of the CTS2 subscales were perceived by the students. For example,

the most notable finding was the pronounced discrepancy between the participants' perceived experience of IPV and their responses to the verbal aggression and sexual coercion subscales of the quantitative CTS2 instrument. Although the participants were aware that IPV can take many forms, milder forms of non-physical violence were not necessarily perceived as IPV. One reason for this may have been that verbal aggression that was not blatantly denigrating, or belittling was common enough to be considered normal. Some types of sexual violence were also considered normal behavior, based on the qualitative responses, and roughly one-third of the group acknowledged using sexual coercion, interestingly equally by both genders (Vera, 2014, p. 141).

Acculturation, Partner Violence, and Psychological

Distress in Refugee Women from Somalia

A study undertaken in 2008 by Nilsson, Brown, Russell, and Khamphakdy-Brown 
“...examined the relations among acculturation, domestic violence, and mental health in

62 married refugee women from Somalia" (p. 1654). The results of this research

“...showed that women who reported greater ability to speak English also reported more

experiences of partner psychological abuse and physical aggression. Experiences of more psychological abuse and physical aggression also predicted more psychological distress"

(Nilsson et al., 2008, p. 1654). Fluency in the English language of Somali wives made the partners of some Somali women feel threatened by their female partner's proficiency in English because they experienced their English ability as a painful reminder of their loss of control and their spouse's move toward greater independence and selfsufficiency. It seems possible that such language ability is associated with the women being more engaged in the U.S. society, more acculturated to U.S. values and beliefs, more independent, and possibly a greater likelihood of being employed (Nilsson et al., 2008, p. 1660).

This situation brings us again to the problems associated with changes in gender roles among African immigrants as one of the major causes of friction in couples' relationships.

It should be noted that because of the cultural worldview of Somalis, which may be generally typical of traditional African culture, coupled with the shame associated with domestic abuse and mental health, women in this study may not have felt the necessity to report the situation they were in when it came to bringing things into the open. Therefore, the study says that

Somali women are in need of mental health counseling and support services. Traditional Westernized mental health services may, however, conflict with Somali cultural traditions. Many authors have suggested the appropriateness of outreach programs and drop-in services when providing services to refugee women. Outreach services include workshops, radio programs in the native language, and involvement with women in low-income housing and homeless shelters (Nilsson et al., 2008, p. 1661). 


\section{Intimate Partner Violence among Adolescents in South Africa and Tanzania}

A dissertation by Wubs (2015) had as its main objective to examine relationship violence occurring among teenagers in South Africa and Tanzania. The dissertation particularly aimed at looking at "prevalences and associated factors" (p. iv) as they related to intimate partner violence. It also sought "...to examine the relation between violent attitudes and violent behavior, and the importance of the Theory of Planned Behavior in predicting sexual debut" (p. iv). One wonders how teenagers in relationships could be involved so much in intimate partner violence; however, the study explained that with the "background-situational" model, intimate partner violence among adolescents can be experienced and learned from parents and background factors. Riggs and O’Leary (1996)

...proposed that variables causally related to courtship aggression can be separated into background factors (e.g., interparental aggression, child abuse, prior aggression) that establish an individual's aggressive pattern of behavior, and situational factors (e.g., drinking, relationship problems), which increase conflict within a relationship and contribute to specific aggressive incidents. Regarding background factors, they suggest that violence in the family of origin contributes to a greater acceptance of aggression as a response to conflict, aggressive/impulsive personality characteristics, psychopathology, and reduced emotion regulation. These factors in turn lead to an increased use of aggression across situations and within romantic relationships particularly (p. 519).

In summary, "this study shows that intimate partner violence is highly prevalent already at a young age in relationships between young people in South Africa and Tanzania" (Wubs, 2015, p. 64).

The study had three sites, and all three sites confirmed that ...violence was prevalent in all sites: depending on site and gender, $10.2-37.8 \%$ has been victim, 3.1-21.8\% perpetrators, and $8.6-42.8 \%$ has been both victim and perpetrator. Being male was associated with perpetration in all sites, while being female was associated with victimization in Dar es Salaam and Mankweng (yet in 
Cape Town victimization was also associated with being male). In all sites, higher age and low socioeconomic status were associated with all types of violence. In Cape Town, being religious and having parents with higher education were protective against all types of violence (Wubs, 2015, p. 47).

Such a study as this may give useful hints that may be very important to a future healthy marital relationship among younger adults who may be contemplating marriage. If adolescents within the African continent have been exposed to intimate partner violence at such tender ages, then pragmatic actions are needed that call for a reorientation of attitudes and behaviors among pre-teenagers as they grow into teenagers and young adults. Future marital relationships should be guided against being characterized by violence and abuse.

What the CTS2 subscales measure in couple's relationships include psychological aggression, sexual coercion, physical assault, injury, and negotiation; the good effects of couples' resorting to the use of negotiation subscale in conflict resolution and management cannot be overstressed; it is very central to promoting harmonious relationships among couples and in society. By and large, this will have positive multiplication effects on husbands, wives, children, family members, and society.

\section{The Level of Parental Conflict and Children's Behavioral Reactions to Divorce}

This dissertation was not just embarked upon to compare the level of conflict among African immigrants and African American couples; my interest went beyond that. Parents who bring children into the world have the responsibility of ensuring that their marital relationship is such that it will be a shining example to the younger generation. This may be an area of study for the near future. However, Settle (2010) “...investigated 
the level of parental conflict as a contributor to children's behavioral difficulties up to one year after parental separation" (p. v).

The summary of the findings in this thesis suggested that "children who were traumatized by domestic violence suffered from anxiety, depression, withdrawal symptoms, attention problems, somatic complaints, rule-breaking behavior, aggressive behavior, thought problems, social problems, internalizing behavior problems and externalizing behavior problems" (Settle, 2010, p. v), whereas in referring to LaHaye (2008), Settle postulated that “the most important factor for children's well-being is limiting the amount and intensity of parental conflict" (p. 1).

Parents should be intentional about guiding the formative years of their children

jealously. The early stage of the child's development should be handled with utmost care because "several studies have reported that children as young as 12 months of age show physiological and psychological reactions to witnessing high levels of conflict between their parents (VonSteen, 1997)" (Settle, 2010, p. 3). The effects of high level conflict and domestic violence on children at infancy, toddler stage, preschool age, school age, and adolescent age are highly impactful on their future. The study concluded that increased parental conflict was a valid predictor of behavioral difficulties demonstrated by children following parental separation. For children between the ages of six and eighteen years of age, externalizing and internalizing problems were significant as were thought and social difficulties when parent report of conflict is elevated. Gender analysis in this study showed that the effects of parental conflict on children's internalizing and externalizing behavioral outcomes were not significantly different for boys and girls (Settle, 2010, pp. 20-21).

\section{Summaries of Findings from Some Studies That Have Used the Attitudes Towards Women Scale}

"The Attitudes toward Women Scale (AWS) is the most widely used instrument 
to assess attitudes about women's right and roles in society" (Jaruseviciene et al., 2014, p. 2). This instrument was originally developed in 1972 by Spence and Helmreich. It was initially a 55-item instrument, but was later reduced to 25-item, 21-item, and 15-item versions. The instrument places respondents "on a continuum of attitudes ranging from traditional to egalitarian (Jaruseviciene et al., 2014, p. 2). In this section, we will look at summaries of findings from a few studies that have used the AWS.

\section{Attitudes towards Women among College Students in Urban India}

Menon carried out this research work in 2015 using the 25-1tem version of the AWS as the measurement. The subjects in this study included "100 students (50 males, 50 females) between 18 years to 21 years of age pursuing graduation from a college in Mumbai. Among the 50 males/females, 25 were Hindus and 25 were Muslims" (Menon, 2015, p. 11).

It should be noted that just as I use the culture of Africans as samples in this dissertation, that study also mentioned that the "Indian society is known to have gender disparities from its early history. The most deep-rooted forms of gender inequality had been built into the structure of traditional Indian society. Women were looked down socially, economically and politically" (Menon, 2015, p. 10). In addition, in India, many prefer sons to daughters for a number of reasons; for instance, "the continued prevalence of dowry becomes another key factor in parents' desire to have sons rather than daughters in India. In a patrilineal system, names and property pass to the next generation only through sons" (Menon, 2015, p. 10).

The findings indicated that "female subjects are more egalitarian and pro feminist 
than male subjects. These results indicate that while young girls seem to believe that they need to be treated equally, young men do not seem to agree on equal treatment for women" (Menon, 2015, p. 12). As a result of this male-female dichotomy, females have become disadvantaged in society. For example, the "... divide between the demands of young Indian girls for equality and the unwillingness of young men to grant this equality is responsible at least partially for crimes against women in urban India" (Menon, 2015, p. 12). Even though most urban women in India have “...become more egalitarian in their attitudes towards women” (Menon, 2015, p. 12), men are generally still prone to perceiving women as not being equal to men.

\section{Definitions of Dating Violence among African American College Students: Their Relationships with Gender Role Beliefs}

This research study was done by four researchers: Bremond, Cannatella, Ahn, and Kang (2013). This study used a sample of "116 African American undergraduate students (62 men and 54 women)" (Bremond et al., 2013, para. 1). The study has the purpose of expanding on "...the understanding of how gender role beliefs influence African American college students' definition of dating violence (para. 1). As a result of their historical past of slavery, racism, oppression, and stereotypes, for example, children raised in African American “...households are experiencing violence as an acceptable norm, experiencing aggressive behavior as normal behavior in their neighborhoods, and viewing negative relationship images in the media" (Bremond et al., 2013, para. 6). In the findings of the study, it is apparent that generally,

the African American college population exhibited liberal viewpoints concerning women. However, a significant difference existed in the gender role beliefs between the men and women students. According to this study, African American male college students believed that men should hold positions of power in the work force 
and women should not succumb to the use of profanity and swearing. African American families have been predisposed to an egalitarian lifestyle to compensate for the limitations placed on them by the larger society. African Americans may dismiss the traditional male and female gender roles held by the dominant society because they reflect a world view perpetuated by white male and female culture (Bremond et al., 2013, para. 18).

Furthermore, men define physical violence differently from women, perhaps because of the fact that "men, regardless of ethnicity, continue to hold patriarchal beliefs and view lesser forms of physical aggression, such as, pushing, slapping, and throwing objects as acceptable behaviors" (Bremond et al., 2013, para. 19). It is explained that because

African American college students tend to perceive dating violence more in physical terms than in psychological terms, verbal or other types of psychological aggressions are not viewed as a problem by African American college students. Consequently, abused African American college students, especially who are victims of psychological aggression do not perceive themselves as victim, which further prevents them from seeking appropriate help (Bremond et al., 2013, para. 20).

Even though, generally speaking, "African American college students who were aware of the range of behaviors that constitute dating violence tended to be more egalitarian towards women" (Bremond et al., 2013, para. 21), the study concludes that "traditional patriarchal ideologies [still] lie at the heart of the culture" (Bremond et al., 2013, para. 23). The authors stated that the ...extent to which African American college students are socialized in patriarchal belief systems will influence future attitudes and behaviors. It is the patriarchal ideologies that legitimize the use of violence in relationships; therefore, the alternative egalitarian relationships should be encouraged (Bremond et al., 2013, para. 23).

Sex-Role Attitudes and Some Selected Background Characteristics of Women in Nontraditional Careers, Women in Traditional Careers, and the Homemakers in Malaysia

A study by Nasir (1984) sought to "compare the differences among the women in 
nontraditional careers, traditional careers, and the homemakers in their attitudes towards women's roles in society and their background characteristics" (p. 75). Nasir (1984) studied the changing roles of women in Malaysia using the AWS as an instrument of measure. "The participation of Malaysian women in various economic, social, and political fields and in nation building has steadily increased over the past few years" (p. 2). This has been made possible by the influx of females into the pursuit of education as a result of the government's encouraging females to go to school. Because of this, more women are getting into the labor market and politics (Nasir, 1984, pp. 3, 6).

Findings in this study "...showed that there is a difference among the three groups of women in their sex-role attitudes" (Nasir, 1984, p. 110). For instance, it was found “....as predicted, that women in the nontraditional careers had the most liberal sex-role attitudes among the three" (p. 110).

The family backgrounds of these three groups of women impacted the types of careers they chose. Hence, the findings about this showed that "the majority of women in nontraditional careers and traditional careers perceived that their parents valued education for them, while the majority of women in the homemakers group perceived that their parents did not value education for them" (Nasir, 1984, p. 111).

Furthermore, it becomes apparent that parents of women in nontraditional and traditional careers would have encouraged their female children not only to go to school, but also to pursue careers that are ennobling. By and large, the socioeconomic situation of parents of career women could facilitate a conducive environment for educational and career development. For example, most of these parents were better educated and they had a higher monthly income to support their children in school (Nasir, 1984, p. 123). 
Thus, "women in nontraditional careers tend to come from a higher socioeconomic background when compared to either women in traditional careers or the homemakers" (Nasir, 1984, p. 119).

In another vein, the environment where these women grew up affected their upbringing in the area of whether or not they were educated and the types of careers they ventured into. Thus, the findings portrayed that the

majority of women in the homemakers group spent most of their childhood and adolescent life in the rural areas in contrast to most of the women in the nontraditional careers group who spent most of their childhood and adolescent life in the urban areas (Nasir, 1984, p. 112).

\section{Rehabilitation Counseling Master's Students: Beliefs and Attitudes about Domestic Violence toward Women}

Davis (2013) used the AWS along with other instruments. "The purpose of this study was to examine Rehabilitation Counseling master's students' beliefs and attitudes toward domestic violence and battered women" (p. 14). In scoring the AWS, it has been explained that "higher scores on the test indicate more egalitarian views and lower scores indicate more traditional views. These results suggest that Caucasian and Latino participants had more egalitarian views of women and African-American participants had more traditional views of women" (Davis, 2013, p. 75). Thus, the

finding indicates that participants who had a traditional view of women were more likely to blame the victim. This is supportive of Bryant and Spencer's (2003) finding that students with egalitarian views are less likely to blame the victim and students with traditional views are more likely to blame the victim in domestic violence relationships (p. 75).

Measuring the participants' ages with the AWS revealed that "participants in the age group 25-30 had more traditional views of women and participants in the 36-40 age group had more egalitarian views of women" (Davis, 2013, p. 75). The conclusion of this 
study with the use of the AWS is that "there was a relationship between attitudes toward women and victim blame" (p. 91) by the participants who tended towards the traditional views.

Those participants who scored higher on the AWS were more likely to be egalitarian in attitudes. Hence, it means that "the results showed that participants with higher scores on the Attitudes Toward Women Scale had higher scores on the Domestic Violence Knowledge Test. This finding suggested that participants with more egalitarian views had higher levels of domestic violence knowledge" (Davis, 2013, p. 98). This simply interprets the fact that participants who scored lower are traditionally inclined and therefore, "...were more likely to attribute blame to the victim" because they "were less knowledgeable of domestic violence" (Davis, 2013, p. 98). This group will definitely have "...more traditional views of women," thus perpetuating "the view of women in more traditional and gender roles such as a homemaker" (p. 99). In order for counselors to function effectively in cases of intervention of domestic violence, they should have the understanding and awareness of "...domestic violence knowledge and assessing attitudes about domestic violence toward battered women (p. 109).

\section{Conclusion}

The quality and stability of marriage and family lives are very important in building and maintaining a healthy society. The general well-being of all spouses and their children will reflect on the community through a peaceful and harmonious coexistence of community members because they already acquire these virtues from their family upbringing. Therefore, it is very pertinent to reduce conflict and violence in homes and among couples. We have to work towards establishing a good community with a 
minimal level of violence. The task now is to underscore the point that families should be permeated by love and nurturing thoughtfulness, as opposed to the horrific psychological abuse, battering, and killing that are a tragic part of couple conflict and domestic violence. Through the cooperation of everyone; the intervention of marriage and family resource persons and counselors; and the assistance of national governments, national organizations, and different international agencies; brilliant, practical, and meaningful approaches to bringing about the prevention and control of conflict and violence in marriage relationships can be engendered. With all this in place, married couples, children, and family members will not be hindered from becoming healthy citizens of a better and greater tomorrow. 


\section{CHAPTER 3}

\section{METHODOLOGY}

\section{Introduction}

This study sought to do an exploratory comparative analysis of conflicts in African immigrant and African American marriages. In this chapter, the research design was discussed. The population sample was identified, the hypotheses were stated, the variables and their definitions were enunciated, the survey instruments were described, the procedure for data collection was established, and an explanation on how the data were collected and analyzed was given.

\section{Research Design}

This was a non-experimental comparative exploratory study of conflict in African immigrant and African American marriages in terms of their scores on the CTS2 and its subscales. This involved administering a combined questionnaire comprised of the CTS2, AWS, and a short questionnaire specific to African immigrants.

Generally speaking, "survey research is ideal for use in education; it is used to gather information about population groups to learn about their characteristics, opinions, attitudes, or previous experiences" (Leedy \& Ormrod, 2005, p. 183). Survey research can be either written or oral. A group of respondents responds to the questions from the survey, and these responses form the basis of data for the study. Gay, Mills, and Airasian 
(2009) defined the questionnaire or survey as "an instrument to collect data that describe one or more characteristics of a specific population" (p. 175).

\section{Population and Sample}

The target populations for this research work fell into two groups: African immigrants and African American ethnic groups living in North America. According to Echeverria-Estrada and Batalova (2019), "slightly more than 2 million immigrants from sub-Saharan Africa lived in the United States in 2018. While this population remains small, representing just 4.5 percent of the country's 44.7 million immigrants, it is a rapidly growing one (para. 1). Therefore, it can be assumed that the population of married African immigrants in the United States as of 2018 is no larger than 2.1 million people.

In the case of African Americans, the "black or African American population as of 2018 is 40,241,818 making up 12.6\% of the total population" (United States Population, 2018, para. 23). The overall population of the two ethnic groups used in this study was approximately 43 million. There were 118 married African immigrant ethnic group respondents— $54.6 \%$ of the total respondents. On the other hand, there were 98 married African American respondents- $45.4 \%$ of the total respondents.

The sampling strategy used for this study was the non-probability sampling method. This included convenience sampling, voluntary response sampling, and snowball sampling. The major challenges faced in locating samples for this study were twofold: First, the sensitivity of the instruments and probing into the private marital lives of respondents served as a barrier to getting enough respondents to respond to the questionnaires. Second, there were not many states where I got the respondents to return their responses and they were not geographically spread out. For instance, the states 
where all the 216 responses came from were Arizona, Colorado, Florida, Georgia, Texas, Michigan, Illinois, New York, Maryland, Indiana, and Pennsylvania. A few responses also came from Canada.

\section{Hypotheses and Objectives}

How can a hypothesis be defined? Locke (2015) defined a hypothesis as "a proposed explanation that can be tested through further experiments and observations. It's a still-unproven idea that requires the collection of more data in order to confirm or reject it" (p. 2). Based on this research work, the hypotheses formulated were as follow:

1a. Hypothesis 1a stated that there would be a difference among ethnic groups in scores for negotiation (self), psychological aggression (self), physical assault (self), sexual coercion (self), and injury (self).

Null Hypothesis for 1a stated that there would be no difference among groups in scores for negotiation (self), psychological aggression (self), physical assault (self), sexual coercion (self), and injury (self).

1b. Hypothesis $1 \mathrm{~b}$ stated that there would be a difference among ethnic groups in scores for negotiation (partner), psychological aggression (partner), physical assault (partner), sexual coercion (partner), and injury (partner).

Null Hypothesis for $1 \mathrm{~b}$ stated that there would be no difference among groups in scores for negotiation (partner), psychological aggression (partner), physical assault (partner), sexual coercion (partner), and injury (partner).

$2 \mathrm{a}$ and $2 \mathrm{~b}$. Hypotheses $2 \mathrm{a}$ and $2 \mathrm{~b}$ stated that there would be a significant correlation between AWS and the total CTS score for self and partner. 
Null Hypotheses $2 \mathrm{a}$ and $2 \mathrm{~b}$ stated that attitudes toward women as measured on the AWS would have no effect on the total CTS2 score for self and partner.

3. To describe how participants in the African immigrant group think their marriage has been affected by immigration stress and acculturation, and what they think specifically caused those problems.

\section{Variables and Their Definitions}

The dependent variables were scores on each of the five subscales of the CTS2. The independent variable was whether the participant was an African American or an African immigrant. Scores on the AWS served as a covariate to strengthen the analyses of the relationship between groups and the CTS2. There were five sub-categories of the dependent variable contained in the CTS2 instrument. These were negotiation, psychological aggression, physical assault, injury, and sexual coercion (see Table 1 for the model of this scale).

Table 1

Dependent and Independent Variable of CTS2

\begin{tabular}{|c|c|c|c|c|c|c|}
\hline & \multicolumn{6}{|c|}{ CTS2 Score } \\
\hline & Overall & Negotiation & $\begin{array}{l}\text { Psychological } \\
\text { Aggression }\end{array}$ & $\begin{array}{l}\text { Physical } \\
\text { Assault }\end{array}$ & Injury & $\begin{array}{l}\text { Sexual } \\
\text { Coercion }\end{array}$ \\
\hline $\begin{array}{l}\text { African } \\
\text { American }\end{array}$ & & & & & & \\
\hline $\begin{array}{l}\text { African } \\
\text { Immigrant }\end{array}$ & & & & & & \\
\hline
\end{tabular}




\section{Negotiation}

Negotiation as one of the subscales of CTS2 encourages couples to seek

alternatives that will enhance resolution of conflict instead of aggravation of conflict.

The negotiation items ask about the frequency of use of six positive conflict tactics that are oriented toward achieving constructive resolution. Three of these represent cognitive problem-solving behaviors-explanation, compromise and openness to suggestions. Three involve the expression of emotional support - care, respect and optimism. Endorsement of items in this area suggests that the partner has a good repertoire of alternatives to abusive or coercive strategies (Straus, Hamby, \& Warren, 2003, p. 65).

i. I explained my side of disagreement to my partner/My partner explained his/her side of a disagreement to me.

ii. I suggested a compromise to a disagreement./My partner suggested a compromise to a disagreement.

iii. I showed my partner I cared even though we disagreed./My partner showed care for me even though we disagreed.

iv. I said I was sure we could work out a problem./My partner said he/she was sure we could work out a problem.

v. I agreed to try a solution to a disagreement my partner suggested./My partner agreed to try a solution to a disagreement I suggested.

vi. I showed respect for my partner's feelings about an issue./My partner showed respect for my feelings about an issue (Straus et al., 2003, pp. 45, 51).

\section{Psychological Aggression}

There is a strong tendency for relationships to lead to aggression if the parties involved do not apply peaceful tactics. Psychological aggression, in particular, can be very detrimental to the health of either of the partners. 
The psychological Aggression items ask about verbal and symbolic acts that are intended to cause psychological pain or fear. The eight items specify tactics including verbal attacks, insults, threats, and other loud, aggressive displays. When items in this area are endorsed, it is likely that therapeutic work will need to include increasing the perpetrator's awareness of the destructive aspects of these kinds of attacks on the relationship (Straus et al., 2003, pp. 65, 72).

\section{Psychological Aggression Scale Items: Minor}

i. I insulted or swore at my partner./My partner insulted or swore at me.

ii. I shouted or yelled at my partner./My partner shouted or yelled at me.

iii. I stomped out of the room or house or yard during a disagreement./My partner stomped out of the room or house or yard during a disagreement.

iv. I did something to spite my partner./My partner did something to spite me.

\section{Psychological Aggression Scale Items: Severe}

i. I accused my partner of being a lousy lover./My partner accused me of being a lousy lover.

ii. I called my partner fat or ugly./My partner called me fat or ugly.

iii. I destroyed something belonging to my partner./My partner destroyed something that belonged to me.

iv. I threatened to hit or throw something at my partner./My partner threatened to hit or throw something at me (Straus et al., 2003, pp. 45, 51).

\section{Physical Attack}

Physical attacks may happen among couples in conflict when peaceful resolution of conflict and understanding between the parties concerned fails. More often than not, the goal of the aggressor is to inflict pain on the victim, and if no intervention is involved, 
it may lead to injury. The physical attack subscale has a 12-item scale grouped into minor and severe categories. "Endorsement of items in this area reflects the general level of assaultive behavior that occurs in the relationship" (Straus et al., 2003, p. 72). The minor category has five items that ask about "tactics such as pushing, grabbing and shoving," while the severe category has seven items that address behaviors such as "punching, kicking, chocking, burning, and using a knife or gun” (Straus et al., 2003, p. 72).

\section{Physical Attack Scale Items: Minor}

i. I threw something at my partner that could hurt./My partner threw something at me that could hurt.

ii. I twisted my partner's arm or hair./My partner twisted my arm or hair.

iii. I pushed or shoved my partner./My partner pushed or shoved me.

iv. I grabbed my partner./My partner grabbed me.

v. I slapped my partner./My partner slapped me.

\section{Physical Attack Scale Items: Severe}

i. I used a knife or gun on my partner./My partner used a knife or gun on me.

ii. I punched or hit my partner with something that could hurt./My partner punched or hit me with something that could hurt.

iii. I choked my partner./My partner choked me.

iv. I slammed my partner against a wall./My partner slammed me against a wall.

v. I beat up my partner./My partner beat me up.

vi. I burned or scalded my partner on purpose./My partner burned or scalded me on purpose. 
vii. I kicked my partner./My partner kicked me.

\section{Injury}

As mentioned above, injury may occur as a result of one partner's physically attacking another partner. Items here are grouped into minor and severe categories. These have to do with level of injury "associated with violent conflict, and this helps to determine the level of danger that is present in a given relationship" (Straus et al., 2003, p. 72). According to these authors, if injuries are not reported, follow-up should still be done to ascertain the safety of the victim (p. 72).

\section{Injury Scale Items: Minor}

i. I had a sprain, bruise, or small cut because of a fight with my partner./My partner had a sprain, bruise, or small cut because of a fight with me.

ii. I felt physical pain that still hurt the next day because of a fight with my partner./My partner still felt physical pain the next day because of a fight we had.

\section{Injury Scale Items: Severe}

i. I passed out from being hit on the head by my partner in a fight./My partner passed out from being hit on the head in a fight with me.

ii. I went to a doctor because of a fight with my partner./My partner went to a doctor because of a fight with me.

iii. I needed to see a doctor because of a fight with my partner, but I didn't./My partner needed to see a doctor because of a fight with me, but didn't.

iv. I had a broken bone from a fight with my partner./My partner had a broken bone from a fight with me (Straus et al., 2003, pp. 45, 51). 


\section{Sexual Coercion}

Sexual coercion may also lead to pain and injury whether mild or severe. The items here are also categorized into minor and severe levels depending on whether or not physical force is used to achieve the sexual coercion. They focus on

...imposing nonconsensual sexual acts, including unprotected oral and anal sex. Minor acts of sexual coercion carry the same focus on intimidation, control, and humiliation as more physically violent forms of rape. It will be important to help couples who endorse these items to discover and cultivate common ground that offers mutual satisfaction in the sexual arena. When items in the severe category are endorsed, appropriate follow-up should be undertaken to protect the victim from further assault (Straus et al., 2003, p. 72).

In the questionnaire, the questions are presented in pairs. The first question in the pair asks respondents to indicate how often they carried out each item in the referent period. The second asks how often the partner carried out each behavior. The response categories ask for the number of times each action occurred during the past year ranging from "Never" to "More than 20 times." The default referent period is the past twelve months, but other referent periods, such as "since starting in this program," could be used.

\section{Sexual Coercion Scale Items: Minor}

i. I made my partner have sex without a condom./My partner made me have sex without a condom.

ii. I insisted on sex when my partner did not want to (but did not use physical force)./My partner insisted that I have sex when I didn't want to (but did not use physical force).

iii. I insisted my partner have oral or anal sex (but did not use physical force)./My partner insisted I have oral or anal sex (but did not use physical force). 


\section{Sexual Coercion Scale Items: Severe}

i. I used force (like hitting, holding down, or using a weapon) to make my partner have oral or anal sex./My partner used force (like hitting, holding down, or using a weapon) to make me have oral or anal sex.

ii. I used force (like hitting, holding down, or using a weapon) to make my partner have sex./My partner used force (like hitting, holding down, or using a weapon) to make me have sex (Straus et al., 2003, pp. 45, 51).

\section{Instrumentations}

The instruments used for this study were the CTS2 and AWS. A multiple-choice questionnaire about the impact of immigration and acculturation specifically for African immigrants was also administered. All the three instruments put together in the SurveyMonkey took about 25 to 30 minutes to complete for each participant, and that was dependent on how educated they were to decipher the contents of the questionnaires.

\section{Conflict Tactics Scale}

The CTS2 instrument was developed by Murray Straus in 1979. It is used for measuring the frequency of conflict among couples.

The Conflict Tactics Scales (CTS) is the most widely used instrument for identifying domestic violence. There are two main versions of the CTS: the CTS2 and the CTSPC. The CTS2 is the version measuring violence against a partner in a dating or marital relationship. The CTS2 has scales to measure victimization and perpetration of three tactics that are often used in conflicts between partners: physical assault, psychological aggression; and negotiation; and scales to measure injury and sexual coercion of and by a partner (Straus, 2007, p. 190).

\section{Attitudes Towards Women Scale}

The second instrument of use in this dissertation was the AWS. This measuring 
instrument was "developed by Janet T. Spence and Robert Helmreich in the early 1970s"

(Buckner, 2010, p. 40). The AWS

...measures attitudes about the rights and roles of women - relative to men-in occupational, educational, and relational domains. As an attitude measure focusing on gender roles, the AWS assesses opinions about the behavioral patterns deemed appropriate for men and women in society. Examples include believing that men should be more responsible for supporting their families, whereas women should be more responsible for nurturing their children. Spence and Helmreich created versions of the AWS with 55 items, 25 items, and 15 items, which were published in 1972, 1973, and 1978, respectively (Buckner, 2010, p. 40).

The 25 -item version was used for this study. It should be noted that "the $25-1$ tem version short form is highly correlated with the original test" (Davis, 2013, p. 62). This short form of the AWS was used in conjunction with a much longer instrument of the CTS2 here, so participant fatigue was taken into account.

\section{Immigration Questionnaire}

A multiple-choice immigration questionnaire containing three questions was administered along with the CTS2 and the AWS to examine how immigration and acculturation have affected the marital relationship of the African immigrant marriage. There was also a section for the respondents to comment on after each question in order to explore and understand their responses further.

\section{Reliability and Validity of the CTS2 Instrument}

The CTS2 scale has been found to be a reliable and valid instrument in measuring couple's conflict among different groups and nationals. According to Straus (1988),

the CTS continues to be the most widely used instrument for research on intrafamily violence, including use by some feminist critics such as Okun (1986), who employ the CTS for want of a better alternative. Although far from a perfect instrument, the comparison presented in this chapter of the CTS with the available alternatives, together with the evidence on stable factor structure, moderate reliability and 
concurrent validity, and the strong evidence of construct validity, suggests that the

CTS is the best available instrument to measure intrafamily violence (pp. 49, 71, 72).

Straus (2004) used the instrument on students' dating relationships in 33

universities. "Although the data refer to dating relationships of university students, the results are sufficiently promising to encourage use of the CTS2 in a variety of cultural settings" (p. 1). Hence, he argued that in the results of the study of the dating relationships of students at the 33 universities in 17 countries, findings show that

the alpha coefficients of reliability for the five CTS2 are generally high across all 33 universities, indicating that the CTS2 have cross-cultural reliability. The absence of test-retest reliability is typical of social and psychological measures, including the CTS2. Of the more than 100 articles that have so far been published reporting results using this instrument, only 3 have reported data on test-retest reliability (Straus, 2004), whereas more than 40 report alpha coefficients. Almost all those studies report reliabilities meeting or exceeding the conventional standard of an alpha of .70. The CTS2 are becoming more widely used each year, and by mid-2004, more than 40 studies provided evidence of reliability (Straus, 2004), most of which are based on studies of nonstudent populations. Some of those studies are of different cultural groups within the United States; the results presented in this article are sufficiently promising to encourage proceeding with that research (pp. 20, 22, 23).

The standard Cronbach's alpha scores reported in the CTS2 manual are “... .86 for negotiation, .79 for physical aggression, .86 for physical assault, .95 for injury, and .87 for sexual coercion" (Straus et al., 2003, p. 45).

\section{Reliability and Validity of the AWS Instrument}

There is no doubt that the "AWS is the most commonly used measure of attitudes toward women. The literature search for this handbook identified almost 270 published studies and 52 ERIC documents that used the AWS" (Beere, 1990, p. 448). This figure was given in 1990 when the handbook by Beere (1990) was published. There would have been some other studies added since 1990 .

The instrument has been proven to be reliable and valid in the study of the 
attitudes toward women. For instance, Smith and Bradley (1980) confirmed that

separate reliability analyses over female and male subjects yielded alphas of .93 for the 55-item scale and .86 and .90, respectively, for the 25-item scale. A Pearson correlation between the short and long forms produced a coefficient of .99. Recently reported doubts about the instrument's validity were groundless (p. 511).

\section{Procedures for Data Collection}

A survey was designed and used for the data collection using SurveyMonkey. The CTS2 and AWS were put in the SurveyMonkey for the African immigrant and African American ethnic groups to respond to. A combined close and open-ended immigration questionnaire was included in the SurveyMonkey specifically for the African immigrant participants. I sent letters to pastors of churches and leaders of national groups to seek their consent to survey their members. I also made personal visits to some of these places. Some personal contacts were made to some pastors and some national group leaders who gave verbal promises to assist.

Members' emails were solicited by the pastors and the national group leaders who were contacted. It was through these emails that the survey containing the three survey questionnaires were sent to all the participants, with the assurance that the survey had been designed in a way that their responses would be kept anonymous after completion. Surveys were continuously sent to more participants until 216 responses were harvested from the two ethnic groups used for this study. It should be noted that "survey research is a commonly used method of collecting information about a population of interest" (Research Connections, 2016, para. 1). "Survey research is used to gain insight into the thoughts, ideas, opinions, and attitudes of a population" (Brewer, 2009, p. 520). 


\section{Data Analysis}

The survey data was analyzed with the use of statistical analysis software called the Statistical Package for the Social Sciences (SPSS).

Analysis Method for Hypothesis $1 \mathrm{a}$ and $1 \mathrm{~b}$

A One-Way Multivariate Analysis of Covariance (MANCOVA) was conducted to determine the effect of ethnicity on each of the five conflict tactics (negotiation self and partner, physical assault self and partner, injury self and partner, psychological aggression self and partner, and sexual coercion self and partner) after controlling for attitude towards women.

Analysis Method for Hypothesis 2a and 2b

The Pearson bivariate correlation analysis was used to test whether there was a significant bivariate relationship between attitudes towards women and the total score of conflict tactics self and total partner.

Multiple Choice Immigration Questionnaire Observation

Descriptive statistics, in percentages, were used to describe the responses of African immigrants to the Immigrant Questionnaire. Open ended responses were grouped into similar categories. 


\section{CHAPTER 4}

\section{RESULTS}

\section{Introduction}

The purpose of this study was to explore marital conflict in African immigrant and African American marriages. Attitudes towards women were explored as a factor that relates to the frequency of marital conflicts as measured by the CTS2. This chapter begins with a description of the sample participants included in the study. This chapter also includes the description of variables used in the study. This chapter provides a presentation of the hypotheses testing with the results generated. This chapter ends with a summary of what is contained in the chapter.

\section{Participant Description}

A total of 216 married participants responded to the survey questionnaire. The participants involved married individuals from two ethnic groups: African immigrants and African Americans living in North America.

The profiles of the participants are presented in Table 2 . In terms of age, $.5 \%$ of the participants was under the age of $18(n=1)$, another $.5 \%$ was 18 to 24 years old $(n=$ 1), about $13.0 \%$ were aged 25 to $34(n=28)$, about $25.9 \%$ were aged 35 to $44(n=56)$, about $35.6 \%$ of participants were aged 45 to $54(n=77)$, about $18.5 \%$ were aged 55 to 64 $(n=40)$, about $4.2 \%$ were 65 and older $(n=9)$, and $1.9 \%$ gave no age $(n=4)$. In terms of 
gender, the majority of the participants were females $(n=140,64.8 \%)$. There were 74 males $(34.3 \%)$. Gender information was missing for $2(.9 \%)$. One hundred eighteen participants were African immigrants (54.6\%), while 98 were African Americans (45.4\%). The annual income of the participants varied: under 15K $(\mathrm{n}=19,8.8 \%), 15-$ $29.999 \mathrm{~K}(\mathrm{n}=24,11.1 \%), 30-49.999 \mathrm{k}(\mathrm{n}=49,22.7 \%), 50-74.999 \mathrm{~K}(\mathrm{n}=55,25.5 \%)$, $75-99.999 k(n=26,12.0 \%), 100-150 K(n=28,13.0 \%)$, and 150K $(n=15,6.9 \%)$. Forty-nine participants were married less than 5 years (22.7\%), 47 were married 6-10 years is (21.8\%), 32 were married $11-15$ years (14.8\%), 31 were married $16-20$ years (14.4\%), 29 were married 21-25 years (12.5\%), 9 were married 26-30 years (4.2\%), 18 were married more than 31 years $(8.3 \%)$, while 3 gave no information (1.4\%). The majority of the participants were Christians ( $\mathrm{n}=198,91.7 \%$ ), while 2 were Muslims (.9\%), 14 were "other" (6.5\%), and 2 (.9\%) gave no information. The following are the educational levels of the participants: 3 participants (1.4\%) had no high school diploma, 25 participants (11.6\%) had a high school diploma, 36 participants (16.7\%) had an associate degree, 56 participants (25.9\%) had a bachelor's degree, 75 participants (34.7\%) had a master's degree, while 19 of the participants (8.8\%) have doctoral degrees; 2 participants (.9\%) gave no information. African immigrant participants were also asked which part of Africa they were from. Five participants (2.3\%) were from Central Africa, 3 participants (1.4\%) came from the East, 6 participants (2.8\%) came from the Southern part of Africa, and 104 participants (48.1\%) were from West Africa. 
Table 2

Frequencies and Percentages of Demographic Characteristics of Participants $(N=216)$

\begin{tabular}{|c|c|c|c|}
\hline \multicolumn{2}{|c|}{$\begin{array}{r}\text { Demographic } \\
\end{array}$} & $\mathbf{N}$ & $\%$ \\
\hline \multicolumn{4}{|c|}{ Age } \\
\hline & Under 18 & 1 & 0.5 \\
\hline & $18-24$ & 1 & 0.5 \\
\hline & $25-34$ & 28 & 13.0 \\
\hline & $35-44$ & 56 & 25.9 \\
\hline & $45-54$ & 77 & 35.6 \\
\hline & $55-64$ & 40 & 18.5 \\
\hline & $65+$ & 9 & 4.2 \\
\hline & Total & 212 & 98.1 \\
\hline & Missing & 4 & 1.9 \\
\hline & Total & 216 & 100.0 \\
\hline \multicolumn{4}{|l|}{ Gender } \\
\hline & Female & 140 & 64.8 \\
\hline & Male & 74 & 34.3 \\
\hline & Total & 214 & 99.1 \\
\hline & Missing & 2 & 0.9 \\
\hline & Total & 216 & 100.0 \\
\hline \multicolumn{4}{|c|}{ Ethnicity } \\
\hline & African Immigrants & 118 & 54.6 \\
\hline & African Americans & 98 & 45.4 \\
\hline & Total & 216 & 100.0 \\
\hline \multicolumn{4}{|l|}{ Income } \\
\hline & Under $\$ 15 \mathrm{~K}$ & 19 & 8.8 \\
\hline & $\$ 15-\$ 29,999 \mathrm{~K}$ & 24 & 11.1 \\
\hline & $\$ 30-\$ 49,999 \mathrm{~K}$ & 49 & 22.7 \\
\hline & $\$ 50-\$ 74,999 \mathrm{~K}$ & 55 & 25.5 \\
\hline & $\$ 75-\$ 99,999 \mathrm{~K}$ & 26 & 12.0 \\
\hline & $\$ 100-\$ 150 \mathrm{~K}$ & 28 & 13.0 \\
\hline & $\$ 150 \mathrm{~K}$ & 15 & 6.9 \\
\hline & Total & 216 & 100.0 \\
\hline \multicolumn{4}{|c|}{ Years of Marriage } \\
\hline & Under 5 Years & 49 & 22.7 \\
\hline & 6-10 Years & 47 & 21.8 \\
\hline & 11-15 Years & 32 & 14.8 \\
\hline & 16-20 Years & 31 & 14.4 \\
\hline & 21-25 Years & 27 & 12.5 \\
\hline
\end{tabular}


Table 2-Continued.

\begin{tabular}{|c|c|c|c|}
\hline & 26-30 Years & 9 & 4.2 \\
\hline & $31+$ Years & 18 & 8.3 \\
\hline & Total & 213 & 98.6 \\
\hline & Missing & 3 & 1.4 \\
\hline & Total & 216 & 100.0 \\
\hline \multicolumn{4}{|c|}{ Religion } \\
\hline & Christian & 198 & 91.7 \\
\hline & Islam & 2 & 0.9 \\
\hline & Other & 14 & 6.5 \\
\hline & Total & 214 & 99.1 \\
\hline & Missing & 2 & 0.9 \\
\hline & Total & 216 & 100.0 \\
\hline \multicolumn{4}{|c|}{ Educational Level } \\
\hline & No High School Diploma & 3 & 1.4 \\
\hline & High School Diploma & 25 & 11.6 \\
\hline & Associate Degree & 36 & 16.7 \\
\hline & Bachelor's Degree & 56 & 25.9 \\
\hline & Master's Degree & 75 & 34.7 \\
\hline & Doctoral Degree & 19 & 8.8 \\
\hline & Total & 214 & 99.1 \\
\hline & Missing & 2 & 0.9 \\
\hline & Total & 216 & 100.0 \\
\hline \multicolumn{4}{|c|}{ For Africans, Which Part of Africa? } \\
\hline & Central & 5 & 2.3 \\
\hline & East & 3 & 1.4 \\
\hline & South & 6 & 2.8 \\
\hline & West & 104 & 48.1 \\
\hline & African American Ethnicity & 98 & 45.4 \\
\hline & $\begin{array}{r}\text { Total } \\
\end{array}$ & 216 & 100.0 \\
\hline
\end{tabular}

\section{Observed Variables Description}

Table 3 presents the means and standard deviations for the African American and African immigrant samples used for this study. The highest mean was reported for the African immigrant sample (86.0202), followed by the African American sample with a mean of 79.4304 . 
Table 3

Observed Variables Mean and Standard Deviations African American and African Immigrant

\begin{tabular}{|l|l|l|}
\hline \multicolumn{1}{|c|}{ Observed Variables } & M & SD \\
\hline African American & 79.4304 & 65.35655 \\
\hline African Immigrant & 86.0202 & 56.54851 \\
\hline
\end{tabular}

Table 4 presents the means and standard deviations for the African American and African immigrant ethnic groups on the five subscale variables (self): negotiation, physical assault, injury, psychological aggression, and sexual coercion of the CTS2. The

Table 4

Observed Variables Mean and Standard Deviations - African American and African Immigrant (self)

\begin{tabular}{|c|c|c|}
\hline Observed Variables & $\mathbf{M}$ & SD \\
\hline \multicolumn{3}{|l|}{ Negotiation (self) } \\
\hline \begin{tabular}{l|l} 
& African American \\
\end{tabular} & 59.3544 & 42.55736 \\
\hline African Immigrant & 68.9293 & 44.45320 \\
\hline Total & 64.6798 & 43.76057 \\
\hline \multicolumn{3}{|l|}{ Physical assault (self) } \\
\hline \begin{tabular}{l|l} 
& African American \\
\end{tabular} & 3.1139 & 16.66948 \\
\hline African Immigrant & 1.3636 & 7.07461 \\
\hline Total & 2.1404 & 12.28510 \\
\hline \multicolumn{3}{|l|}{ Injury (self) } \\
\hline \begin{tabular}{l|l} 
& African American \\
\end{tabular} & 1.9241 & 10.74742 \\
\hline African Immigrant & 0.7778 & 5.68484 \\
\hline Total & 1.2865 & 8.31389 \\
\hline \multicolumn{3}{|l|}{ Psych aggression (self) } \\
\hline \begin{tabular}{l|l} 
& African American \\
\end{tabular} & 9.1266 & 14.51468 \\
\hline African Immigrant & 3.9798 & 8.71309 \\
\hline Total & 6.2640 & 11.89326 \\
\hline \multicolumn{3}{|l|}{ Sexual coercion (self) } \\
\hline \begin{tabular}{l|l} 
& African American \\
\end{tabular} & 5.9114 & 12.71703 \\
\hline African Immigrant & 10.9697 & 14.36510 \\
\hline Total & 8.7247 & 13.85182 \\
\hline
\end{tabular}


highest mean for these variables was reported on the negotiation (self) subscale variable (64.6798) and the lowest mean on the injury (self) subscale variable (1.2865).

Table 5 presents the means and standard deviations for the African American and African immigrant ethnic groups on the five subscale variables (partner): negotiation, physical assault, injury, psychological aggression, and sexual coercion of the CTS2. The highest mean for these variables was reported on the negotiation (partner) subscale variable (59.0106) and the lowest mean on the injury (self) subscale variable (1.2234).

Table 5

Observed Variables Mean and Standard Deviations - CTS2 Subscale Variables (partner)

\begin{tabular}{|c|c|c|}
\hline Observed Variables & $\mathbf{M}$ & SD \\
\hline \multicolumn{3}{|l|}{ Negotiation (partner) } \\
\hline \begin{tabular}{l|l} 
& African American
\end{tabular} & 54.4824 & 43.11822 \\
\hline African Immigrant & 62.7476 & 44.14564 \\
\hline Total & 59.0106 & 43.76248 \\
\hline \multicolumn{3}{|l|}{ Physical assault (partner) } \\
\hline \begin{tabular}{l|l} 
& African American \\
\end{tabular} & 3.3412 & 17.82758 \\
\hline African Immigrant & 1.4272 & 8.14405 \\
\hline Total & 2.2926 & 13.41101 \\
\hline \multicolumn{3}{|l|}{ Injury (partner) } \\
\hline African American & 2.0706 & 10.85268 \\
\hline African Immigrant & 0.5243 & 4.40108 \\
\hline Total & 1.2234 & 8.00422 \\
\hline \multicolumn{3}{|l|}{ Psych aggression (partner) } \\
\hline \begin{tabular}{l|l|} 
& African American \\
\end{tabular} & 11.3529 & 20.32047 \\
\hline African Immigrant & 6.0485 & 14.02965 \\
\hline Total & 8.4468 & 17.31626 \\
\hline \multicolumn{3}{|l|}{ Sexual coercion (partner) } \\
\hline \begin{tabular}{l|l} 
& African American \\
\end{tabular} & 6.9059 & 14.39546 \\
\hline African Immigrant & 10.8544 & 15.11032 \\
\hline Total & 9.0691 & 14.88316 \\
\hline
\end{tabular}




\section{Hypotheses Testing and Description of Objective}

Four hypotheses were tested in this study. Two of them were comparative and the other two were bivariate correlational. Hypothesis 1a stated that there would be a difference among ethnic groups in scores for negotiation (self), psychological aggression (self), physical assault (self), sexual coercion (self), and injury (self). The null hypothesis for 1a stated that there would be no difference among groups in scores for negotiation (self), psychological aggression (self), physical assault (self), sexual coercion (self), and injury (self). The results are presented below:

A One-Way MANCOVA was conducted to determine the effect of ethnicity on each of the five conflict tactics (negotiation self, physical assault self, injury self, psych aggression self, and sexual coercion self) after controlling for attitude towards women. The main effect of ethnicity (Wilks' Lambda $=.868, \mathrm{~F}[5,171]=5.192$, sig. $=.000$, multivariate eta squared $=.132$ ) indicated a significant effect on the combined conflict tactics. The covariate attitude towards women had a significant influence on the combined dependent variables [Wilks' Lambda $=.864, \mathrm{~F}(5,171)=5.368$, sig. $=.000$, multivariate eta squared $=.136$, power $=.99]$. Univariate ANOVA results indicated that ethnicity had a significantly small effect on psychological aggression (self) $[\mathrm{F}(1,175)=$ 8.395$, sig. $=.004$, partial eta squared $=.046$, power $=.82]$ and sexual coercion $($ self $)[\mathrm{F}$ $(1,175)=6.888$, sig. $=.009$, partial eta squared $=.038$, power $=.74]$. The covariate attitude towards women had a significant effect on negotiation (self) $[\mathrm{F}(1,175)=6.133$, sig. $=.014$, partial eta squared $=.034$, power $=.69]$, physical assault $($ self $)[\mathrm{F}(1,175)=$ 9.597, sig. $=.002$, partial eta squared $=.052$, power $=.87]$, injury $($ self $)[\mathrm{F}(1,175)=$

10.898, sig. $=.001$, partial eta squared $=.059$, power $=.91]$, and sexual coercion: self $[\mathrm{F}$ 
$(1,175)=11.960$, sig. $=.001$, partial eta squared $=.064$, power $=.93]$. Table 6 presents the adjusted and unadjusted group means for aggression (self) and sexual coercion (self). A comparison of the adjusted aggression (self) indicated that African Americans had higher aggression (self) and that African Immigrants had higher sexual coercion (self) in comparison to the other ethnic group.

Table 6

Adjusted and Unadjusted Group Means for Psychological Aggression Self, and Sexual Coercion Self

\begin{tabular}{|c|c|c|c|c|}
\hline & \multicolumn{2}{|c|}{ Psychological Aggression Self } & \multicolumn{2}{c|}{ Sexual Coercion Self } \\
\cline { 2 - 5 } & Adjusted & Unadjusted & Adjusted & Unadjusted \\
\hline Ethnicity & & & & \\
African American & 9.09 & 9.13 & 5.80 & 5.91 \\
African Immigrant & 4.04 & 3.98 & 11.05 & 10.97 \\
\hline
\end{tabular}

Hypothesis $1 \mathrm{~b}$ stated that there would be a difference among ethnic groups in scores for negotiation (partner), psychological aggression (partner), physical assault (partner), sexual coercion (partner), and injury (partner). The null hypothesis for $2 \mathrm{~b}$ stated that there would be no difference among groups in scores for negotiation (partner), psychological aggression (partner), physical assault (partner), sexual coercion (partner), and injury (partner). Results are presented below:

A One-Way MANCOVA was conducted to determine the effect of ethnicity on each of the five conflict tactics (negotiation [partner], physical assault [partner], injury [partner], psychological aggression [partner], and sexual coercion [partner] after controlling for attitude towards women. The main effect of ethnicity (Wilks' Lambda = $.895, \mathrm{~F}[5,181]=4.246$, sig. $=.001$, multivariate eta squared $=.105$, power $=.96)$ 
indicated a significant effect on the combined conflict tactics. The covariate attitude towards women had a significant influence on the combined dependent variables [Wilks' Lambda $=.916, \mathrm{~F}(5,181)=3.131$, sig. $=.007$, multivariate eta squared $=.084$, power $=$ .89]. Univariate ANOVA results indicated that ethnicity had a significantly small effect on psychological aggression (partner) $[\mathrm{F}(1,185)=4.371$, sig. $=.038$, partial eta squared $=.023$, power $=.55]$ and sexual coercion $($ partner $)[F(1,185)=4.010$, sig. $=.047$, partial eta squared $=.021$, power $=.52]$. The covariate attitude towards women had a significant effect on physical assault (partner) $[\mathrm{F}(1,185)=6.790$, sig. $=.010$, partial eta squared $=$ .035 , power $=.74]$, injury $($ partner $)[\mathrm{F}(1,185)=6.499$, sig. $=.012$, partial eta squared $=$ .034 , power $=.72]$, and sexual coercion $($ partner $)[F(1,185)=9.946$, sig. $=.002$, partial eta squared $=.051$, power $=.88]$. Table 7 presents the adjusted and unadjusted group means for psychological aggression (partner) and sexual coercion (partner). A comparison of the adjusted psychological aggression (partner) indicated that African Americans had higher psychological aggression (partner) and that African immigrants had higher sexual coercion (partner) in comparison to the other ethnic group.

\section{Table 7}

Adjusted and Unadjusted Group Means for Psychological Aggression Partner, and Sexual Coercion Partner

\begin{tabular}{|c|c|c|c|c|}
\hline & \multicolumn{2}{|c|}{ Psychological Aggression Partner } & \multicolumn{2}{c|}{ Sexual Coercion Partner } \\
\cline { 2 - 5 } & Adjusted & Unadjusted & Adjusted & Unadjusted \\
\hline Ethnicity & & & & \\
African American & 11.34 & 11.35 & 6.74 & 6.90 \\
African Immigrant & 6.06 & 6.05 & 10.98 & 10.85 \\
\hline
\end{tabular}


Hypotheses $2 \mathrm{a}$ and $2 \mathrm{~b}$ stated that there would be a significant correlation between AWS and the total CTS score for self and partner. The null hypothesis stated that attitudes toward women as measured on the AWS will have no effect on the total CTS2 score for self and partner. The results are presented below:

Pearson bivariate correlation analyses were used to test whether there was a significant bivariate relationship between attitude towards women and the total score of conflict tactics (self and partner). The result indicated that there was not a significant correlation between attitude towards women and total CT scores [self] (Pearson $\mathrm{r}=-.02$ sig. $=.762, \mathrm{~N}=178)$. Similar results showed that there was no significant correlation coefficient between attitude towards women and total CT scores [partner] (Pearson $\mathrm{r}=$ .06 , sig. $=.417, \mathrm{~N}=188$ ). A summary of results is presented in Table 8 .

Table 8

Correlation Analysis between AWS and CTS Total Scores

\begin{tabular}{|c|c|c|c|c|}
\hline \multicolumn{3}{|c|}{ AWS } & $\begin{array}{l}\text { Total } \\
\text { CTS }\end{array}$ & $\begin{array}{l}\text { Total } \\
\text { CTS }\end{array}$ \\
\hline \multirow{3}{*}{ AWS } & Pearson Correlation & 1 & -.060 & -.023 \\
\hline & Sig. (2-tailed) & & .417 & .762 \\
\hline & $\mathrm{N}$ & 204 & 188 & 178 \\
\hline \multirow{3}{*}{$\begin{array}{c}\text { Total CTS } \\
\text { Partner }\end{array}$} & Pearson Correlation & -.060 & 1 & $.919^{* * *}$ \\
\hline & Sig. (2-tailed) & .417 & & .000 \\
\hline & $\mathrm{N}$ & 188 & 195 & 174 \\
\hline \multirow{3}{*}{$\begin{array}{l}\text { Total CTS } \\
\text { Self }\end{array}$} & Pearson Correlation & -.023 & $.919^{* *}$ & 1 \\
\hline & Sig. (2-tailed) & .762 & .000 & \\
\hline & $\mathrm{N}$ & 178 & 174 & 183 \\
\hline
\end{tabular}

**Correlation is significant at the 0.01 level (2-tailed). 


\section{Immigration and Acculturation Questionnaire}

The immigration and acculturation questionnaire was designed to elicit responses from African immigrants only. Descriptive statistics, using percentages, were used to describe the responses of African immigrants on the Immigrant Questionnaire. The observations were based on each of the three questions on the questionnaire. The openended responses were categorized into related emergent groups

The first question on the questionnaire asked participants whether their marriage relationship had been affected in any way since they arrived in the United States. A total of 67 participants responded that their marriage had been affected when they moved to the United States (56.3\%), while 52 participants responded that their marriage had not been affected when they moved to the United States (43.7\%). The participants were also asked how their marriage relationship had been affected since arriving in the United States. A total of 62 participants responded that it had been affected both positively and negatively $(51.67 \%)$. About $27.5 \%$ of participants responded that it had been affected positively $(n=33)$, while $6.67 \%$ responded that it had been affected negatively $(n=8)$. Finally, the participants were asked what accounted for the changes in their marriage relationship. The reason of adjustment to the American culture got the most response $(\mathrm{n}=$ $38,33.04 \%)$, followed by lack of adequate time with each other $(\mathrm{n}=14,12.17 \%)$. The responses showed that immigration and acculturation issues impacted the marriages of African immigrants in the United States. A summary of the responses is presented in Table 9 below. 
Table 9

Frequencies and Percentages of Immigrant Questionnaire Responses

\begin{tabular}{|l|l|r|r|}
\hline \multicolumn{2}{|l|}{} & Frequency & Percent \\
\hline Q1 & No & 52 & 43.7 \\
& Yes & 67 & 56.3 \\
& Total & 119 & 100.0 \\
\hline Q2 & Both Positively and Negatively & 62 & 51.67 \\
& Negatively & 8 & 6.67 \\
& Positively & 33 & 27.5 \\
& Unsure & 17 & 14.17 \\
& Total & 120 & 100.0 \\
\hline Q3 & Adjustment to the American Culture & 38 & 33.04 \\
& Economic and Money Issues & 13 & 11.30 \\
& Educational Challenges Facing International Students & & \\
& and Their Spouses & 13 & 11.30 \\
& Immigration Related Problems & 4 & 3.48 \\
& Lack of Adequate Time with Each Other & 14 & 12.17 \\
& Lack of Communication & 10 & 8.70 \\
& Psychosocial Factors & 4 & 3.48 \\
& Pursuing the American Dream & 5 & 4.35 \\
& Sex and Infidelity & 4 & 3.48 \\
& Work Related Issues & 10 & 8.70 \\
& Total & 115 & 100.0 \\
\hline
\end{tabular}

Open Ended Responses from the Immigration/Acculturation Questionnaire were categorized into groups as follow:

Time Related Issues

1. "My coming to the US pays me because I did not experience abuse from my husband. The only area my coming to the USA has affected, is that I don't get to see my husband as I used to see him back home in Africa because of the regimented work life. What I discover is that I must be intentional to create time to spend with my family.” 
2. Positive: "I feel that my husband and I have more connection here in North America than when we were home (Africa) because we are both new with very few friends and no family members. So we come back home after work and share our successes and challenges. We were not doing as much of this at home because we had friends and some family members to share with."

3. Negative: "We worked professional jobs requiring lesser physical energy back in our country but here in North America, we have to take up many entry levels jobs to make ends meet. This means that we both spend longer hours outside the home, resulting in having lesser time with each other and with our children. In addition, we work entry level jobs which are more taxing to what we were doing at home. This is somehow affecting our sexual lives because especially with me, I feel tired a lot, and this reduces my urge or response to sex."

4. "Migrating to North America has not produced any negative impact on my marriage. I strongly believe that it's just because the foundation of our home is on Christ. We allow Jesus to lead while we follow. Occasionally, we struggle with tight and conflicting schedules which sometimes affect the time we spend together as husband and wife. Also, pursuit of education has been another time killing factor. In it all, God's grace has been sufficient for us."

5. "Being married in America has been a blessing. My husband and I make an effort to eat dinner together and talk about our day. We make decisions about our children together and spent time with our children when they were younger. So overall it has been positive." 
6. "I wish life wasn't this busy here in America, we would have had time for each other; however, we try to make conscious effort for family vacation at least once every year."

7. "We get to spend more time together here in the USA because my wife and I live together, unlike back home in Africa where we were working in different states."

\section{Social Support Related Issues: Extended Family Issues}

1. "The influence of extended family members on our marriage is better controlled in the USA, mostly by design. Unlike in Africa, where family members have a huge influence on marriages, that is not common in this part of the world. This difference has been positive for our family as we have learned to mostly deal with our issues and work it out privately without any external influence. We believe the positives outweigh the negatives."

2. "The only way it affected my marriage is not being able to get help most especially when you just have a baby unlike back in Africa where you have multiple supports in one way or the other. Here everybody is busy; you learn to manage your tasks by yourself."

3. "My coming to America is beneficial to me because by God's grace I do not have any experience such as physical abuse with my wife. I would have loved to be able to have more family support as we had back in Africa, especially with childcare but we are trying to make it work."

4. "My coming to the United States of America is beneficial for my marriage because here they practice individualism which helps to prioritize my immediate family over the extended." 


\section{Culture Related Issues}

1. "I would have loved for my wife to value and respect me more, but it is what it is."

2. "Coming to America means we have to change the way we raise our children. I was raised by very tough-minded disciplinary parents, but American culture sees African style of traditional child discipline as child abuse. American culture makes it difficult for me to raise my children the same way I was raised. My wife begs to disagree as she supports the American style of discipline for our children."

3. 'My experience in America is that of a 'culture shock' simply because husband's and wife's roles are not defined or differentiated, unlike Africa where the reverse is the case."

4. "My migration to the United States has changed my ideas about what I had considered to be appropriate filial relationships. Fortunately, my wife was born in the United States, but she was raised in Africa; so, she understands what it means to be married in our culture. So, the family tone has not been adversely affected by the 'American ways of life."”

5. "Coming from a culture where the male is predominantly the financial provider of the home, it was a challenge to be in a situation where the roles were reversed while still maintaining the role that the woman should take care of the home. On the other hand, I am fortunate that the laws of the US frowns strongly against physical abuse, so I have never been a victim of domestic violence from my spouse."

6. "My wife and I were married when one of us was in the US and the other in Africa. We dated long distance for about 2 years before marrying and then living together 
in the US. Our ability to immigrate opened up the ability to date at a distance knowing we could be married and end up together. Merging US culture and values with African regarding marriage relationships was not major since we were also learning about our roles in marriage and also making that transition. We were fortunate to have been mature when transitioning, fostering a culture of open communication, and having planning discussions prior to marriage on how our relationship would unfold. Having a spouse that lived in the US and the other join them made the transition easier, although it could have also posed problems since we were familiar with other couples in similar situations that struggled."

7. "The impact of immigration on my marriage has been incredibly positive based on the following reasons:

i. I have been more westernized by imbibing the good culture of caring for my spouse as it relates to the man caring more for the woman

ii. The male ego is reduced where there is more equality here than back in Nigeria

iii. Better affection to my spouse displayed here without being frowned upon."

\section{Job Related Issues}

1. "Immigrating to the United States has largely been a positive experience on our marriage. Before coming over, a job was almost optional for my spouse. We were quite comfortable with one income. However, in the US, we both need to work, which is a good thing, but it also means our personal and family life is impacted (sometimes determined) by the jobs we do. This consequently means a readjustment/realignment of 
spousal roles; for instance, household chores are no longer the duty of any one person, but that of whoever is available."

2. "Challenges of career change has been a big setback. We're praying and working towards our goal by God's grace."

3. "Working is tiring here, especially because my wife and I started with lower entry level jobs. This had some strains on our relationship, but we have been very intentional about making our marriage work before we arrived at the USA."

\section{Parenting Related Issues}

1. "My coming to the United States of America is beneficial for my marriage because here they practice individualism which helps to prioritize my immediate family over the extended. The only way it affected my marriage is not being able to get help most especially when you just have a baby unlike back in Africa where you have multiple supports in one way or the other. Here everybody is busy; you learn to manage your tasks by yourself."

2. "My relocation to North America is a blessing to me, my family, and my marriage. Back home in Africa, my husband's work required frequent travelling and meetings, meaning I had to train my kids mostly my own way and I'm easily overwhelmed by stress. But here, our joint efforts have helped train these kids with a father figure in their lives. He has taught them excellent cooking skills and together we build in them Christian VIRTUES. Also, this relocation to North America made me discover that my husband is my best friend."

3. "The positive my wife and I enjoy from coming to the USA is that we were able to have kids because we had issues with childbirth back home." 


\section{Achieving American Dreams and Goals}

1. "I have always wanted to come to America to ride those big cars and live in those big houses that I used to see in films and on television. Here I am today, thinking, is it really worth pursuing? Yes, I have achieved my American dream and goal; however, the tension here is too much."

2. "Coming to the USA actually improved my lifestyle. Though there are other husband \& wife issues that I did not anticipate. These issues have negatively impacted my marriage. Nevertheless, the positive aspects of my journey in America overshadow the negative issues."

3. "I love it here in America. It's a different culture from home (Africa), but it is a land of opportunities where couples can achieve their goals if they understand each other and shut the door to third party's interference (friends, money, etc.). I am loving my marriage."

\section{Summary}

A total of 216 married participants were included in the study which was comprised of two ethnic groups: African Americans and African immigrants. The demographic characteristics of these participants were described with a table that made the description clear. Three tables were constructed to describe the variables in this study. The means and the standard deviation of each observed variable were reported in each table. Four hypotheses were tested in this study, and the results of the testing of each hypothesis, with tables to reinforce the outcome of the results, are given in this chapter. There was a separate immigration/acculturation questionnaire solely for African immigrants. For the observed objectives in this questionnaire, descriptive statistics, by 
using percentages, were used to describe the responses of African immigrants to the Immigration Questionnaire. Open-ended responses were categorized into similar groups. A table was constructed to make the participants' responses more graphic. 


\section{CHAPTER 5}

\section{SUMMARY, DISCUSSION OF RESULTS, CONCLUSIONS}

AND RECOMMENDATIONS

\section{Introduction and Summary of Study}

The contents of chapters 1 to 4 will be summarized in chapter 5 . The purpose of the study will be described, the existing literature will be briefly discussed, and the methodology will be outlined, while the results of the current study will be presented. The findings will be discussed as they relate to the existing literature; the limitations of the present study will also be enumerated. This chapter will conclude with a discussion pertaining to the implications for future practice and future research opportunities.

This research study aims to provide an exploratory comparative evaluation of the experience of couple conflict within the African immigrant population in America, as well as within the African American population. Considering these populations together is essential, since "...to understand African American marriages and families, it is important to first understand African marriages and families" (Dixon, 2017, p. 2). To determine how couple conflict impacts these two ethnic groups, attitudes toward women comprised the primary factor as it relates to the frequency of conflict within couples. The first three chapters of this research study can be summarized well with an evaluation of the key points discussed given in the following paragraphs:

Issues such as immigration, racism, past historical experiences, ethnicity, and 
culture, as well as acculturation and socioeconomic status may create conflict in a couple's relationship; by acknowledging these problems, it is possible to grasp better the experiences of African immigrant and African American couples. The "historical and present-day ecological systems such as structural racism that impact African Americans..." may constitute some of the factors affecting their marriage and family dynamics and how long the marriage and family bonds endure (Kelly et al., 2013, p. 264). The role of Christian spirituality also proves essential to the maintenance of these relationships.

The original position of Eve as a suitable helper to Adam became altered to that of the position of subservience after the entrance of sin. This clarifies why attitudes toward women remain distant from egalitarianism in so many cultures of the world today. Patriarchy and male-dominant cultures, such as those of some African countries which practice patriarchy, exemplify this. This domination often leads to conflict among African couples, especially when they relocate to America. African men “...grow up with an inflated, hyper-masculine view of manhood and are therefore more prone to violence" (United Nations, 1996, p. 108). The cycle of violence may be broken, and the experience of couple conflict reduced or managed, if the theory of catharsis is put into practice.

The inevitability of conflict does not necessarily characterize all conflict as dysfunctional. In fact, conflict can provide the foundation for the practice of healthy communication principles, among other strategies that improve the union of couples and the well-being of society overall. Negative communication can increase conflict, whereas strong rapport can positively impact marital conflict. Cooperation, collaboration, and negotiation, as examples of such rapport, help to reduce marital tensions. 
Marriage and family experts should endeavor to beam more searchlights on this institution. Without tackling couple conflict and thereby allowing it to metastasize into violence and aggression, homes may become a training ground for violent children. We should not ignore the dangers that dysfunctional marriages and families can pose by focusing our attention only on violence in the streets.

With regard to couple conflict, a better understanding of the challenges facing African immigrant couples, and the impact of the African heritage on African American couples, remain areas of research that can contribute significantly to better strategies for family life education and marital counseling among African immigrant and African American families in North America.

This research study endeavors to examine the expression of these essential points by considering the research questions posed at the outset. These questions are as follows:

1. Which of the CTS2 subscales will be highest and lowest among the African American and African immigrant marriages?

2. Do scores on the AWS interact with the relationship between groups and scores on the CTS2?

3. How do participants in the African immigrant group respond when asked in the form of a separate multiple-choice questionnaire how they think their marriage has been affected by immigration stress and acculturation, and what specifically they think caused those problems?

This research study and the data it has produced offer a modest yet noteworthy contribution to the discussion of American family life for both African immigrants and African Americans. As a reminder of the methods used to conduct this study's research, 
216 people (118 African immigrants and 98 African Americans) agreed to the administration of an in-depth questionnaire. The questionnaire utilized two pivotal instruments: the CTS2 and the AWS. This questionnaire was designed to probe the respondents' opinions and sentiments regarding their experiences of couple conflict in action, as well as with their views of the role of women in relationships. An additional brief questionnaire was given to the African immigrants as well, assessing their responses as to whether and how the transition to America had impacted their experience as a couple.

The contents of this chapter revolve around a summation of the results of this research, namely, that the necessity for solution-oriented approaches toward the reduction and management of couple conflict in the surveyed communities that are already vulnerable as minorities whose historical challenges linger through to their current struggles, remains urgent and imperative. The findings and conclusions reinforce this importance for African immigrant couples, in particular; addressing their concerns will also do much to remedy the impact of couple conflict for African Americans. A myriad of recommendations based on this study hinge on deeper cultural studies, wider-ranging examinations of Christianity in these populations, and the ramifications of understanding couple conflict on American family life better and the acculturation process, at large. The implications of this study should inspire more nuanced approaches to studying the African immigrant experience and the impact of Christian living as a strategy to neutralize the negative aspects of couple conflict.

\section{Statement of the Problem}

There has been a high level of marital conflict in immigrant families from 
patriarchal cultures. There are negative attitudes toward women that contribute to couple conflict. In the same vein, African American couples experience conflicts that militate against the stability of their marriages. With regard to couple conflict, a better understanding of the challenges facing African immigrant couples and the impact of the African heritage on African American couples are germane to this study.

\section{Purpose of the Study}

The purpose of this research was to identify which of the CTS2 subscales would be highest and lowest among African American and African immigrant couples with AWS serving as a covariate. Whether scores on the AWS interacted with the relationship between groups and scores on the CTS2 was also explored. The study further examined the impact of acculturation and immigration on African immigrants' ethnic group. It was hoped that examination of these variables would contribute significantly to better strategies for family life education and marital counseling among African immigrants and African American families in North America.

\section{Research Hypothesis and Objective}

Based on this research work, the hypotheses formulated are as follow:

1a. Hypothesis 1a stated that there would be a difference among ethnic groups in scores for negotiation (self), psychological aggression (self), physical assault (self), sexual coercion (self), and injury (self). The null hypothesis for 1a stated that there would be no difference among groups in scores for negotiation (self), psychological aggression (self), physical assault (self), sexual coercion (self), and injury (self). 
1b. Hypothesis $1 \mathrm{~b}$ stated that there would be a difference among ethnic groups in scores for negotiation (partner), psychological aggression (partner), physical assault (partner), sexual coercion (partner), and injury (partner). The null hypothesis for $1 \mathrm{~b}$ stated that there would be no difference among groups in scores for negotiation (partner), psychological aggression (partner), physical assault (partner), sexual coercion (partner), and injury (partner).

$2 \mathrm{a} / 2 \mathrm{~b}$. Hypotheses $2 \mathrm{a}$ and $2 \mathrm{~b}$ stated that there would be a significant correlation between AWS and the total CTS score for self and partner. The null hypotheses stated that attitudes toward women as measured on the AWS would have no effect on the total CTS2 score for self and partner.

3. The immigration/acculturation questionnaire's objective was to observe the impact that immigration and acculturation have on the marriages of the African immigrant ethnic group through the responses.

\section{Significance of the Study}

There is a need to build on existing information and further develop a knowledge and an understanding of both African immigrant families and other minority immigrant families. It is also important to examine the challenges that may incite conflicts among African American couples in comparison to African immigrant couples. Because the health of marriages and families is very central to the health of society, information from this research may help to increase the knowledge that can be garnered and used to reshape frameworks, theories, and research methods in the study of marriage and family relationships, especially in curtailing couple conflicts before they escalate into uncontrollable violence. This study may be a useful source of information for the various 
categories of marriage and family resource professionals who are involved in helping to form policy and implement decision-making concerning the marital and family needs of these two groups of people.

\section{Summary of the Literature Review}

African immigrants come to the United States for various reasons. They come from what may be defined as the five regions of Africa: Eastern, Western, Northern, Southern, and Central Africa. They all bring with them their different cultural heritages (Nyamwange, 2014, p. 43). According to Capps et al. (2012), "Black African immigrants represent one of the fastest-growing segments of the U.S. immigrant population, increasing by about 200 percent during the 1980s and 1990s and by 100 percent during the 2000s" (p. 1). They mentioned that "black Africans are much more likely than other groups to have entered the United States as refugees or gained asylum after coming to the country" (p. 6).

African Americans, on the other hand, have a history that is characterized by servitude. They are "... one of the largest of the many ethnic groups in the United States. African Americans are mainly of African ancestry" (Lynch, 2018, para. 1). The first set of Africans arrived in the new world, that is, the present-day United States, in 1619. The history of African Americans contributes to the way their worldview has been shaped; it also adversely affects the way they live and relate in society. This history apparently also has a retrogressive effect on the marriage and family life of this group of people. For instance, Williams (2010) has suggested that “... slavery not only inhibited family formation but made stable, secure family life difficult if not impossible" (para. 2).

Generally speaking, human relationships, including marriage relationship, have 
been adversely affected since the inception of sin into the world, and both African immigrants and African American marriage relationships are not exempt. At this point, it is good to put emphasis on the fact that marriage was specifically instituted by God for relationships. A genuine display of love, with the maintenance of cordial relationships among humanity, is a central theme in the Bible, beginning in Genesis and culminating in Revelation. God designed man and woman for relationships with Him and other fellow human beings. Hammer (2011, p. 106) reiterated that the Bible, in its entirety, educates us on how to maintain relationships with God and with our fellow human beings. It is this perversion of the horizontal and vertical relationships that has brought marital relationship conflict.

Conflict has indisputably become unavoidable in human interaction. In view of this, what should be devised by human society is a mechanism by which conflict can be drastically reduced because growth and development may accompany conflicts if they are well managed. That brings us to a brief discussion of catharsis theory. The catharsis theory is based on the notion that "if you express your feelings you will purge yourself of your troubles" (Tolboll, 2014, p. 1). In order to explain this better, this theory says that “...engaging in an aggressive act in response to frustration should lead to both (a) tension reduction and (b) aggressive drive reduction" (Verona \& Sullivan, 2008, p. 331). The catharsis theory suggests that expressing feelings can help those engaged in conflict not to have their feelings aggravated to the point of misbehaving. However, for the catharsis theory to be effective, marriage relationship experts must emphasize to concerned parties that this theory has to be utilized discretionally in the right direction, with the right tools, in a conducive environment, and with rational feelings and thoughts. 
Marital and societal conflicts have come to stay because of the problem of sin. This has entrenched the great controversy motif in the world. Since family and society interact with each other, it is pertinent to mention that Köstenberger (n.d.) postulated that the institution of marriage and family is not immune from the cosmic conflict (p. 16) that goes on in the world. There is a serious attack on the institution of marriage and family because it is the basic unit and the building block of the society; if the institution is stabilized very well, society will experience peace; hence, destabilizing the institution of marriage and family is the primary objective of evil forces. It becomes apparent that "spiritual warfare surrounding marriage and the family is a reality, and awareness of this conflict as well as skill in engaging in it is imperative" (Köstenberger, n.d., p. 16).

From the contemporary perspective, society sees more and more differences in beliefs, opinions, and worldviews which cause myriads of conflict. Conflict arises when one spouse pursues a goal or talks about pursing that goal, and in so doing, interferes with the goals the partner holds. These incompatibilities adversely affect the indexes of marital functioning (Gere \& Schimmack, 2011, pp. 38, 39). The inability to let go of the goal being pursued is characterized by selfishness and self-esteem and this triggers different ill-feelings that may eventually lead to conflicts which may be mild or severe. Without tackling couple conflict on time and allowing it to aggravate into violence and aggression, homes may become more and more a training ground for violent children. "Our task is to accurately present the facts of early life in a way that raises awareness and leads to dialogue and change. People everywhere need to be involved in discussions of how early life affects all of us" (Bezruchka, 2015, p. 219). We all begin from the family.

One of the very fundamental ways of curbing marital conflict is to put in place a 
very solid supportive system that will help neutralize the toxic effects of conflict on couples, children, and society. Human beings are created to live in communities where people help and support one another. It is especially important that marriages and families have supports that will become catalysts to building up the institution; reducing or eradicating conflict among couples is especially pivotal to this. "The connections that couples develop with their family, peers, and community offer a source of meaning, purpose, and support that influence the health and vitality of their couple relationship" (Futris et al., 2016, p. 3). A well-structured social support put in place with intentionality will no doubt help in mediating couple conflict among African immigrant and African American couples.

The literature review further identified the possible causes of couple conflict. Marital or couple conflicts tend to center on certain recurring issues such as communication, couples' lack of adequate time for each other, children, sex and infidelity, money, personality differences, power and control, in-laws, poor quality time spent together by couples, communication problems, housekeeping, as well as issues like pride, egocentricity, and male dominance. Acculturation and immigration issues may cause conflict among couples in the diaspora, while educational challenges may arise for couples who are in school. All these are issues to be grappled with regarding conflict among couples. These identified causes of couple conflict can lead from mild conflict issue to a severe one if not well handled and on time.

The intensity of a couple's conflict can increase with time as a result of poor management and late intervention. Conflicts can progress from a minor war of words to slapping and beating, and finally, to even more serious domestic violence (Feld \& Straus, 
1989, pp. 141-142). "Even though the bulk of the assaults that occur in couples' conflict in marriage are minor, they could continue indefinitely and escalate into more severe assaults. A number of studies report such a pattern (Giles-Sims, 1983; Pagelow, 1981; Walker, 1979)" (Feld \& Straus, 1989, p. 142). The intention of the perpetrator of conflict or domestic violence is to satisfy a particular goal or objective. The victimized is seen as a barrier to achieving such a goal or objective. Hence, the perpetrator wants to do whatever he or she thinks possible in order to remove the object of obstruction. Verbal and physical aggression, which leads to aggravated domestic violence, does not start in one day; it is most likely the results of accumulated conflicts that have been neglected or not seriously confronted over time. By and large, such a situation may lead to unresolved conflict.

There comes a point in some families and between couples when unresolved conflicts make living together no longer workable. When a husband or wife or both become disillusioned, believe that the marriage no longer offers security, or that it is impossible to get one's basic needs met, the marriage is on its way to dissolution. Unresolved conflicts graduate from petty things that could have been taken care of to huge issues that could completely destroy the marital relationship. Unresolved conflicts may lead to domestic violence, separation, or divorce. Sometimes, it may lead to the death of one of the partners. According to Tucker and Tucker (2017), "nowadays, the studies of many researchers indicate that the most important factor when it comes to explaining the high rate of divorce is the inability to manage disagreements" (p. 108). Some couples try to resume working on their conflicts after a lot of issues have been swept under the carpet and they have become unbearable (Scot et al., 2013, p. 13). 
One major thing identified by this study in the literature review that could probably mitigate couple conflict is religiosity and spirituality. Tucker and Tucker (2017) mentioned the importance of spirituality in marriage and the role it plays in marital stability, marital satisfaction, and in the resolution of conflicts:

It is difficult to overstate the importance of the spiritual component of marriage. For centuries, preachers have touted the value of spirituality in the marriage relationship. "The family who prays together stays together..." In multiple studies, relationship researchers come to the same conclusions: Couples who possess and practice faith in God have stronger marriages. One study states that, "the deeper the religious experience the greater the marital satisfaction." Religion offers couples guidelines to resolve conflict. Greater religiousness is tied to more constructive conflict resolution strategies (pp. 80-81).

In addition, according to University of Wisconsin researcher Bumpass (2000), "persons who attend church at least weekly are about 40 percent less likely to have their relationship break up than are those who do not" (p. 8). This was aptly buttressed by Lambert and Dollahite (2006) when they found that "couples often expressed that their religious involvement has helped them to develop conflict deterring virtues" (p. 446). Dudley and Kosinski (1990), in discussing the effects of religiosity on marriage, also posited that "religious participation helped couples more often think of the needs of others, be more loving and forgiving, treat each other with respect, and resolve conflict" (p. 82).

In consonance with the above, the American Psychological Association (2014) has ascertained in their research that "praying for partners, spiritual intimacy, attending services with parents may improve quality of life" (para.1) among couples and in the family generally; it also expounded more on the benefits of spirituality on couples' relationship: 
The more spiritual intimacy couples say they share, the better they handle their top three topics of conflict, according to this study. Additionally, couples who viewed their marriage as sacred had more positive marital interactions. Couples' ratings of their spiritual intimacy were based on how often they revealed their spiritual beliefs, questions and doubts to each other, and listened supportively to each other's spiritual disclosures. It didn't matter whether the spouses were blue-collar employees with

high school educations or wealthy professionals with advanced college degrees - the results were the same (para. 15).

Finally, this review of literature presented the summary of a number of studies which used the CTS2 and the AWS scale in their research. These summaries help to bring to light the relevance of the two instruments used in this study. The summaries of these studies also have some bearings on this.

\section{Methodology}

The target populations for this research work fell into two groups: African immigrants and African Americans living in North America. This is a quantitative, nonexperimental, exploratory study of conflict in African immigrant and African American marriages in terms of their scores on CTS2 subscales. This involves administering a combined questionnaire comprising of the CTS2, the AWS, and a short questionnaire specific to African immigrants, and demographic questions and comparisons of the answers among African immigrants and African Americans.

The two major instruments used for this study, the CTS2 and the AWS, are instruments used to measure the frequency of couple conflict and attitudes of men towards women, respectively. When the concept of the study was first conceived, it became necessary to find appropriate instruments to carry out the research; hence, a rigorous internet search was embarked upon; after much effort, these two instruments were discovered, and the instruments have proved to be a huge benefit to the study. 
A survey was designed and used for data collection using SurveyMonkey. The CTS2 and AWS were included in a single survey for both the African immigrant and African American participants. A separate demographic, multiple choice answers, and an open-ended immigration questionnaire is specifically designed for African immigrants to examine the impact of immigration on their marriages. The SurveyMonkey contained all the three instruments, and a link to the SurveyMonkey was generated. The link was then sent to the participants' emails and phones, and the responses were sent back to the SurveyMonkey anonymously.

African immigrant participants were recruited from churches through the pastors and reverends of the churches and from national/regional groups of some African countries through the leaders of these groups. Some friends also invited other friends to participate. In the same way, African American participants were recruited using the churches through their pastors and reverends. In addition, three African American friends helped to recruit some of their friends, while some were recruited from a medical clinic located in the middle of an African American neighborhood through the Medical Director. It took a period of ten months to collect the data and to put them together.

The survey data was analyzed with the use of the Statistical Package for the Social Sciences (SPSS). A multivariate analysis of covariance was used to test statistically significant differences between immigrant groups for all subscales of the CTS2 collectively, and for each subscale individually. This analysis was controlled for variation accounted for by AWS scores by including it as a covariate. A single multivariate analysis of covariance was performed to answer the first research questions. Descriptive statistics were listed to illustrate differences for each group by subscale. 
For the second research question, a mediation analysis was performed for AWS on the larger relationship between ethnic groups, and CTS2 scores for self and partner. This involves performing separate bi-variate regressions and analyzing them for interaction.

All answers to the questions for the immigration/acculturation questionnaire for the African immigrant participants were counted by option, and percentages reported for each question. Open-ended questions were divided into emergent categories and reported in much the same way. These categories differ by question, and these differences were reported in a table. This qualitative analysis could provide a direction for future research and a broader explanation for phenomena observed in evaluating research questions 1a, $1 \mathrm{~b}$, and $2 \mathrm{a}, 2 \mathrm{~b}$.

\section{Summary of Findings}

In testing for hypothesis 1a, the ethnicity and the covariate attitude towards women had a significant influence on the combined dependent variables (Wilks' Lambda $=.864, \mathrm{~F}[5,171]=5.368$, sig. $=.000$, multivariate eta squared $=.136$, power $=.99)$. Univariate ANOVA results indicated that ethnicity had a significantly small effect on psychological aggression $($ self $)[\mathrm{F}(1,175)=8.395$, sig. $=.004$, partial eta squared $=.046$, power $=.82]$, sexual coercion: $($ self $)[\mathrm{F}(1,175)=6.888$, sig. $=.009$, partial eta squared $=$ .038 , power $=.74)]$ The covariate attitude towards women had a significant effect on negotiation $($ self $)[F(1,175)=6.133$, sig. $=.014$, partial eta squared $=.034$, power $=.69]$, physical assault $($ self $)[\mathrm{F}(1,175)=9.597$, sig. $=.002$, partial eta squared $=.052$, power $=$ $.87]$, injury $($ self $)[F(1,175)=10.898$, sig. $=.001$, partial eta squared $=.059$, power $=$ $.91]$, and sexual coercion (self) $[\mathrm{F}(1,175)=11.960$, sig. $=.001$, partial eta squared $=$ 
.064 , power $=.93]$. Table 2 presents the adjusted and unadjusted group means for aggression (self) and sexual coercion (self). A comparison of the adjusted aggression (self) indicated that African Americans had higher aggression (self) and that African immigrants had higher sexual coercion (self) in comparison to the other ethnic group.

The main effect of ethnicity in testing for hypothesis $1 \mathrm{~b}$ (Wilks' Lambda $=.895$, $\mathrm{F}[5,181]=4.246$, sig. $=.001$, multivariate eta squared $=.105$, power $=.96)$ indicated a significant effect on the combined conflict tactics. The covariate attitude towards women had a significant influence on the combined dependent variables [Wilks' Lambda $=.916$, $\mathrm{F}(5,181)=3.131$, sig. $=.007$, multivariate eta squared $=.084$, power $=.89]$. Univariate ANOVA results indicated that ethnicity had a significantly small effect on psychological aggression $($ partner $)[\mathrm{F}(1,185)=4.371$, sig. $=.038$, partial eta squared $=.023$, power $=$ $.55]$ and sexual coercion (partner) $[\mathrm{F}(1,185)=4.010$, sig. $=.047$, partial eta squared $=$ .021 , power $=.52]$. The covariate attitude towards women had a significant effect on physical assault (partner) $[\mathrm{F}(1,185)=6.790$, sig. $=.010$, partial eta squared $=.035$, power $=.74]$, injury $($ partner $)[F(1,185)=6.499$, sig. $=.012$, partial eta squared $=.034$, power $=.72]$, and sexual coercion $($ partner $)[\mathrm{F}(1,185)=9.946$, sig. $=.002$, partial eta squared $=.051$, power $=.88]$. Table 3 presents the adjusted and unadjusted group means for psychological aggression (partner) and sexual coercion (partner). A comparison of the adjusted psychological aggression (partner) indicated that African Americans had higher psychological aggression (partner) and that African immigrants had higher sexual coercion (partner) in comparison to the other ethnic group.

In testing for hypotheses $2 \mathrm{a}$ and $2 \mathrm{~b}$, a Pearson bivariate correlation analysis was used to test whether there was a significant bivariate relationship between attitude 
towards women and the total score of conflict tactics (self and partner). The results indicated that there was no significant correlation between attitude towards women and total CT scores (self) [Pearson $\mathrm{r}=-.02 \mathrm{sig} .=.762, \mathrm{~N}=178$ ]. Similar result showed that there was no significant correlation coefficient between attitude towards women and total CT scores (partner) [Pearson $\mathrm{r}=-.06$, sig. $=.417, \mathrm{~N}=188]$.

For the immigration/acculturation questionnaire, responses of African immigrant ethnic group revealed that immigration and acculturation impacted marriages of African immigrants' ethnic group in the North America.

\section{Discussion of the Findings}

The main effect of ethnicity indicated a significant effect on the combined conflict tactics. The covariate attitude towards women had a significant influence on the combined dependent variables. Univariate ANOVA results indicate that ethnicity has significant small effect on psychological aggression (self and partner), as well as sexual coercion (self and partner). The covariate attitude towards women has significant effect on negotiation (self and partner), physical assault (self and partner), injury (self and partner), and sexual coercion (self and partner). Thus, there is a marked prevalence of negative aspects of couple conflict within African immigrants and African Americans. This holds especially true regarding the prevalence of sexual coercion among African immigrants and the prevalence of psychological aggression among African Americans. These adverse expressions of couple conflict demonstrate the importance of even more specific research on the marital relationship of African Americans and the intersection of the African immigrant experience and the dynamics of couple conflict as they impact these immigrants' assimilation into American life. 


\section{Discussion of Hypotheses 1a and 1b Testing Results}

Hypotheses $1 \mathrm{a}$ and $1 \mathrm{~b}$ stated that there would be a difference among ethnic groups in scores for negotiation (self and partner), psychological aggression (self and partner), physical assault (self and partner), sexual coercion (self and partner), and injury (self and partner). The null hypotheses for $1 \mathrm{a}$ and $1 \mathrm{~b}$ stated that there would be no difference among groups in scores for negotiation (self and partner), psychological aggression (self and partner), physical assault (self and partner), sexual coercion (self and partner), and injury (self and partner). These hypotheses delved into which expressions of couple conflict was both the most and the least impactful on each surveyed ethnic group. This was found to be true in all subscales, allowing for a rejection of the null hypothesis. An in-depth look into the result of hypotheses 1a and 1b might encourage an understanding that both African immigrant and African American ethnic groups required remedial aid against the impact of couple conflict. This research study presents contributions from research that support this understanding. For instance, the literature confirmed the fact that "African American families are at a critical crossroad - the Black family is in worse shape now than at any other point in American history" (National Black Church Initiative, 2018, para. 2). A spiral down this pathway “... has proven to lead to violence, poverty, moral depravity, and failure" generally for African American families (National Black Church Initiative, 2018, para. 2). Referring to the acculturation problems faced by African immigrant couples, Dalla et al. (2009) made reference to Ingoldsby and Smith (2005), Kalita (2003), Min (2005), Petievich (1999), and Trask and Hamon (2007):

American culture can have a powerful effect upon the marriage and family life of new immigrants. The American media, the secular social norms such as; egalitarianism, individualism, humanism, and American political values such as democracy, freedom of speech, and multiculturalism, may all combine together to influence various 
aspects of marital interaction. Aspects of marital relationship that may be affected include; increasing or decreasing sexual interaction, parenting patterns and behaviors, challenges to authoritarian discipline, and less family time as well as less leisure activity time. Thus, new immigrants face a challenge when they are overwhelmed by the demands of American culture: How much assimilation will they embrace or permit and how much will they retain of the values and behaviors of their homeland culture (pp. 93-94).

The African immigrant and African American communities, and their experiences of couple conflict are linked. This connection is not undermined by the African immigrant ethnic group's demonstrating more alarming results than the African American ethnic group (African American [self and partner] adjusted mean in Psychological aggression subscale $=9.09$ and 11.34, African immigrants' self and partner adjusted means in sexual coercion subscale $=11.05$ and 10.98). The "African cultural retentions in African and African American marriage and family structure and functioning..." remain critical to understanding marital discord for both groups (Dixon, 2017, p. 2). What is occurring in the couple conflict of African immigrants, therefore, could eventually reveal itself in the marital experiences of African Americans. It is important to remember that both partners bear responsibility in the coercive cycle of conflict, hostile response to conflict, and capitulation to the other as the quickest method to conclude the conflict (Koerner \& Jacobson, 1994, p. 208).

It may be important at this juncture to examine the possible reason why African Americans have higher psychological aggression (self and partner) in the adjusted mean (9.09 and 11.34). The historical strife suffered by African Americans goes some way to substantiate this cycle happening within its community. As a ramification of their historical past of slavery, racism, oppression, and stereotypes, for example, children raised in African American “... households are experiencing violence as an acceptable 
norm, experiencing aggressive behavior as normal behavior in their neighborhoods, and viewing negative relationship images in the media" (Bremond et al., 2013, para. 6). Looking at the general sociocultural situation of African Americans, it has been argued that since "many violent African American males are from single parent households or unwed households" (Alvin, 2007, p. 35), it has increased to a large extent, "the risk for the presence of a number of others such as absence of discipline, economic and social deprivation, and insufficient positive exposure" (Alvin, 2007, p. 35). Some fallouts of this situation for the average African American may include aggression and violence in all their forms as possible responses to this unpleasant situation. "The stereotypes of African American males as aggressive and violent have persisted to the point that the victims of the stereotype have assumed their ascribed position" (Alvin, 2007, pp. 35-36).

In addition, I can only surmise that the deeper establishment of cultural regard and mainstream cultural acceptance can characterize why African immigrants had a higher score in sexual coercion subscale than the African American ethnic group. There is a dichotomy of the sociocultural view about marital rape between Africans and African Americans. Thus, while African Americans will view marital rape as an offense punishable under the law, African immigrants, because of their cultural orientation, may view marital rape as normal. One of the cultural practices is the payment of bridewealth which is “... sometimes seen as a way of validating a man's right to 'own' his wife so that wives are sometimes viewed as the property of their husbands" (Kamau et al., 2013, p. 8). Therefore, it is not surprising to hear that in the debate on passing the Sexual Offences Act in Kenya, a Member of Parliament used the practice of dowry payment to negate arguments for the possibility of marital rape: 
I have paid a dowry for my wife and we are formally married. I cannot rape her by any chance. You can see the damage that western indoctrination has done to us. I cannot rape my wife! I don't think there is one man who can rape his wife...you can rape someone else (Kenya National Assembly Official Record (Hansard), Second Reading of the Sexual Offences Bill, April 27, 2006, as cited in Kamau et al., 2013, p. 10).

By and large, raping women is a pandemic that has not been completely eliminated from the African sociocultural environment. For example, "According to the World Bank Research on Women, Business and Law, only 14 countries in Africa have legislation in place that specifically criminalizes marital rape" (Chakamba, 2016, para. 5). This is a result that we see in a culture where the submission of women to men is taken out of the biblical context: it is "... a degree of commodifying women, commodifying their sexuality, and commodifying their availability, so she's just something there for him” (Morgan, 2018, p. 71).

The result of hypotheses $1 \mathrm{a}$ and $1 \mathrm{~b}$ renewed awareness of the significance of this study, namely its potential usefulness in reshaping frameworks and research methods in the study of marriage and family relationships, particularly in a move to neutralize couple conflicts before they reach levels of violence.

\section{Discussion of Hypotheses $2 \mathrm{a}$ and $2 \mathrm{~b}$ Testing Results}

The relationship between the AWS and CTS2 questionnaire assessments and the scores associated with each assessment for each ethnic group (partner and self) comprised the goal of hypotheses $2 \mathrm{a}$ and $2 \mathrm{~b}$. Hypotheses $2 \mathrm{a}$ and $2 \mathrm{~b}$ stated that there would be a significant correlation between AWS and the total CTS score for self and partner. The null hypotheses stated that attitudes toward women as measured on the AWS would have no effect on the total CTS2 score for self and partner. The results indicated that there was 
no significant correlation between attitude towards women and total CT scores (self) [Pearson $r=-.02$ sig. $=.762, \mathrm{~N}=178]$. Similar results showed that there was no significant correlation coefficient between attitude towards women and total CT scores (partner) [Pearson $\mathrm{r}=-.06$, sig. $=.417, \mathrm{~N}=188]$.

This finding suggested that African Americans and African immigrants have an egalitarian view of women. It is not surprising that African Americans lean towards this view because of their integration into American culture - they are born here! However, it is somewhat interesting to note that African immigrants have the same view. A closer look at the gender of the participants-female $=\mathrm{n}=140(64.8 \%)$, while male $=\mathrm{n}=74$, (34.3\%) - may lend some credence to why this is so. Apart from this, the literature review for this study recalls the experience of Kenyan immigrant couples: “...When separated from their native cultural setting, the relationship best practices that previously worked began to falter in effectiveness, due to the impact of the host culture on their connection to traditional lifestyle customs" (Musyoka, 2014, p. 2). African immigrant couples, overall, may fall back to learning fast about their host cultural values as a coping mechanism in the battle to make family life work in a country that requires several years or more to acculturate adequately, if not fully.

It is explained that acculturation requires adaptations which “...occur through developmental and socialization processes in the home and broader community" (Dalla et al., 2009, p. 11). Thus, apart from African immigrants' being influenced by egalitarianism within the American cultural set up, Dalla et al. (2009), making reference to Ingoldsby and Smith (2005), Kalita (2003), Min (2005), Petievich (1999), and Trask and Hamon (2007), explained other ways by which acculturation can influence the 
worldview of immigrants about their marriage and family life. He opined that

American culture can have a powerful effect upon the marriage and family life of new immigrants. The American media, the secular social norms such as; egalitarianism, individualism, humanism, and American political values such as democracy, freedom of speech, and multiculturalism, may all combine together to influence various aspects of marital interaction. Aspects of marital relationship that may be affected include; increasing or decreasing sexual interaction, parenting patterns and behaviors, challenges to authoritarian discipline, and less family time as well as less leisure activity time. Thus, new immigrants face a challenge when they are overwhelmed by the demands of American culture: How much assimilation will they embrace or permit and how much will they retain of the values and behaviors of their homeland culture (pp. 93-94).

Put succinctly, African immigrants may "increasingly reflect the unprecedented shifts in marriage and family life in the United States" (Waters \& Pineau, 2015, p. 371) in order to adapt their marriage and family life to the prevalent cultural situation. The question is this: Are all the existing cultural situations in America favorable to the healthy growth of marriage and family life? The antidote to this disturbing question is for African immigrant new arrivals to seek support from those they meet here. It is especially important that African immigrant couples, as they integrate into the new culture, try to find support from credible people who will become catalysts to help in building up their marital relationship in the new culture they find themselves in: "The connections that couples develop with their family, peers, and community offer a source of meaning, purpose, and support that influence the health and vitality of their couple relationship" (Futris et al., 2016, p. 3).

The significance of this study revolves around an understanding that the vitality, or lack thereof, of a couple remains central to the well-being of a society overall. Given the high rates of African immigration to the United States and the marriage and family life conditions of African Americans, it therefore holds that the continued egalitarian 
view about women of the two ethnic groups in this study will continue to help mitigate regard toward women, and this will have an impact on the factors that leave them vulnerable to couple conflict scenarios like sexual coercion and psychological aggression. This will apparently and potentially create a proactive impact on the larger communities they occupy. In short, a progressive improvement of immigrants' attitudes toward women could actually work to help them assimilate into American life better, more quickly, and more easily and even to relate well and better with African Americans.

\section{Discussion of Immigration/Acculturation Questionnaire Objective Observations}

The additional multiple-choice questionnaire was directed exclusively to African immigrant participants. The questionnaire sought to explore the impact of immigration stress and acculturation on their union as a couple. The data collected revealed an inconclusive response to my expectations since participants largely (at 51.67\%) responded that their marriage relationship had changed both positively and negatively. More than half $(56.3 \%)$ of the respondents asserted that the immigration experience impacted their relationship, yet only about $7 \%$ of respondents claimed that this impact was negative. The main reasons for any type of change, either positive and negative or solely negative, were adjustment to the American culture (33\%) and insufficient quality time as a couple (12\%). Closely following these responses were money issues and educational challenges (both at 13\%), as well as lack of communication and work-related issues (roughly $9 \%$ each).

These findings underscored the significance of this particular study to marriage and family resource professionals who are involved in helping to form policy and 
implement decision-making on the marital and family needs of not only African immigrants to America, but also African Americans. It is rarely just one area of strife that creates an intensity of couple conflict that leads to breakdown. It is, rather, the accumulation of an array of challenges which can permanently halt the flow of positive interplay in a relationship, especially in a vulnerable community such as that of African immigrants (Foner, 1997, p. 962). These challenges clearly interact with one another and can intensify couple conflict to an irreparable degree. Acculturation to America may add pressure to the urge to navigate the educational arena and secure a degree, which can also reduce quality couple time and foment a lack of communication (Ben-David \& Lavee, 1994, p. 134). A financial burden may hasten all of the above as well.

This explains, in part, why the majority of respondents claimed both positive and negative effects of immigration on their couple experience. Relocating to America is often inspired by a drive for a better situation regarding money, education, or quality of life, and America does present opportunities to achieve these enhanced situations at the same time that it poses challenges to the fruition of this enhancement. Zooming in on couple conflict management, therefore, can create an environment where an even larger proportion of African immigrants can claim a wholly positive experience on their journey to settle in the United States.

At this juncture, it is necessary to mention that the literature review of this study painted a disturbing picture of conflicts among married couples. It is true that "the contemporary culture is in a deep crisis regarding marriage and family today..." (Köstenberger, 2016, p. 6). It is incontrovertible that "the issue of Intimate Partner Violence [IPV] in the African American community is large and complex..." (Al'Uqdah, 
Maxwell, \& Hill, 2016, p. 880). We cannot rule out the fact that African immigrants do not find things easy coming to a new culture; they "encounter many stressors as they begin to adapt to American life ... Africans, like other immigrants, experience a deep sense of loss of their culture" (Kamya, 2005, p. 103). In all of this, comparing the results of this study's findings to the literature on couple's conflict, it is important to state that this study's findings did not portray a horrific picture of couple's conflict as seen in the literature review.

In relation to the above, this study desires to refer to two assumptions about why the scores on the CTS2 might have been less compared to the intensity of couple conflict as evident in the literature. First, the factor of self-selection (those who really struggled with conflicts in their marital relationship resisted taking the survey) may contribute to the low conflict score in the research. Pastors and group leaders found it difficult to convince some of their members to respond to the questionnaires and send back the completed survey link. This may be because of their marital condition which they may not have wanted to report. For instance, Halim et al. (2018) found in their research that "Tanzanian women may not disclose victimization fearing blame, shame, divorce, abandonment, and loss of the custody of children (p. 4). This may be true of those who refused to return their responses — which follows through to assume that those who returned their questionnaires had less-malignant couple conflict. It is worrisome to mention that about 1,117 SurveyMonkey links were sent out to respondents, only 216 responses came back after 10 months of labor. In the second assumption, could it be that the respondents' high educational achievement helped to reduce the lower score on the CTS2? In the educational demography of respondents, there were 36 participants $(16.7 \%)$ 
with an associate degree, 56 participants (25.9\%) with bachelor's degree, and 75

participants (34.7\%) with a master's degree, while 19 participants $(8.8 \%)$ had a doctoral degree. Pew Research has reported that "college-educated women are more likely to have long-lasting marriages" (Wang, 2015, para. 1), which means less problematic conflict in their marriages. Specific results of Pew Research's outcome suggested that

college-educated women have an almost eight-in-ten chance of still being married after two decades. Researchers at the National Center for Health Statistics estimate that $78 \%$ of college-educated women who married for the first time between 2006 and 2010 could expect their marriages to last at least 20 years. But among women who have a high school education or less, the share is only $40 \%$. (Wang, 2015, paras. $1-2)$

Assessed overall, the findings do indicate that couple conflict represents a critical area of focus in the study of family life among African immigrants and African Americans, as well as in the pursuit of professional positions created to improve family life and offer treatment when it goes awry. The roots of more effective remedies to the challenges faced by these ethnic groups in couple conflict—and it follows, in the realms of society outside their homes — can be found, modestly, yet unmistakably, in a serious examination of this study's findings. In short, rectifying couple conflict in these groups means rectifying, at least to some degree, the challenges American society faces as a whole.

\section{Theoretical Implications}

Two theories undergirded this research study and shed clarifying light on its findings: conflict theory and catharsis theory. The former framework operates from the assumption of an innate human instinct for conflict and its role within the human experience as inevitable and helpful to explain such matters as injustice and 
discrimination; conflict theory exposes a natural disparity in a society that causes these problems (Corporate Finance Institute, 2018, paras. 2-3). This theory also pinpoints the family unit as the originator of this conflict for those within it (University of Minnesota, 2010, para. 3). Therefore, the prevalence of CTS2 subscale scores in both ethnic groups is more understandable. Reiterating this, the family lives of the African Americans may have been adversely affected by their historical experiences and the contemporary condition in which they find themselves. Moras, Shehan, and Berardo (2007) mentioned the difficult situations of African Americans that have affected their marriage and family life down the road. They explained that

...in crucial respects the experience and the development of African American families in the United States represent a sharp contrast to that of other racial and ethnic groups. The distinct historical circumstances that have impacted this family system have been unusually complicated and in some ways without parallel in comparison to other segments of our multiethnic, multiracial society. The unique experience of forced migration from Africa into a system of extended slavery, and continued systematic exclusion from major U.S. social institutions, coupled with a large history of institutionalized racism characterized by severe violence and oppression, are just a few of the factors that have significantly influenced the structure and well-being of Black families...The contemporary experiences of Black families are intimately connected with the historical, economic, and social conditions encountered by generations past (pp. 145-146).

From the above, it is apparent that African Americans' marital and family issues were not dependent on the acculturation process and the great conflict it could create, whereas the African immigrants' experiences directly confronted acculturation and its subsequent conflict, along with the lack of resources to allow that conflict to resolve and not grow into couple conflict actions such as sexual coercion.

Consideration of the catharsis theory can help to substantiate this vantage point. This premise, which suggests the necessity of relieving the negative feelings of conflict at their nascent stages in order to prevent a more psychologically costly eruption of 
emotion, does not hold redemptive value in isolation. Although expressing what was once repressed can be integral for therapeutic recovery, this expression demands an appropriate setting for the catharsis to take effect and create the desired change (Kellermann, 1992, pp. 80-82). This resonates with African Americans having a higher aggression score in self and partner and African immigrants having a higher sexual coercion score in self and partner, which may hint at these ethnic groups' collective frustration with their historical past and present marginalized situation as seen in African Americans and acculturation/immigration challenges as manifested by African immigrants. For both ethnic groups, there may well be a lack of access to, or awareness of, healthy outlets to allow their frustrations to discharge.

The study's methodology lends further credibility to how the findings identified a potential crisis in African American and African immigrant ethnic groups. The data warns of potential discord in their ability to cope emotionally with their frustrations without falling into couple conflict scenarios. The CTS2, the most widely used instrument in measuring intimate partner violence in couples, reinforces this viewpoint (Criminal Justice, n.d., para. 1; Jory, 2006, p. 88). This lies largely in the CTS2's "high reliability" regarding the scale's five measured sub scores, as well as in its "cross-cultural reliability" (Strauss, 2004, pp. 20, 22, 23). This supports the efficacy of the study's measurement of couple conflict in African immigrants who had higher score in the sexual coercion subscale as a parallel to African Americans, whose CTS2 scores generated a higher score in the psychological aggression subscale. The AWS, the most widely used instrument to assess attitudes about women's rights and roles in society, used in conjunction with the CTS2, helped to paint a fuller picture regarding the interplay of the 
groups' views on women and their subsequent reporting of couple conflict vis-a-vis the CTS2's subscales. In addition, fundamental to this study's methodology were the Thomas-Mann Conflict Modes, which evaluate the assertiveness or cooperativeness of an individual's behavior regarding episodes of couple conflict. Although these modes were not directly tested alongside the CTS2 and AWS, the perspective they espouse supported the entire ethos of the research study as a whole.

\section{Practical Implications}

Suggestion of a correlation between couple conflict and challenges faced outside of a relationship has been touched on throughout this study. It follows, then, that a prime arena for practical research would be the effect of couple conflict on African immigrants and African Americans in sectors where the well-being of their relationship can exert either harmful or helpful influence. These sectors can include employment (both procurement and maintenance), education, church, neighborhood, and social mobility, generally. If couple conflict is a precursor to couple dissolution, and constructive conflict and negotiation deeply benefit relationships, studying the couple conflict relationship to the sectors just mentioned can reveal how they intertwine (Booth et al., 2009, p. viii). It can also reinforce the possibility that lessening couple conflict can ease other areas of life and even more thoroughly guard against divorce, domestic violence, separation, and subpar parenting.

This research also implies a serious benefit in pragmatic research focused on the reincorporation of reverence for God into the couple experiences of the African immigrant and African American community. This can help them access better the ideal of marital union in the eyes of God, a union best characterized as one where 
...each partner lives to serve the interest of the other partner. They are so committed to this relationship that each one is willing to die for the other and both husband and wife are ready to sacrifice all that they have for God who brought them together as a couple (Nwaomah, 2012, p. 23).

Each family constitutes the basic building block of the society. As long as a family is groomed in such a way as to become others-centered, the people who are raised in such a family will go out into the community to network with others who belong to different families, thereby making society a place where everyone selflessly seeks to look after the welfare of others. The intention of God, accordingly, is to create pockets of Christian families all over the world, which will attract others who are outside this big family into God's family as a result of genuine and sincere love being displayed to one another by members within (John 13:34-35). The world will become a better place to live in if, inside all the families of the world, the members being reared there become selfless, not only to family members within, but also to others outside the circle of their immediate family (Garland, 2012, pp. 102-103).

\section{Future Implications}

This research study can provide valuable information for further nuanced and concentrated evaluations of relationships experienced by the two groups assessed here. A major venue could be a segmentation of the study based on geographical regions, such as studying the couple conflict experience in the Northeast versus the Southwest, or in the West versus the Midwest. Exploring, via research, whether African immigration into predominantly African American neighborhoods has any effect on the couple conflict experience would also prove worthwhile.

I can also foresee this study creating space for an exploration of how African 
immigrant and African American men and women personally experience their Christianity. If their understanding of religion truly meets the standards of spiritual authorities, the statistics regarding them and couple conflict would be far more reassuring than what this study has uncovered. The prevalence of sexual coercion and psychological aggression in African immigrants' and African Americans' couple conflict experiences suggest a misunderstanding of how unions should function in light of Christ, for it is the “...believer's responsibility to submit first to Christ, and then the outworking of submitting to one another" (Hammer, 2011, p. 113). This also harmonizes with the view that "only a spiritual return to the biblical foundations will address the root issue of the current" crisis (Köstenberger, 2016, p. 6).

Finally, I am positive that this study will create an awareness that may henceforth help couples to become more proactive in the way conflict is handled in their relationships. Conflict degenerates into violence because of the way the parties concerned respond to it. Conflict is inevitable in human relationships. What is important to be mindful of is how the conflict is handled and how it is eventually resolved. "The primary goal should be for family members to learn how to manage the conflict so that it doesn't escalate and alienate others and lead to estranged relationships" (Ray, 2015, para. 4).

\section{Strengths and Weaknesses of the Study}

The study found limitations in five critical regards. The first involved the difficulty in attracting the desired number of participants for the survey. The sensitivity of the subject matter (submitting to an assessment of a personal relationship through the CTS2 and AWS that directly tackle an intimate area of life) resulted in very few responses garnered from the survey. There may be a need for more cases to improve the 
magnitude of eta squared and power size effect. A sample size of 300 or more would increase the eta squared and the power sizes, thereby engendering a boost of more normal distribution.

Second, the lack of disposition to respond accounted for a number of missing cases, while some did not even complete the survey. Because the survey was not obligatory for people to participate in, those who had problems with their marriages may not have been willing to fill out the survey. For instance, the Association of Black Social Workers (Harambee, (2002, para. 9), referring to Bent-Goodley (2001), White (1994), Bent-Goodley (1998), Bent-Goodley (2004), and Wyatt, Axelrod, Chin, Carmona and Loeb (2000), established that

women of African ancestry often do not report domestic violence for fear that such reporting would be a betrayal of the race or would contribute to negative stereotypes. Dealing with the complexity of trying to protect their men and negotiating the realities of their situation, women of African ancestry typically first turn to family, friends, and their faith-based community for support and assistance.

Third, the major characteristic of the sample population was religious (198:

92.5\% Christians) and thus, there was the assumption that the majority of the participants possessed Christian values and virtues to handle conflicts effectively in their marital relationships, and so that the participants may not have had too many severe marital problems to report. Tucker and Tucker (2017) brought this point to the limelight when they discussed the importance of spirituality in marriage and the role it plays in marital stability, marital satisfaction, and in the resolution of conflicts:

It is difficult to overstate the importance of the spiritual component of marriage. For centuries, preachers have touted the value of spirituality in the marriage relationship. "The family who prays together stays together..." In multiple studies, relationship researchers come to the same conclusions: Couples who possess and practice faith in God have stronger marriages. One study states that, "the deeper the religious experience the greater the marital satisfaction." Religion offers couples guidelines to 
resolve conflict. Greater religiousness is tied to more constructive conflict resolution strategies (pp. 80-81).

Fourth, the time and travel expenses I used in looking for respondents were enormous. Various church and group leaders consulted promised to help administer the survey, but members of these churches and groups finally declined or delayed in responding to the survey. It took me a couple of months of travelling to and fro before I was able to secure the 216 responses for this study.

Finally, the structure of the CTS2 and AWS themselves also created a limitation on how well those who did respond were able to communicate truths about their situations. The wording and format of the AWS could be described as more straightforward than those of the CTS2. The AWS calls for respondents to indicate their opinions on societal attitudes toward women on a 4-point scale, from "Agree strongly" to “Disagree strongly." In contrast, the CTS2 requests a more intellectual and less opinionbased approach via selections on frequency of couple conflict events that do not necessarily correspond with the respondents' exact answer: For example, " $0=$ never" and " $1=$ once," but " $4=6-10$ times" and " $6=20$ or more times." This chasm in approachability and possible comprehension could have comprised the efficacy of the results the surveys collected, especially coupled with the sensitivity of the questionnaires.

Despite the limitations mentioned, the study exhibits strength and resonance in its effort to consider the African immigrant and African American experiences through the vastly underused and under-regarded lens of couple conflict. Since "Black African immigrants represent one of the fastest-growing segments of the U.S. immigrant population," this study's serious consideration of the Black African immigrant marital experience earns validity as a means toward the well-being of American society as a 
whole (Capps et al., 2012, p. 1). The African immigrant population's being such an important group means that evaluating the group on a personal level can shed light on ways to acculturate it more effectively into American society and improve the feel of American society overall as a result. This also galvanizes the study's concentration on the importance of couple conflict and its resolution strategies on the well-being of African immigrant and African American communities at large.

That this study does not place in the foreground its assumption of Christianity as the dominant religion for the studied groups in any historical or sociological contexts serves as an issue with the research. While a portion of the literature review concentrates on the theological foundations of marriage, understanding the foundations of the Christian religion in the two studied groups would be beneficial toward persuasively anchoring the research overall in theological and biblical contexts. In addition, the study does not distinguish between the various forms of relationship that constitute a "couple." For example, a married couple can live together, as can a couple who is dating and cohabitating. The Bible strongly promotes marriage and not cohabitation. Is there a difference in the experience and extent of couple conflict between married couples and cohabitating couples? The study did not observe or explore this.

\section{Recommendations}

\section{Recommendations for Future Research}

The evaluation of the cultural heritages and marital traditions within specific African countries is a focus ripe for consideration in future research. African immigrants come to the United States from what may be defined as the five regions of Africa: Eastern, Western, Northern, Southern, and Central Africa. Yet not all of these regions 
migrate to and populate in the United States at the same rate. The majority of African immigrants responded that they were from the west $(n=104,48.1 \%)$. This suggests an under-representation of other key African immigrant populations. These immigrants may have unique indigenous cultural, religious, or societal traditions and practices which bear greatly on the susceptibility, or lack thereof, of African immigrant marital relations to couple conflict when transposed to an American setting. This segues into another suggestion for additional research: Deeper exploration of the roots of Christianity within African immigrant and African American cultures and examination of the Christian religion's role in comparison to Islam and niche (i.e., personal or private) or indigenous religious practices. Both of these groups exhibit vulnerabilities when it comes to acculturation to the American culture climate and the pursuit of the American dream. Exploring how the practice of specific religions specifically fuels or fractures these journeys deserves even more intense consideration.

In addition, in the future, it may be necessary to research into how the respondents' educational level, years of marriage, and income could affect their marital conflict. This may be needed in order to see whether findings in this regard will corroborate what the literature suggests. For instance, some studies have shown that "...when couples are better educated, they have a better understanding of the realities of life, which makes them better equipped to solve their problems and avoid conflicts" (Tavakol1, Nasrabadi, Moghadam, Salehiniya, and Rezaei, 2017, para. 10). Again, a study by San Francisco State University, (2013, para. 1), “...followed older couples over a 13-year period and found that as couples aged, both husbands and wives increased their tendency to avoid conflict, for example by changing the subject or diverting attention 
away from the conflict." Regarding the effect of income on marital conflict, studies have found out that "...money as a topic of disagreement is particularly troublesome for marriages... money is a significant source of marital conflict" (Papp, Cummings, and Goeke-Morey, 2009, p. 1).

In another vein, practitioners who play active roles in the well-being and fostering of African American and African immigrant communities could utilize this research study's findings as an impetus for advocacy on the bearing of couple conflict on politics, local government, and community-focused legislation. Since current policymaking trends acknowledge how the American family breakdown and many social issues intersect, the environment for the incorporation of such community-focused research as this study offers to the legislative and political fields has never been riper (Fagan, 1995, para. 1).

This study could also serve as an initiative for all those close to the African immigrant community to incorporate couple-enhancing ethos into their mission statements and event programming as a way to ease the acculturation process. My research cited acculturation as a potential cause of couple conflict; since the success or failure of an immigrant's American experience lies in how well they acculturate, it only follows that an improvement of couple conflict could provide a solution to enhancing immigrants' integration into American life on a myriad of levels. As demonstrated by research, Dalla et al. (2009), making reference to Ingoldsby and Smith (2005), Kalita (2003), Min (2005), Petievich (1999), and Trask and Hamon (2007), noted that the American cultural experience might commingle with its secular social realities to impact marital relationships in various ways (pp.93-94). A reversal of this perspectiveconcentrating on marital interaction - could demonstrate how resolving immigrant couple 
conflict could influence their experience of American culture, better equipping them to surmount the odds and challenges of the American experience.

\section{Recommendations for Future Practice}

Younger couples, particularly in the 18-24 age group, stand to benefit enormously from implementing this study's results, as the majority of respondents were classified in the $25-34,35-44$, and $45-54$ age groups ( $\mathrm{n}=28,56$, and 77 respectively). There was only one respondent in the 18-24 age group. This again suggests again the importance of the elders' council, especially for African immigrants, in mitigating couple conflict. Couples in this youngest age group are very likely, at the nascent stages of their relationship or marriage, to be prime candidates for successfully implementing couple conflict strategies with the goal of supporting the longevity and vibrancy of their union. For members of this age group to hear from the experiences, and glean from the strategies, of couples of older age groups can do much to impart effective mechanisms that neutralize conflict and thereby promote the flourishing of connection. at a time when their relationship is just truly beginning to take shape.

Women in African immigrant and African American populations will also benefit from this study, as in terms of gender, the majority of the participants were females $(\mathrm{n}=$ $140,64.8 \%)$. This recommendation hearkens back to this study's awareness of the reversal in the female role regarding the earning of income, in particular; one effect of acculturation in African immigrant communities is the economic leverage women hold over men (Kalunta-Crumpton, 2015, p. 2). A better understanding of how women's enhanced societal position can impact their relationship can help to offset couple conflict 
scenarios in their embryonic stages and promote women's well-being both at home and in the workplace.

At this juncture, it should be well noted that "male privilege is more than just a 'double standard,' because it is based on attitudes or actions that come at the expense of women" (Woods, 2008, para. 4). Therefore, it becomes very pertinent to accentuate that this study would be relevant to creating more awareness for marriage and family life practitioners to know the urgency of increasing programs and activities more practically that would serve as a means of intervention to address Black male privilege over women, especially in patriarchal cultures where the operators of the patriarchy system are slow to imbibe the removal of this cultural concept.

More important, this study's insights regarding couple conflict could serve as a preemptive measure and educational, counseling, and emotional preparation for young Black men, particularly at the high school or early college levels, a time when they themselves experience heightened risk of incarceration or violence. According to Fagan (1995), the evidence demonstrates that young people from troubled families lack strong ties to their communities and therefore, may exploit community members as a symptom of their dissatisfaction (para. 5). Enlightening young men of color about the realities of couple conflict and remedies against it, even in small doses, could provide them with awareness about how their relationships exert influence on other areas of their lives. This awareness could serve as a critical first step in helping them sidestep the difficulties they experience in creating full lives in America.

Furthermore, this study's awareness of the church's impact on couple conflict provides another fruitful avenue for implementation of its findings. It could prompt 
discussion to gauge ways to increase couples' church attendance as a strategy for couple conflict management. It could also inspire an examination of how the frequency of church attendance plays against or toward couple conflict levels. According to University of Wisconsin researcher Bumpass (2000), attending church once weekly is a significant tactic to prevent a breakup of a relationship (p. 8). Lambert and Dollahite (2006) supported this when they discovered that couples cited their religious activities as a means to endow their relationships with conflict-preventing qualities (p. 446). Dudley and Kosinski (1990), in evaluating the effects of religiosity on marriage, also suggested that an active religious life prompts empathy, forgiveness, mutual respect, and enhanced conflict resolution capacity (p. 82). The relationship between the church and couple conflict deserves even more attention, and this study can be appreciated as a gesture toward the encouragement of such attention.

In addition to the above, local churches should be proactive in looking at ways to reduce couple conflict in their congregations. Church administrators should be intentional in embarking on pragmatic programs that can increase communication skills, organize seminars on conflict resolution skills, arrange Bible studies on what genuine agape Christian love looks like as described in the Bible, and how it can become a realistic thing among couples and in members' homes. These, put into practice, will help mold couples in the congregation into well-differentiated, positively impactful persons. Biblical workshops on the blueprints of marriage and what the Bible says on sensitive issues such as male domination, gender roles, headship, submission, discipleship, and spirituality will no doubt shape couples into selfless persons over time if such programs are resourcefully and constantly planned and executed. Local churches could also team 
up as districts to organize the following programs: Amplify messages to advance the objectives of family stability through media campaigns, phones, Facebook, Instagram, Twitter, and email; social program awareness to help people develop skills and knowledge needed to prepare for and build healthy marriages; financial incentives to help struggling families; improve career prospects for younger men and women from dysfunctional marriages; and provide counseling services for couples in conflict at very affordable rates (U.S. Senate, Joint Economic Committee-Republicans., 2020, pp. 31$37)$.

Finally, I boldly opine that this study should serve as a clarion call to curriculum planners from middle school right through to all levels of college and university undergraduate degrees and that courses in marriage and family life be designed and included as integral parts of prerequisites needed for graduation. Just as courses such as general studies, languages, and mathematics are among the requirements for graduation, so also pragmatic marriage and family life courses should be appropriately designed and included as part of the needed requirements for graduation. This will sensitize the younger generation concerning the urgent necessity to take marriage and family life very seriously. This is very crucial because

while family life in our society is experiencing terrible disorganization and distress, our schools have taken very little cognizance of the condition. This certainly is not as it should be. The schools are in a strategic position to help strengthen and reorganize family life, and unless they undertake to do so soon in deadly earnestness society will suffer further unnecessary damage and loss (Miller, 1956, p. 173).

While we are putting significant emphasis on training other professionals such as pilots, lawyers, medical doctors, pastors, teachers and professors, accountants, pharmacists, nurses, and so on, it should be taken into account that all these professionals 
come from a particular home, and hence, if the homes they come from are dysfunctional, it will no doubt have adverse effects on their professional performance, which will eventually take a toll on society. Dobson (2020) drove this point home:

Marriage represents the very foundation of human social order. Everything of value sits on that base. Institutions, governments, religious fervor and the welfare of children are all dependent on its stability. When it is weakened or undermined, the entire superstructure begins to wobble (para. 3). 
APPENDIX A

PROJECTED SEQUENCE OF EVENTS 
January 2018 - January 2019

1. Complete Chapters 1-3

2. Procure the CTS2 instrument

3. Defend the proposal (Chapters 1-3)

4. Secure IRB permission to collect data

February 2019

1. Send out letters to secure permission to collect data

2. Collect replies to the letters

March 2019 - December 2019

1. Send out the questionnaire to the research participants

January 2020 - March 2020

1. Analyze the data from the returned questionnaires.

March 2020

1. Complete the data analyses, write chapters 4 and 5, and submit them for evaluation. Prepare the completed document for the doctoral defense.

June - September 2020

1. Final defense and revisions

December 2020 - March 2021

1. Graduation: May 2021 
APPENDIX B

LETTER TO PASTORS AND GROUP LEADERS 
Department of Discipleship and Religious Education, Seventh-day Adventist Theological Seminary, Andrews University, Berrien Springs, MI 49104, USA

Dear Pastors and National/Ethnic African Immigrants and African American Group Leaders,

\section{Request for Permission and Assistance to Administer and Collect a Research Survey Questionnaire}

My name is Cornelius Ayodeji Osuntade, I am a PhD. student at the Seventh-day Adventist Theological Seminary, Andrews University, Berrien Springs, Michigan. My course major is Religious Education with an emphasis in Family Life Education.

I am embarking on a research study titled: "An Exploratory Analysis of Conflict in African Immigrant and African American Marriages." The chairman of my committee is a seasoned Family life and Social Work Professor in the person of Professor David Sedlacek, while the two other Professors in my committee, Professor Peter Swanson, and Professor Tevni Grajales, are high caliber Professors of notable repute in the world of academia.

I am hereby humbly requesting permission to use the members of your Churches/ National/Ethnic Group as the sample to administer the questionnaire for this study.

Please kindly note that a survey using SurveyMonkey will be used for data collection. We are asking for emails of potential participants and upon receipt of the emails, the SurveyMonkey link will be sent through the obtained emails from the participants. The data collected will only be the questionnaire items on the survey with no identifying information. The responses will come back to the principal researcher anonymously for analyses.

It is expected that this research work will benefit African immigrant and African American marriages and families in the area of relationship conflict management.

If you have any questions, please contact the chairman of my dissertation committee at sedlacek@andrews.edu. You can also contact me at cosuntade@gmail.com.

Thank you for your anticipated help in this matter.

Yours Sincerely,

Cornelius Ayodeji Osuntade 
APPENDIX C

CTS2 QUESTIONNAIRE 


\section{Please kindly note that completing this survey indicates your implied consent.}

Date

Gender: Male

Female

Highest education attained-

Religious affiliation:

Christian------------

Islam-

Other (please specify)

Race/Ethnicity:

For Africans only: (Country of origin in Africa)

African American------------------

Years of marriage

No matter how well a couple gets along, there are times when they disagree, get annoyed with one another, want different things from each other, or just have spats or fights because they are in a bad mood, are tired, or are upset for some other reasons. Couples also have many different ways of trying to settle their differences. This is a list of things that might happen when you have differences. Some questions are about you and others are about your partner. Please circle the response that describes how many times these things happened in the past year. $1=$ once, $2=$ twice, $3=3-5$ times, $4=6-10$ times, $5=$ 11-20 times, $6=$ more than 20 times, while $0=$ never. If one of these things did not happen in the past year, but it happened before that, circle "7"

\begin{tabular}{r|l|l|l|l}
\multicolumn{1}{r|}{ Item \# } & Question & SubScale & Perp/Vict & Severity \\
\hline & I showed my partner I cared even though we disagreed & Negotiation & Perpetration & Minor \\
3 & My partner showed care for me even though we disagreed & Negotiation & Victimization & Minor \\
4 & I explained my side of a disagreement to my partner & Negotiation & Perpetration & Minor \\
5 & I showed respect for my partner's feelings about an issue & Negotiation & Victimization & Minor \\
6 & My partner showed respect for my feelings about an issue & Negotiation & Perpetration & Minor \\
7 & I said I was sure we could work out a problem & Negotiation & Victimization & Minor \\
8 & My partner was sure we could work it out & Negotiation & Perpetration & Minor \\
9 & I suggested a compromise to a disagreement & Negotiation & Victimization & Minor \\
10 & My partner suggested a compromise to a disagreement & Negotiation & Perpetration & Minor \\
11 & I agreed to try a solution to a disagreement my partner suggested & Negotiation & Perpetration & Minor \\
12 & My partner agreed to try a solution I suggested & Negotiation & Victimization & Minor \\
13 & I insulted or swore at my partner & Psychological & Aggression & Perpetration \\
14 & My partner insulted or swore at me & Psychological & Aggression & Vinor \\
15 & I shouted or yelled at my partner & Psychological & Aggression & Perpetration
\end{tabular}


My partner shouted or yelled at me

I stomped out of the room or house or yard during a disagreement

My partner stomped out of the room or house or yard during a

18

I did something to spite my partner

My partner did something to spite me

I called my partner fat or ugly

My partner called me fat or ugly

I destroyed something belonging to my partner

My partner destroyed something that belonged to me

I accused my partner of being a lousy lover

My partner accused me of being a lousy lover

I threatened to hit or throw something at my partner

My partner threatened to hit or throw something at me

I threw something at my partner that could hurt

My partner threw something at me that could hurt

I twisted my partner's arm or hair

My partner twisted my arm or hair

I pushed or shoved my partner

My partner pushed or shoved me

I grabbed my partner

My partner grabbed me

I slapped my partner

My partner slapped me

I used a knife or gun on my partner

My partner used a knife or gun on me

I punched or hit my partner with something that could hurt

My partner punched or hit me with something that could hurt

I choked my partner

My partner choked me

I slammed my partner against a wall

My partner slammed me against a wall

I beat up my partner

My partner beat me up

I burned or scalded my partner on purpose

My partner burned or scalded me on purpose

I kicked my partner

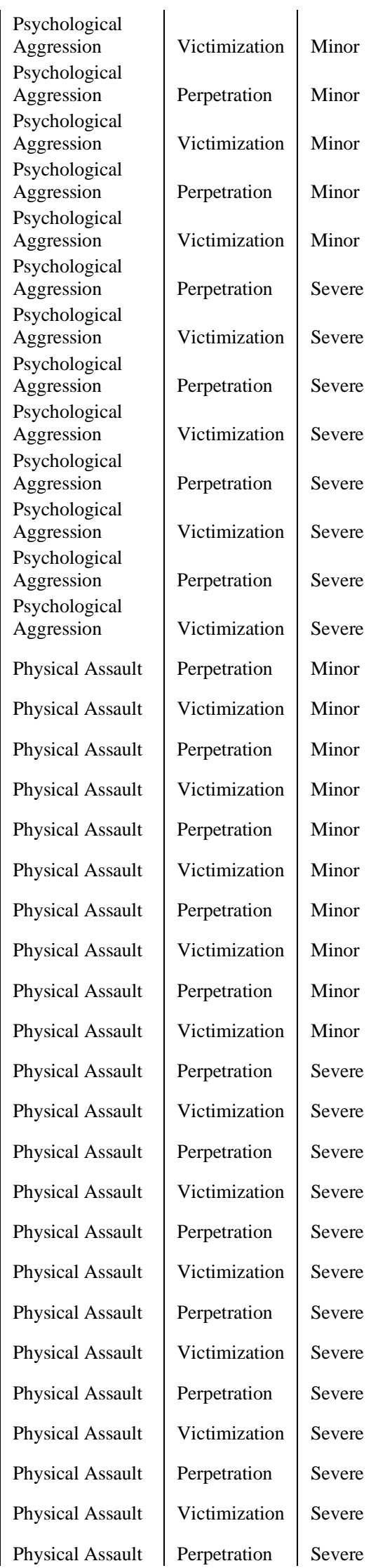




\begin{tabular}{|c|c|c|c|c|}
\hline 52 & My partner kicked me & Physical Assault & Victimization & Severe \\
\hline 53 & I had a sprain, bruise, or small cut because of a fight with my partner & Injury & Perpetration & Minor \\
\hline 54 & $\begin{array}{l}\text { My partner had a sprain, bruise, or small cot because of a fight with } \\
\text { me }\end{array}$ & Injury & Victimization & Minor \\
\hline 55 & $\begin{array}{l}\text { I felt physical pain that still hurt the next day because of a fight with } \\
\text { my partner }\end{array}$ & Injury & Perpetration & Minor \\
\hline 56 & $\begin{array}{l}\text { My partner still felt physical pain the next day because of a fight we } \\
\text { had }\end{array}$ & Injury & Victimization & Minor \\
\hline 57 & I passed out from being hit on the head by my partner in a fight & Injury & Perpetration & Severe \\
\hline 58 & My partner passed out from being hit on the head by me in a fight & Injury & Victimization & Severe \\
\hline 59 & I went to a doctor because of a fight with my partner & Injury & Perpetration & Severe \\
\hline 60 & My partner went to a doctor because of a fight with me & Injury & Victimization & Severe \\
\hline 61 & $\begin{array}{l}\text { I needed to see a doctor because of a fight with my partner, but I } \\
\text { didn't. }\end{array}$ & Injury & Perpetration & Severe \\
\hline 62 & $\begin{array}{l}\text { My partner needed to see a doctor because of a fight with me, but } \\
\text { didn't }\end{array}$ & & Victimization & \\
\hline 63 & I had a broken bone from a fight with my partner & Injury & Perpetration & Severe \\
\hline 64 & My partner had a broken bone from a fight with me & Injury & Victimization & Severe \\
\hline 65 & I made my partner have sex without a condom & Sexual Coercion & Perpetration & Minor \\
\hline 66 & My partner made me have sex without a condom & Sexual Coercion & Victimization & Minor \\
\hline 67 & $\begin{array}{l}\text { I insisted on sex when my partner did not want to (but did not use } \\
\text { physical force) }\end{array}$ & Sexual Coercion & Perpetration & Minor \\
\hline 68 & $\begin{array}{l}\text { My partner insisted that I have sex when I didn't want to (but did not } \\
\text { use physical force) }\end{array}$ & Sexual Coercion & Victimization & Minor \\
\hline 69 & $\begin{array}{l}\text { I insisted my partner have oral or anal sex (but did not use physical } \\
\text { force) }\end{array}$ & Sexual Coercion & Perpetration & Minor \\
\hline 70 & $\begin{array}{l}\text { My partner insisted I have oral or anal sex (but did not use physical } \\
\text { force) }\end{array}$ & Sexual Coercion & Victimization & Minor \\
\hline 71 & $\begin{array}{l}\text { I used force (like hitting, holding down, or using a weapon) to make my } \\
\text { partner have oral or anal sex }\end{array}$ & Sexual Coercion & Perpetration & \\
\hline 72 & My partner used force to make me have oral or anal sex & Sexual Coercion & Victimization & Severe \\
\hline 73 & $\begin{array}{l}\text { I used force (like hitting, holding down, or using a weapon) to make } \\
\text { my partner have sex }\end{array}$ & Sexual Coercion & Perpetration & Severe \\
\hline 74 & My partner used force to make me have sex & Sexual Coercion & Victimization & Severe \\
\hline 75 & I used threats to make my partner have oral or anal sex & Sexual Coercion & Perpetration & Severe \\
\hline 76 & My partner used threats to make me have oral or anal sex & Sexual Coercion & Victimization & Severe \\
\hline 77 & I used threats to make my partner have sex & Sexual Coercion & Perpetration & Severe \\
\hline 78 & My partner used threats to make me have sex & Sexual Coercion & Victimization & Severe \\
\hline
\end{tabular}

\author{
"Sample CTS2 form copyright @ 2003 by Western Psychological Services. Reprinted by \\ Cornelius. Ayodeji Osuntade, Andrews University, for the sole purpose of internal \\ scholarly review. Not to be reprinted in whole or in part for any other purpose without the \\ prior, written authorization of WPS (rights@wpspublish.com)."
}


APPENDIX D

AWS 
A. Attitudes Towards Women Scale (Spence, Helmrich \& Stapp, 1973) - Short version Instructions:

The statements listed below describe attitudes toward the roles of women in society which different people have. There are no right or wrong answers, only opinions. You are asked to express your feeling about each statement by indicating whether you (A) agree strongly, (B) agree mildly, (C) disagree mildly, or (D) disagree strongly. Please circle your opinion in each item

1. Swearing and obscenity are more repulsive in the speech of a woman than of a man.

A

B

Agree strongly

Agree mildly

Disagree mildly

Disagree strongly

$2^{*}$ Women should take increasing responsibility for leadership in solving the intellectual and social problems of the day.
A
B
$\mathrm{C}$
$\mathrm{D}$

Agree strongly Agree mildly Disagree mildly Disagree strongly

3.* Both husband and wife should be allowed the same grounds for divorce.

A

B

Agree strongly

Agree mildly
D

Disagree strongly

4. Telling dirty jokes should be mostly a masculine prerogative.
A
B
$\mathrm{C}$
$\mathrm{D}$

Agree strongly Agree mildly Disagree mildly Disagree strongly 
5. Intoxication among women is worse than intoxication among men.
A
B
$\mathrm{C}$
$\mathrm{D}$

Agree strongly Agree mildly Disagree mildly Disagree strongly

6.* Under modern economic conditions with women being active outside the home, men should share in household tasks such as washing dishes and doing the laundry.
A
B
$\mathrm{C}$
$\mathrm{D}$

Agree strongly Agree mildly Disagree mildly Disagree strongly

7.* It is insulting to women to have the "obey" clause remain in the marriage service.
A
B
$\mathrm{C}$
$\mathrm{D}$

Agree strongly Agree mildly Disagree mildly Disagree strongly

8. ${ }^{*}$ There should be a strict merit system in job appointment and promotion without regard to sex.
A
B
$\mathrm{C}$
$\mathrm{D}$

Agree strongly Agree mildly Disagree mildly Disagree strongly

9.* A woman should be free as a man to propose marriage.
A
B
$\mathrm{C}$
D

Agree strongly Agree mildly Disagree mildly Disagree strongly 
10. Women should worry less about their rights and more about becoming good wives and mothers.
A
B
$\mathrm{C}$
$\mathrm{D}$

Agree strongly Agree mildly Disagree mildly Disagree strongly

11.* Women earning as much as their dates should bear equally the expense when they go out together.
A
B
$\mathrm{C}$
$\mathrm{D}$

Agree strongly Agree mildly Disagree mildly Disagree strongly

12.* Women should assume their rightful place in business and all the professions along with men.
A
B
$\mathrm{C}$
$\mathrm{D}$

Agree strongly Agree mildly Disagree mildly Disagree strongly

13. A woman should not expect to go to exactly the same places or to have quite the same freedom of action as a man.
A
B
$\mathrm{C}$
$\mathrm{D}$

Agree strongly Agree mildly Disagree mildly Disagree strongly

14. Sons in a family should be given more encouragement to go to college than daughters.
A
B
$\mathrm{C}$
$\mathrm{D}$

Agree strongly Agree mildly Disagree mildly Disagree strongly 
15. It is ridiculous for a woman to run a locomotive and for a man to darn socks.
A
B
$\mathrm{C}$
D

Agree strongly Agree mildly Disagree mildly Disagree strongly

16. In general, the father should have greater authority than the mother in the bringing up of children.
A
B
$\mathrm{C}$
$\mathrm{D}$

Agree strongly Agree mildly Disagree mildly Disagree strongly

17. Women should be encouraged not to become sexually intimate with anyone before marriage, even their fiancés.
A
B
$\mathrm{C}$
$\mathrm{D}$

Agree strongly Agree mildly Disagree mildly Disagree strongly

18.* The husband should not be favored by law over the wife in the disposal of family property or income.
A
B
$\mathrm{C}$
$\mathrm{D}$

Agree strongly Agree mildly Disagree mildly Disagree strongly

19. Women should be concerned with their duties of childbearing and house tending rather than with desires for professional or business careers.
A
B
$\mathrm{C}$
$\mathrm{D}$

Agree strongly Agree mildly Disagree mildly Disagree strongly 
20. The intellectual leadership of a community should be largely in the hands of men.
A
B
$\mathrm{C}$
D

Agree strongly Agree mildly Disagree mildly Disagree strongly

21.* Economic and social freedom is worth far more to women than acceptance of the ideal of femininity which has been set up by men.
A
B
C
$\mathrm{D}$

Agree strongly Agree mildly Disagree mildly Disagree strongly

22. On the average, women should be regarded as less capable of contributing to economic production than are men.
A
B
$\mathrm{C}$
$\mathrm{D}$

Agree strongly Agree mildly Disagree mildly Disagree strongly

23. There are many jobs in which men should be given preference over women in being hired or promoted.
A
B
$\mathrm{C}$
$\mathrm{D}$

Agree strongly Agree mildly Disagree mildly Disagree strongly

24.* Women should be given equal opportunity with men for apprenticeship in the various trades.
A
B
$\mathrm{C}$
$\mathrm{D}$

Agree strongly Agree mildly Disagree mildly Disagree strongly 
25.* The modern girl is entitled to the same freedom from regulation and control that is given to the modern boy.
A
B
$\mathrm{C}$
$\mathrm{D}$

Agree strongly Agree mildly Disagree mildly Disagree strongly

In scoring the items, $\mathrm{A}=0, \mathrm{~B}=1, \mathrm{C}=2$, and $\mathrm{D}=3$ except for the items with an asterisk where the scale is reversed. A high score indicates a profeminist, egalitarian attitude while a low score indicates a traditional, conservative attitude. 
APPENDIX E

IMMIGRATION QUESTIONNAIRE 
(Specifically, for African immigrants)

\section{Please tick the appropriate responses to the following questions}

1). Has your marriage relationship been affected in any way since you arrived into the US?
A) Yes
B) No
C) If yes, please describe how your marriage relationship has been affected

2). In what manner has your marriage relationship been affected since arriving the US?
A) Positively
B) Negatively
C) Both positively and negatively
D). Not sure
Please explain 
3). What do you think accounted for the changes in your marriage relationship? Tick all that apply
A) Adjustment to the American culture
B) Economic and money Issues
C) Work related issues
D) Language problem
E) Immigration related problems
F) Lack of adequate time with each other
G) Pursuing the American dream
H) Sex and infidelity

I) Educational challenges facing international students and their spouses

J) Lack of Communication

K) Psychosocial Factors

L) Other personal identified stressors (Please specify)

Please add any comments that might help us understand your response above 
REFERENCE LIST 


\section{REFERENCE LIST}

Abbott, D. A., \& Gupta, P. M. (2009). Influence of American culture on East Indian immigrants' marriage and family life. In R. L., Dalla, J. Defrain, J. Johnson, \& D. A. Abbott (Eds.), Strengths and challenges of new immigrant families: Implications for research, education, policy and service. Lanham, MD: Lexington Books.

African Immigrant and Refugee Foundation. (2021). Welcome to the African immigrant and refugee foundation. Retrieved from https://www.airfound.org/about

Allen, W. D., \& Olson, D. H. (2001). Five types of African-American marriages. Journal of Marital and Family Therapy, 27 (3), 301-314. Retrieved from https://research .prepare-enrich.com/wp-content/uploads/2019/09/Allen-Olson-Five-types-ofafrican-american-marriages.pdf

Al'Uqdah, S., Maxwell, C., \& Hill, N. (2016). Intimate Partner Violence in the African American Community: Risk, Theory, and Interventions. Journal of Family Violence. 31(7). 877-884. Retrieved from https://www.researchgate.net/ publication/303466897_Intimate_Partner_Violence_in_the_African_American_C ommunity_Risk_Theory_and_Interventions

Alvin, T. (2007). Aggression in African American males: A review of selected literature on environmental influence. Challenge, 13(1), 29-38. Retrieved from https://www .researchgate.net/publication/281737527_Aggression_in_African_American_Mal es_A_Review_of_Selected_Literature_on_Environmental_Influence

American Psychological Association. (2014). Religion or spirituality has positive impact on romantic/marital relationships, child development, research shows [Press release]. Retrieved from http://www.apa.org/news/press/releases/2014/12/ religion-relationships.aspx

Ampim, M. (2003, September). The five major African initiation rites. Africana Studies. Retrieved from http://www.manuampim.com/AfricanInitiationRites.htm

Anim, M. T. (2013). Psychosocial factors influencing marital distress in Ghanaian married couples. Research on Humanities and Social Sciences, 3(1), 161-171. Retrieved from https://www.iiste.org/Journals/index.php/RHSS/article/view/ $4119 / 4198$ 
Archive, (2009). Book reveals challenges facing African married couples in US - Part 3 of 5. Retrieved from https://www.voanews.com/archive/book-reveals-challengesfacing-african-married-couples-us-part-3-5

Arthur, J. A. (2000). Invisible sojourners: African immigrant diaspora in the United States. Westport, CT: Praeger.

Association of Black Social Workers (Harambee). (2002, October). Domestic violence in the African American community. Retrieved from https://cdn.ymaws.com/www .nabsw.org/resource/resmgr/position_statements_papers/domestic_violence_ position_p.pdf

Atkinson, D. (1990). The message of Genesis 1-11: The Bible speaks today. Downers Grove, IL: InterVarsity Press.

Aubel, J. (2010). Elders: A cultural resource for promoting sustainable development. 2010 State of world report: Transforming culture. The World Watch Institute, 41-46, 201-202. Retrieved from http://blogs.worldwatch.org/ transformingcultures/wp-content/uploads/2010/07/Elders-Aubel.pdf

Balswick, J. O., \& Balswick, J. K. (2014). The family: A Christian perspective on the contemporary home. Grand Rapids, MI: Baker Academic.

Barbarin, O. A., \& McCandies, T. (2020). African-American families. Encyclopedia.com. Retrieved from https://www.encyclopedia.com/reference/ encyclopedias-almanacs-transcripts-and-maps/african-american-families

Bartos, O. J., \& Wehr, P. (2002). Using Conflict Theory. Cambridge, England: Cambridge University Press. Retrieved from http://www.cambridge.org/us/ academic/subjects/sociology/social-theory/using-conflict-theory?format= PB\&isbn=9780521794466\#mVqLzlkFE5SCqXRe.97

Beere, C. A. (1990). Gender roles: A handbook of tests and measures. New York, NY: Greenwood Press.

Ben-David, A., \& Lavee, Y. (1994). Migration and marital distress: The case of Soviet immigrants. Journal of Divorce \& Remarriage, 21(3/4). Retrieved from http://research.haifa.ac.il/ lavee/Papers/1994-16-migration-marital-distressJDR.pdf

Bent-Goodley, T. B. (1998). A poor African American community's response toward domestic violence. Dissertation Abstracts International, 58,4808.

Bent-Goodley, T. B. (2001). Eradicating domestic violence in the African American community: A literature review and action agenda: Trauma, violence, and abuse. A Review Journal, 2, 316-330. 
Bent-Goodley, T. B. (2004). Perceptions of domestic violence: A dialogue with African American women. Health and Social Work, 29(4), 307-316.

Bent-Goodley, T. B. (2014). African American marriages at the intersection: Challenges, strengths, and resilience (chap. 1). In T. B. Bent-Goodley (Ed.), By grace: The challenges, strengths, and promise of African American marriages. Washington, DC: NASW Press. Retrieved from https://www.naswpress.org/publications/ diversity/inside/african-american-marriages-chapter.html

Bezruchka, S. (2015). Early life or early death: Support for child health lasts a lifetime. International Journal of Child, Youth and Family Studies, 6(2), 204-229. Retrieved from https://journals.uvic.ca/index.php/ijcyfs/article/viewFile/ $13499 / 4312$

Bigio, J., \& Vogelstein, R. (2016). How women's participation in conflict prevention and resolution advances U.S. interests. New York, NY: Council on Foreign Relations Press. Retrieved from https://www.cfr.org/sites/default/files/pdf/2016/10/ Discussion_Paper_Bigio_Vogelstein_Women\%20in\%20CPR_OR.pdf

Björkqvist, K. (2009). The inevitability of conflict but not of violence: Theoretical considerations on conflict and aggression. In D. P. Fry, \& K. Björkqvist (Eds.), Cultural variation in conflict resolution: Alternatives to violence (pp. 25-36). London, United Kingdom: Psychology Press.

Black, M. C., Basile, K. C., Breiding, M. J., Smith, S. G., Walters, M. L., Merrick, M. T., \& Stevens, M. R. (2011). National intimate partner and sexual violence survey. Atlanta, GA: Centers for Disease Control and Prevention.

Blum, W. G. (1989). Forms of marriage: Monogamy reconsidered. Nairobi, Kenya: Gaba.

Booth, A., Crouter, A. C., \& Clements, M. (Eds.). (2009). Couples in conflict. Abingdon, England: Taylor \& Francis e-Library.

Bremond, T., Cannatella, J., Ahn, B., \& Kang, H. (2013). Definitions of dating violence among African American college students: Their relationships with gender role beliefs. Undergraduate Research Journal for the Human Sciences, 12. Retrieved from http://www.kon.org/urc/v12/bremond.html

Brewer, E. W. (2009). Conducting survey research in education. In V. C. X. Wang (Ed.), Handbook of research on E-learning applications for career and technical education: Technologies for vocational training, (Vol. 11, pp. 519-533). Hershey, NY: Information Science Reference. 
Briscoe, D. L. (2000). Distinctive features of the African-American family: Debunking the myth of the deficit model. Ethnic Studies Review, 23(1), 97-122. Retrieved from https://scholarscompass.vcu.edu/cgi/viewcontent.cgi?article= $1132 \&$ context $=$ esr

Brody, G., Stoneman, Z., Flor, D., \& McCrary, C. (1994). Religion's role in organizing family relationships: Family process in rural, two-parent African American families. Journal of Marriage and Family, 56, 878-888.

Bromiley, G. W. (1980). God and marriage. Grand Rapids, MI: Eerdmans.

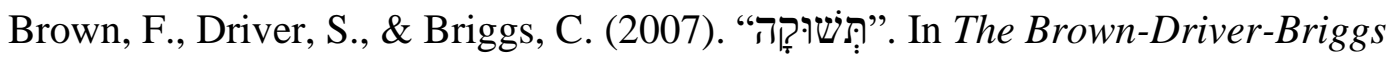
Hebrew and English Lexicon. Peabody, MA: Hendrickson.

Brown, S. L., Van Hook, J., \& Glick, J. E. (2008). Generational differences in cohabitation and marriage in the U.S. Population Research and Policy Review, 27(5), 531-550. Retrieved from https://www.ncbi.nlm.nih.gov/pmc/articles/ PMC3242441/pdf/nihms341612.pdf

Bryant, C. M. (2010, October). Understanding the intersection of race and marriage: Does one model fit all? Longitudinal study is identifying multiple factors affecting marital relationships among African Americans. Psychological Science Agenda. Retrieved from https://www.apa.org/science/about/psa/2010/10/racemarriage

Buckner, C. (2010). Attitudes toward women scale. In J. M. Levine, \& M. A. Hogg (Eds.). Encyclopedia of group processes \& intergroup relations (pp. 40-42). Thousand Oaks, CA: Sage. doi:10.4135/9781412972017.n13

Bumpass, L. (2000, September 4-5). Family-related attitudes, couple relationships, and union stability. (NSFH Working Paper No. 87: A national survey of families and households). Paper presented at the forum on values orientations and life cycle decisions, Royal academy of arts and sciences, Brussels, Belgium. Retrieved from http://www.ssc.wisc.edu/cde/nsfhwp/nsfh87.pdf

Burholt, V., Dobbs, C., \& Victor, C. (2018). Social support networks of older migrants in England and Wales: The role of collectivist culture. Ageing and Society, 38(7), 1453-1477. doi:10.1017/S0144686X17000034. Retrieved from https://bura.brunel .ac.uk/bitstream/2438/14180/3/FullText.pdf

Busenitz, I. A. (1986). Woman's desire for man: Genesis 3:16 reconsidered. Grace Theological Journal 7(2), 203-12. Retrieved from http://faculty.gordon.edu/ hu/bi/ted_hildebrandt/OTeSources/01-Genesis/Text/Articles-Books/BusenitzGen3-GTJ.pdf 
Bushman, B. J., \& Phillips, C. M. (2002). Catharsis theory and media effects. Encyclopedia of communication and information. Retrieved from http://www .encyclopedia.com/media/encyclopedias-almanacs-transcripts-and-maps/ catharsis-theory-and-media-effects

Caarls, K., \& Mazzucato, V. (2015). Does international migration lead to divorce? Ghanaian couples in Ghana and abroad. Population, 1(1), 135-161. https://doi.org/10.3917/popu.1501.0135

Calvin, J., \& King, J. (2010). Commentary on the first book of Moses called Genesis. Bellingham, WA: Logos Bible Software.

Capps, R., McCabe, K., \& Fix, M. (2012). Diverse streams: Black African migration to the United States [Webpage]. Retrieved from http://www.migrationpolicy.org/ research/CBI-african-migration-united-states

Carlson, R. J. (2013, March 6). God is the author of marriage. St. Louis Review. Retrieved from http://stlouisreview.com/article/2013-03-06/god-author-marriage

Caucutt, E., Guner, N., \& Rauh, C. (2019). Incarceration, unemployment, and the blackwhite marriage gap in the US. Retrieved from https://voxeu.org/article/ incarceration-unemployment-and-black-white-marriage-gap-us

Chakamba, R. (2016, October 21). The Push to Get Every African Country to Criminalize Marital Rape [Women and Girls]. Retrieved from https://www.newsdeeply.com/ womenandgirls/articles/2016/10/21/push-get-every-african-country-criminalizemarital-rape

Chapman, K. (1994, December). At the beginning: A study of marriage: Matthew 19:1-13 [Webpage]. The expository files. Retrieved from http://www.bible.ca/ef/ expository-matthew-19-1-13.htm

Charny, I. W. (1980). Why are so many (if not really all) people and families disturbed? Journal of Marital and Family Therapy, 6, 37-45.

Cochran, N. B. (2011). Bowen family systems theory and its relationship to teachers: Does differentiation of self predict teacher job satisfaction? (Unpublished doctoral dissertation). University of Southern Mississippi, Hattiesburg. Retrieved from https://aquila.usm.edu/cgi/viewcontent.cgi?referer=https://www.google $. c o m / \&$ httpsredir $=1 \&$ article $=1446 \&$ context $=$ dissertations

Coogan, M. D., Brettler, M. Z., Newsom, C. A., \& Perkins, P. (Eds.). (2001). The Oxford annotated Bible. New York, NY: Oxford University Press. 
Corporate Finance Institute. (2018). Conflict theory: Never-ending competition for resources [Webpage]. Retrieved from https://corporatefinanceinstitute.com/ resources/knowledge/economics/conflict-theory/

Crenshaw, A. O., Christensen, A., Baucom, D. H., Epstein, N. B., \& Baucom, B. R. W. (2017). Revised scoring and improved reliability for the communication patterns questionnaire. Psychological Assessment, 29(7), 913-925. doi:10.1037/ pas0000385

Criminal Justice. (n.d.). Conflict tactics scales (CTS) [Webpage]. Retrieved from http:// criminal-justice.iresearchnet.com/crime/domestic-violence/conflict-tactics-scalescts/

Crossman, A. (2019, July 3). Understanding conflict theory [Webpage]. Retrieved from https://www.thoughtco.com/conflict-theory-3026622

Cunradi, C. B., Caetano, R., \& Schafer, J. (2002, April). Alcohol-related problems, drug use, and male intimate partner violence severity among US couples. Alcoholism: Clinical and Experimental Research, 26(4), 493-500. Retrieved from http:// onlinelibrary.wiley.com/doi/10.1111/j.15300277.2002.tb02566.x/epdf?r3_referer $=$ wol\&tracking_action=preview_click\&show_checkout $=1$ \&purchase_referrer $=\mathrm{w}$ ww.ncbi.nlm.nih.gov\&purchase_site_license=LICENSE_DENIED_NO_CUSTO MER

Curry-Stevens, A., \& Coalition of communities of color. (2013). The African immigrant and refugee community in Multnomah county: An unsettling profile. Portland, OR: Portland State University. Retrieved from https://www.portlandoregon.gov/ oehr/article/713236

Dalla, R. L., Defrain, J., Johnson, J., \& Abbott, D. A. (Eds.), (2009). Strengths and challenges of new immigrant families: Implication for research, education, policy, and service. Lanham, MD: Lexington Books.

Davis, D. M. (2013). Rehabilitation counseling master's students: Beliefs and attitudes about domestic violence toward women. (Unpublished doctoral dissertation). University of Iowa, Iowa City. Retrieved from https://ir.uiowa.edu/cgi/ viewcontent.cgi? article $=4835 \&$ context $=$ etd

De Souza, E. B. (2015). Was Adam with Eve at the scene of temptation? A short note on "with her" in Genesis 3:6. Silver Spring, MD: General Conference of Seventhday Adventists, Biblical Research Institute. Retrieved from https://www .adventistbiblicalresearch.org/sites/default/files/pdf/Was\%20Adam\%20with\%20E ve $\% 20$ at $\% 20$ the $\% 20$ Scene $\% 20$ of $\% 20$ Temptation.pdf

Deutsch, M. (1973). The resolution of conflict: Constructive and destructive processes. New Haven, CT: Yale University Press. 
Dew, J., \& Dakin, J. (2011). Financial disagreements and marital conflict tactics. The Journal of Financial Therapy, 2(1), 23-42. Retrieved from http://digitalcommons .usu.edu/cgi/viewcontent.cgi?article $=1069 \&$ context=fchdfacpub

Dixon, P. (2009). Marriage among African Americans: What does the research reveal? Journal of African American Studies, 13(1), 29-46. Retrieved from https:// www.researchgate.net/publication/226130819_Marriage_Among_African_Ameri cans_What_Does_the_Research_Reveal

Dixon, P. (2017). African American relationships, marriages, and families: An introduction (2nd ed.). New York, NY: Routledge.

Dobson, J. (2020). Marriage under fire [Webpage]. Retrieved from http://drjamesdobson .org/news/commentaries/marriage_under_fire

Doss, G. R. (1999). Spiritual growth through family ministries. Ministry Magazine, 72(2), 18-20. Retrieved from https://www.ministrymagazine.org/archive/1999/02/ spiritual-growth-through-family-ministries

Drewry, H. (2018). African American history [Webpage]. Retrieved from https://www .scholastic .com/teachers/articles/teaching-content/african-american-history/

Dudley, M. G., \& Kosinski, F. A. (1990). Religiosity and marital satisfaction: A research note. Review of Religious Research, 32(1), 78-86.

Duffin, E. (2020). Number of Black families with a single mother in the United States from 1990 to 2019 (in 1,000s) [Webpage]. Retrieved from https://www.statista .com/statistics/205106/number-of-black-families-with-a-female-householder-inthe-us/

Echeverria-Estrada, C., \& Batalova, J. (2019, November 6). Sub-saharan African immigrants in the United States [Webpage]. Retrieved from https://www .migrationpolicy.org/article/sub-saharan-african-immigrants-united-states-2018

Edmonds, L. (2008). Mission of motherhood: You are a life-giver! [Webpage]. Retrieved from https://www.passionatehomemaking.com/2008/09/mission-of-motherhoodchapter-2.html

Emmy, Q. Z. (n.d.). Promoting positive peer relationships: A sample of recent references [Webpage]. Retrieved from http://smhp.psych.ucla.edu/pdfdocs/peers.pdf

Engel, B. (2020, March 3). Intimate Partner Sexual Assault: The trauma of being assaulted or raped in a relationship [Webpage]. Psychology today: The Compassion Chronicle. Retrieved from https://www.psychologytoday.com/us/ blog/the-compassion-chronicles/202003/intimate-partner-sexual-assault 
Ewing, J. (n.d.). 10 most beautiful mother Teresa quotes on the family [Web log post]. Retrieved from https://www.coraevans.com/blog/article/10-most-beautifulmother-teresa-quotes-on-the-family

Fagan, P. (1995). The real root causes of violent crime: The breakdown of marriage, family, and community [Webpage]. Retrieved from http://www.heritage.org/ crime-and-justice/report/the-real-root-causes-violent-crime-the-breakdownmarriage-family-and

Farrington, K., \& Chertok, E. (1993). Social conflict theories of the family. In P. G. Boss, W. J. Doherty, R. LaRossa, W. R. Schumm, \& S. K. Steinmetz (Eds.), Sourcebook of family theories and methods: A contextual approach (pp. 357-381). New York, NY: Plenum.

Feld, S. L., \& Straus, M. A. (1989). Escalation and desistance of wife assault in marriage. Criminology, 27(1), 141-161.

Fincham, F. D., Bradbury, T. N., \& Grych, J. H. (2014). Conflict in close relationships: The role of intrapersonal phenomena. In S. Graham \& V. S. Folkes (Eds.), Attribution theory: Applications to achievement, mental health and interpersonal conflict (pp. 161-184). New York, NY: Psychology Press.

Finepoints, (2015). Thomas-Kilmann leading through conflict. Retrieved from http://www.finepointsleadership.com/conflict-leadership

Focus on the Family. (2018). Spending enjoyable time together [Webpage]. Retrieved from https://www.focusonthefamily.com/marriage/promos/healthy-marriagetraits/spending-enjoyable-time-together

Foner, N. (1997). The immigrant family: Cultural legacies and cultural changes. International Migration Review, 31(4), 961-974.

Fowler, J. M. (2005). Ephesians: The gospel of relationships. Retrieved from https:// absg.adventist.org/assets/public/files/lessons/2005/4Q/TE/PDFs/ETQ405_11.pdf

Futris, T. G., Mallette, J., Schramm, D. G., Ahsan, N., \& O'Connor, C. (2016). Strengthening families, a protective factors framework: Making the link between strengthening families and relationship and marriage education [Webpage]. Retrieved from https://www.cssp.org/reform/strengtheningfamilies/ practice/body/CSSP-RME-Link.pdf

Garland, D. R. (2012). Family ministry: A comprehensive guide (2nd ed). Downers Grove, IL: IVP Academic.

Gay, L. R., Mills, G. E., \& Airasian, P. (2009). Educational research (9th ed.). Upper Saddle River, NJ: Pearson Education. 
Gelles, R., \& Straus, M. A. (1989). Intimate violence: The causes and consequences of abuse in the American family. New York, NY: Simon \& Schuster.

Geography. (n.d.). Gender roles and sexuality [Webpage]. Retrieved from http://geography.name/ gender-roles-and-sexuality/

Gere, J., \& Schimmack, U. (2011). When romantic partners' goals conflict: Effects on relationship quality and subjective well-being. Journal of Happiness Studies, 14, 37-49. doi:10.1007/s10902-011-9314-2

Gilles, G. (2016, February 17). What is cohabitation? Statistics \& effects [Webpage]. Retrieved from https://study.com/academy/lesson/what-is-cohabitation-statisticseffects-quiz.html

Glazer, N., Greeley, A., Patterson, O., \& Moynihan, D. (1974). What is ethnicity? Bulletin of the American Academy of Arts and Sciences, 27(8), 16-35. doi:10.2307/3822652

GLOBE. (2020). Country list: Sub-Saharan Africa. Retrieved from https://globeproject .com/results/clusters/sub-saharan-africa?menu=list\#list

Groothuis, R. (1997). Good news for women: A biblical picture of gender equality. Grand Rapids, MI: Baker.

Grossmann, I., Santos, H. C., \& Varnum, M. E. (2017). Global increases in individualism. Psychological science, 28(9), 1228-1239. Retrieved from http:// journals.sagepub.com/doi/pdf/10.1177/0956797617700622\#articlePermissions Container

Halim, N., Steven, E., Reich, N., Badi, L., \& Messersmith, L. (2018). Variability and validity of intimate partner violence reporting by couples in Tanzania. PloS one, 13(3), e0193253. https://doi.org/10.1371/journal.pone.0193253

Halloran, M. J. (2019). African American health and posttraumatic slave syndrome: A terror management theory account. Journal of Black Studies, 50(1), 45-65. https://doi.org/10.1177/0021934718803737

Hammer, C. (2011). A theology of marriage. In M. Anthony \& M. Anthony (Eds.), A theology for family ministries. Nashville, TN: B\&H.

Heath, J. (2013). Why money issues still ruin marriages. Financial post. Retrieved from http://business.financialpost.com/personal-finance/why-money-issues-still-ruinmarriages/wcm/ff418c0b-4ff5-4705-aaf1-75a04b224885

Henry, M. (n.d.). Commentary on Genesis 2:21-25. Retrieved from https://www .biblegateway.com/resources/matthew-henry/Gen.2.21-Gen.2.25 
Hill, C. A. (2008). Human sexuality: Personality and social psychological perspectives. Los Angeles, CA: Sage.

Holland, K. (2015, February 4). Fighting with your spouse? It's probably about this. Personal Finance. CNBC. Retrieved from https://www.cnbc.com/2015/02/04/ money-is-the-leading-cause-of-stress-in-relationships.html

Horowitz, J. M., Graf, N., \& Livingston, G. (2019, November 6). Marriage and Cohabitation in the U.S.: 1 . The landscape of marriage and cohabitation in the U.S. Pew Research Center-Social and Demographic Trends. Retrieved from https://www.pewresearch.org/social-trends/2019/11/06/the-landscape-ofmarriage-and-cohabitation-in-the-u-s/

How frequently are people divorcing in 2020? (2020, February 21). SMU Daily Campus. Retrieved from https://www.smudailycampus.com/sponsoredcontent/promoted/ how-frequently-are-people-divorcing-in-2020

Hudgins, J. L., Holmes, B. J., \& Locke, M. E. (1990). The impact of family structure variations among black families on the under remuneration of black males. (Ethnographic Exploratory Research Report \#7). Retrieved from https:// www.census.gov/srd/papers/pdf/ex90-07.pdf

Hughes, R. K. (2004). Genesis: Beginning and blessing, preaching the word. Wheaton, IL: Crossway Books.

Hutchison, J. (2011). The perfect storm: Handling conflict in marriage [Web log post]. Retrieved from http://www.thegoodbookblog.com/2011/mar/25/the-perfectstorms-handling-conflict-in-marriage/\#

Icheoku. (2008). Nigerian men wife-killers [Web log post]. Retrieved from http:// meniru.blogspot.com/2008/06/nigerian-men-wife-killers.html

Iheduru, A. C. (2013). Examining the social distance between Africans and African Americans: The Role of internalized racism (Unpublished doctoral dissertation). Wright State University, Dayton, OH. Retrieved from https://corescholar.libraries .wright.edu/cgi/viewcontent.cgi?article $=1802 \&$ context=etd_all

Iheduru, O. (2006). Social values, democracy, and the problem of African American identity. Journal of Black Studies, 37(2), 209-230. Retrieved from http://www .jstor.org/stable/40034411

International Social Service, Family Institute. (2015). The Bowen family systems theory. Retrieved from http://www.isshk.org/files/3_6_3_FI_Bowen_Theory_ PDF_EN_26_Oct_2015.pdf 
Isike, C., \& Uzodike, U. O. (2011). Towards an indigenous model of conflict resolution: Reinventing women's roles as traditional peacebuilders in neo-colonial Africa. African Journal on Conflict Resolution, 11(2), 33-59.

Islami, H. (2017). Resolving marital conflicts. SEEU Review, 12(1), 69-80. doi:10.1515/seeur-2017-0005

Jaruseviciene, L., De Meyer, S., Decat, P., Zaborskis, A., Degomme, O., Rojas, M., \& Lazarus, J. V. (2014). Factorial validation of the attitudes toward women scale for adolescents (AWSA) in assessing sexual behaviour patterns in Bolivian and Ecuadorian adolescents. Global Health Action, 7(10), 1-13. Retrieved from https://www.ncbi.nlm.nih.gov/pmc/articles/PMC3901847/pdf/GHA-7-23126.pdf

Jewell, K. S. (2003). Survival of the African American family: The institutional impact of U.S. social policy. Westport, CT: Praeger.

Johnstone, R. L. (2008). Religion in society: A sociology of religion. (8th ed.). New York, NY: Routledge. Cited in The Association of Religious Data Archives. Retrieved from http://wiki.thearda.com/tcm/concepts/religiosity/

Jonasi, S. (2007). What is the role of a grandmother in a Malawian society and how can we as health care workers support her? Malawi Medical Journal: The Journal of Medical Association of Malawi, 19(3), 128-129. Retrieved from https://www.ncbi .nlm.nih.gov/pmc/articles/PMC3345633/

Jones, J. M., \& Campbell, S. (2011). Cultural psychology of African Americans. Online Readings in Psychology and Culture, 3(1). Retrieved from https://scholarworks .gvsu.edu/cgi/viewcontent.cgi?article $=1023 \&$ context $=$ orpc

Jordan, L. M. (2015). Domestic violence in the African American community: The role of the Black church. Retrieved from http://pluralism.org/wp-content/uploads/2015/ 08/Jordan.pdf

Jory, B. (2006). Intimate violence between African-American couples: Seeking intimate justice in the midst of social injustice. In R. L. Hampton, \& T. P. Gullotta (Eds.). Interpersonal violence in the African-American community: Evidence-based prevention and treatment practices (pp. 81-106). New York, NY: Springer.

Kalra, G., \& Bhugra, D. (2013). Sexual violence against women: Understanding crosscultural intersections. Indian Journal of Psychiatry, 55(3), 244-249. https:// doi.org/10.4103/0019-5545.117139. Retrieved from https://www.ncbi.nlm.nih .gov/pmc/articles/PMC3777345/ 
Kalunta-Crumpton, A. (2015). Intersections of patriarchy, national origin and immigrant Nigerian women's experiences of intimate partner violence in the United States. International Journal of Sociology of the Family, 41(1). 1-29. Retrieved from http://www.serialsjournals.com/serialjournalmanager/pdf/1470643126.pdf

Kamau, W., Nyaundi, P., \& Serwanga, J. (2013). The legal impunity for marital rape in Kenya: A women's equality issue. Retrieved from http://theequalityeffect.org/wpcontent/uploads/2013/04/Marital-Rape-Paper-Winnie-Kamau-Final-edited-July18.pdf

Kamya, H. (2005). African immigrant families. In M. McGidrick, J. Giordano, \& N. Garcia-Preto (Eds.), Ethnicity and family therapy (3rd ed., pp. 101-116). New York, NY: Guilford Press.

Kariuki, F. (n.d.). Conflict resolution by elders in Africa: Successes, challenges and opportunities. Retrieved from https://zdoc.site/conflict-resolution-by-elders-inafrica-chartered-institute-.html

Kassa, A. (2013). Dimensions of the new diaspora: African immigrant communities \& organizations in New York, Washington, D.C., and Atlanta. Prepared for Nunu Kidane, priority Africa network. Retrieved from https://ccis.ucsd.edu/_files/ wp189.pdf

Kellermann, P. F. (1992). Focus on psychodrama: The therapeutic aspects of psychodrama. Philadelphia, PA: Kingsley.

Kelly, S., Maynigo, P., Wesley, K., \& Durham, J. (2013). African American communities and family systems: Relevance and challenges. Couple and Family Psychology: Research and Practice, 2(4), 264-277. Doi:10.1037/cfp0000014. Retrieved from http://psycnet.apa.org/record/2014-00822-003

Kenneally, C. (2020, July 23). Large DNA study traces violent history of American slavery. The New York Times. Retrieved from https://www.nytimes.com/2020/07/ 23/science/23andme-african-ancestry.html

Kibria, N. (1993) Family tightrope: The changing lives of Vietnamese Americans. Princeton, NJ: Princeton University Press.

Koerner, K., \& Jacobson, N. S. (1994). Emotion and behavioral couple therapy. In S. M. Johnson \& L. S. Greenberg (Eds.). The heart of the matter: Perspectives on emotion in marital therapy (pp. 207-226). New York, NY: Brunner/Mazel.

Köstenberger, A. J. (n.d.) The biblical framework for marriage. Retrieved from http://www.biblicalfoundations.org/wp-content/uploads/2012/01/36-BiblicalFramework-for-Marriage.pdf 
Köstenberger, A. J. (2016). The Bible's teaching on marriage and family. Retrieved from http://www.frc.org/brochure/the-bibles-teaching-on-marriage-and-family

Köstenberger, A. J., \& Jones, D. W. (2010). God, marriage, and family: Rebuilding the biblical foundation (2nd ed.). Wheaton, IL: Crossway Books.

Kutsoati, E., \& Morck, R. (2012). Family ties, inheritance rights, and successful poverty alleviation: Evidence from Ghana. (Working paper series 18080). Boston, MA: National Bureau of Economic Research.

Kwakye-Nuako, K. (2006). Still praisin' God in a new land: African immigrant Christianity in North America. In K. Konadu-Agyemang, B. K. Takyi, \& J. A. Arthur (Eds.). The new African diaspora in North America: Trends, community building and adaptation (chap. 8). Oxford, England: Lexington Books.

Ladepo, A. (2014, January 22). An epidemic: Nigerian men killing their nurse wives in the US. Sahara Reporters. Retrieved from http://saharareporters.com/2014/01/22/ epidemic-nigerian-men-killing-their-nurse-wives-us-abiodun-ladepo

Lafraniere, S. (2005, August 11). Entrenched epidemic: Wife-beatings in Africa. The New York Times. Retrieved from https://www.nytimes.com/2005/08/11/ world/africa/entrenched-epidemic-wifebeatings-in-africa.html

Lambert, N. M., \& Dollahite, D. C. (2006). How religiosity helps couples prevent, resolve, and overcome marital conflict. Family Relations, 55, 439-449. Retrieved from http://americanfamiliesoffaith.byu.edu/Content/pdf/Marriage\% 20and \%20Religion/S_40HowreligiosityLambertDollahite2006pdf.pdf

Leedy, P. D., \& Ormrod, J. E. (2005). Practical research: Planning and design (8th ed.). Upper Saddle River, NJ: Pearson.

Leupold, C. (1942). Exposition of Genesis. Grand Rapids, MI: Baker Books.

Library of Congress. (n.d.). Africans in America: Life in a Slave Society [Webpage]. Retrieved on July 30,2020 from https://www.loc.gov/teachers/classroommaterials/ presentationsandactivities/presentations/immigration/african4.html

Locke, S. (2015, May 20). 8 ways to be a more savvy science reader: Your guide on how to evaluate scientific evidence [Web log post]. Retrieved from https://www.vox .com/cards/savvy-science-reader/difference-between-hypothesis-theory-science

Los Angeles Police Department. (2018). Making children, families, and communities safer from violence. Retrieved from http://www.lapdonline.org/crime_prevention/ content_basic_view/8807 
Luscombe, B. (2018). The divorce rate is dropping. That may not actually be good news. Retrieved from https://time.com/5434949/divorce-rate-children-marriagebenefits/

Lynch, H. (2018). African Americans. Encyclopaedia Britannica. Retrieved from https://www.britannica.com/ topic/African-American

Mafumbate, R. (2019). The undiluted African Community: Values, the family, orphanage and wellness in traditional Africa. (Information and Knowledge Management. Vol. 9, No. 8, 7-13). Retrieved from University of Eswatini, Department of Educational Foundations and Management, https://bettercarenetwork.org/sites/ default/files/2019-12/Undiluted\%20African\%20Community.pdf b

Malley-Morrison, K., \& Hines, D. A. (2004). Family violence in a cultural perspective: Defining, understanding and combating abuse. Thousand Oaks, CA: Sage.

Malveaux, J. (2008, March 7). Perspectives: The status of African-American women. Diverse: Issues in Higher Education. Retrieved from http://diverseeducation.com/ article/10797/

Marzi, H. (1994). Old age in Rwanda: A problem? Bold (Malta), 5(1), 3-7.

McAdoo, H. P., Younge, S., \& Getahun, S. (2007, January) Marriage and family socialization among Black Americans and Caribbean and African immigrants. In Yoku Shaw-Taylor and Steven A. Touch (Eds.), The other African Americans: Contemporary African and Caribbean immigrants in the United States. New York: Rowman \& Littlefield.

McCleary-Sills, J., Namy, S., Nyoni, J., Rweyemamu, D. Salvatory, A., \& Steven, E. (2016). Stigma, shame and women's limited agency in help-seeking for intimate partner violence. Global public health: An International Journal for Research, Policy and Practice; 11(1-2):224-35. https://doi.org/10.1080/ 17441692.2015.1047391 PMID: 26156577

Menon, S. A. (2015). Attitudes towards women among college students in urban India. Journal of Humanities and Social Science, 20(11), 10-12. Retrieved from http://www.iosrjournals.org/iosr-jhss/papers/Vol20-issue11/Version2/B0201121012.pdf

Micheletti, S. J., Bryc, K., Ancona Esselman, S. G., Freyman, W. A., Moreno, M. E., Poznik., G. D., \& Shastri, A. J. (2020). Genetic consequences of the transatlantic slave trade in the Americas. American Journal of Human Genetics, 107(2), 265277. Retrieved from https://www.cell.com/action/showPdf?pii=S00029297\%2820\%2930200-7 
Milek, A. (2015). Spending time with one's beloved ones: The interplay between dimensions of shared time, external stress, and couples' relationship functioning (Unpublished doctoral dissertation). University of Zurich, Switzerland). Retrieved from https://www.researchgate.net/publication/281030459_Spending_Time_with _One's_Beloved_Ones_The_Interplay_Between_Dimensions_of_Shared_Time_E xternal_Stress_and_Couples'_Relationship_Functioning

Miller, H. (1956). Family life education in schools and colleges with special reference to Tennessee. Journal of Educational Sociology, 30(4), 173-180. doi:10.2307/ 2264487. Retrieved from https://www.jstor.org/stable/2264487?seq=1

Mills, C., Usher, D., \& McFadden, E. (1999). Kinship in the African American community. Michigan Sociological Review, 13, 28-45. Retrieved from http://www.jstor.org/stable/40969034 email

Moafrika Tours. (2020). How many countries are in Africa? 54 in short [Webpage]. Retrieved from https://moafrikatours.com/how-many-countries-are-in-Africa

Moras A., Shehan C., \& Berardo F.M. (2007). African American families: Historical and contemporary forces shaping family life and studies. In: H. Vera \& J. R. Feagin (Eds.), Handbook of the sociology of racial and ethnic relations (pp. 145-160). Boston, MA: Springer. Retrieved from https://doi.org/10.1007/978-0-387-708454_10

Morgan, R. E., \& Oudekerk, B. A. (2019, September). Criminal Victimization, 2018. U.S. Department of Justice, Bureau of Justice Statistics. Retrieved from https://www .bjs.gov/content/pub/pdf/cv18.pdf

Morgan, S. (2018, April 20). The global scourge of violence against women [Interview with Elaine Storkey]. Christianity Today. Retrieved from https://www .christianitytoday.com/ct/2018/may/elaine-storkey-scars-across-humanity.html

Mowczko, M. (2015, November 7). Teshuqah: The woman's “desire” in Genesis 3:16 [Web log post]. Retrieved from https://margmowczko.com/teshuqah-desire/

Musyoka, J. K. (2014). Kenyan couples in the American diaspora: Marital problems experienced by Kenyan immigrants couples in the United States (Unpublished doctoral project report). Winebrenner Theological Seminary, Findlay, Ohio. Retrieved from http://www.winebrenner.edu/Portals/47/Documents/ DMin\%20Projects/Justus\%20Musyoka\%20Publication\%20Ready\%20Dissertatio n\%2010-18-14.pdf 
Nasir, R. (1984). Sex-role attitudes and some selected background characteristics of women in nontraditional careers, women in traditional careers, and the homemakers in Malaysia. (Unpublished doctoral dissertation). Western Michigan University, Kalamazoo. Retrieved from https://scholarworks.wmich.edu/cgi/ viewcontent .cgi ?article $=3398 \&$ context $=$ dissertations

National Academies of Sciences, Engineering, and Medicine. (2015). The integration of immigrants into American society. Washington, DC: The National Academies Press. doi:10.17226/21746

National Black Church Initiative. (2018). The national Black church initiative's African American family circle initiative: A ten-year plan [Webpage]. Retrieved from http://www.naltblackchurch.com/healing-family.html\#

Ngazimbi, E. E. (2009). Exploring the relationship between marital expectations and marital and marital satisfaction between married African immigrant couples and United States born married couples (Unpublished doctoral dissertation). University of Central Florida, Orlando. Retrieved from http://etd.fcla.edu/CF/ CFE0002629/Ngazimbi_Evadne_E_200905_PhD.pdf

Ngubane, S. J. (2010). Gender roles in the African culture: Implications for the spread of HIV/AIDS. (Unpublished master's thesis). University of Stellenbosch, South Africa. Retrieved from https://www.k4health.org/sites/default/files/ gender\%20roles\%20in\%20the\%20african\%20culture.pdf

Nichol, F. D. (Ed.). (1953). Seventh-day Adventist Bible commentary (Vol. 1). Washington, DC: Review \& Herald.

Nilsson, J. E., Brown, C., Russell, E. B., \& Khamphakdy-Brown, S. (2008). Acculturation, partner violence, and psychological distress in refugee women from Somalia. Journal of Interpersonal Violence, 23(11), 1654-1663. Retrieved from http://citeseerx.ist.psu.edu/viewdoc/download?doi=10.1.1.830.4768\&rep= rep1\&type $=$ pdf

Nwaomah, E. N. (2012). Developing and implementing a domestic violence intervention strategy in the Seventh-day Adventist Church in Port Harcourt, Nigeria. (Unpublished doctoral project). Andrews University, Berrien Springs, MI.

Nyamwange, M. (2014). Analysis of demographic and socioeconomic characteristics of African immigrants in USA. International Journal of Humanities and Social Science, 4(5), 43-49. Retrieved from http://www.ijhssnet.com/journals/ Vol_4_No_5_March_2014/5.pdf 
Nyang, S. S. (2013). The African immigrant family in the United States: Challenges and opportunities. Washington, DC: Howard University, Department of Africana Studies. Retrieved from http://www.cippusa.com/the-african-immigrant-familyin-the-united-states-of-america-challenges-and-opportunities/

Olsen, P. (2018). Catharsis in psychology: Theory, examples \& definition. In Study.com, Glencoe understanding psychology: Online textbook help (chap. 10). Retrieved from https://study.com/academy/lesson/catharsis-in-psychology-theory-examplesdefinition.html

Omorogbe, S. K., Obetoh, G. I., \& Odion, W. E. (2010). Causes and management of domestic conflicts among couples: The Esan case. Journal of Social Sciences, 24(1), 57-63. Retrieved from https://pdfs.semanticscholar.org/c978/ 3fc5d7557bfd5b59b3826dc6e2534c637275.pdf

Ooms, T. (2009). Policy responses to couple conflict and domestic violence: A framework for discussion. In A. Booth, A. C. Crouter, \& M. Clemens (Eds.). Couples in conflict. Abingdon, England: Taylor \& Francis e-Library.

Overview: Conflict theory. (2018). In Oxford reference. Retrieved from http:// www.oxfordreference.com/view/10.1093/oi/authority.20110803095631699

Oyebade, A. (2016). African immigrants and their churches. In T. Falola \& A. Oyebade (Eds.), The new African diaspora in the United States (pp. 41-58). New York, NY: Routeledge. Retrieved from https://www.taylorfrancis.com/books/e/ 9781315544670/chapters/10.4324/9781315544670-13

Papp, L. M., Cummings, E. M., \& Goeke-Morey, M. C. (2009, February). For richer, for poorer: Money as a topic of marital conflict in the home. Family Relations, 58(1), 91-103. doi:10.1111/j.1741-3729.2008.00537.x

Pendaz, S. (2010). Collective Identity and African American Views of Africa, African Immigrants, and Immigrant Entitlements (Unpublished doctoral dissertation). University of Minnesota, Minneapolis. Retrieved from https://conservancy.umn .edu/bitstream/handle/11299/94036/Pendaz_umn_0130E_11183.pdf;jsessionid=9 B3FA4BE62D47E6D921475AFC747096B? sequence=1

Perry, M. R. (2019). Exegesis on Genesis 3:16. Paper presented for the course Integrating Christian faith and practice, Midwestern Baptist Theological Seminary, Kansas City, MO. Retrieved from https://www.academia.edu/39410390/ An_Exegesis_of_Genesis_3_16 
Peterson, G. (2013). The Beginning of Curses ... and Blessings: An Exegetical Commentary of Genesis 3:16-19. Paper presented for the course Exegesis of Genesis 1-11, The Master's Seminary, Sun Valley, CA. Retrieved from https://www.academia.edu/5914096/THE_BEGINNING_OF_CURSES_AND_B LESSINGS_A_Exegetical_Commentary_on_Genesis_3_16_19

Pleaner, A. (2017). Gottman couples and marital therapy [Webpage]. Retrieved from http://couplestraininginstitute.com/gottman-couples-and-marital-therapy/

Podgorski, C., \& Rumer, C. (2009). The effects of immigration on the family. Institute for Latino Studies, 3(1), 1-17. Retrieved from https://latinostudies.nd.edu/assets/ 95243/original/3.1_effects_of_immigration.pdf

Powell, E. ( n.d.). Catharsis in psychology and beyond: A historic overview [Webpage]. Retrieved from http://primal-page.com/cathar.htm

Ray, L. (2015). Conflict theory \& the family. Retrieved from https://www.livestrong.com/ article/345499-conflict-theory-the-family/

Reitz, A. K., Zimmermann, J., Hutteman, R., Specht, J., \& Neyer, F. J. (2014). How peers make a difference: The role of peer groups and peer relationships in personality development. European Journal of Personality, 28(3), 279-288. https://doi.org/10.1002/per.1965

Research Connections. (2016). Survey research and questionnaires [Webpage]. Childcare and early education. Retrieved from http://www.researchconnections.org/ childcare/datamethods/survey.jsp

Riggs, D. S., \& O’Leary, K. D. (1996). Aggression between heterosexual dating partners: An examination of a causal model of courtship aggression. Journal of Interpersonal Violence, 11(4), 519-540.

Roberts, D. E. (1993). Racism and patriarchy in the meaning of motherhood. (Faculty Scholarship Paper 595). Retrieved from University of Pennsylvania, Carey Law School, https://scholarship.law.upenn.edu/cgi/viewcontent.cgi?article= $1594 \&$ context=faculty_scholarship

Rockymore, M. (2006). A practice guide for working with African American families in the child welfare system: The role of the caseworker in identifying, developing, and supporting strengths in African American families involved in child protection services. Minnesota Department of Human Services. Retrieved from http://centerforchildwelfare.fmhi.usf.edu/kb/cultcomp/Practice\%20Guide\%20for $\% 20$ African $\% 20$ American\%20families.pdf 
Rolwing, R. (2012, February 1). The importance of couples spending quality time together. Southeast Missourian. Retrieved from http://www.semissourian.com/ story/1810552.html

Rubin, J. Z., Pruitt, D. G., \& Kim, S. H. (1994). Social conflict. Escalation, stalemate, and settlement. New York, NY: McGraw-Hill.

Ruggles, S. (1994, February). The origins of African American family structure. American Sociological Review, 59(1), 136-151. Retrieved from http://users.hist .umn.edu/ ruggles/Articles/Af-Am-fam.pdf

Sable, M. R., Danis, F., Mauzy, D. L., \& Gallagher, S. K. (2006). Barriers to reporting sexual assault for women and men: perspectives of college students. Journal of American College Health, 55(3), 157-162. https://doi.org/10.3200/ JACH.55.3.157-162

Sam, D. L., \& Berry, J. W. (Ed.). (2006). The Cambridge Handbook of Acculturation Psychology. New York, NY: Cambridge University Press. Retrieved from https://eclass.uoa.gr/modules/document/file.php/PPP101/\%CE\%92\%CE\%B9\%C E\%B2\%CE\%BB\%CE\%B9\%CE\%BF\%CE\%B3\%CF\%81\%CE\%B1\%CF\%86\%C $\mathrm{E} \% \mathrm{AF} \% \mathrm{CE} \% \mathrm{~B} 1 /$ The $\% 20$ Cambridge $\% 20$ handbook\%20of\%20acculturation\%20p sychology $\% 20 \% 28$ Sam $\% 20 \% 26 \% 20$ Berry $\% 2$ C $\% 202006 \% 29$.pdf\#page $=52$

San Francisco State University. (2013, July 1). Age affects how married couples handle conflict. ScienceDaily. Retrieved March 15, 2021 from www.sciencedaily.com/ releases/2013/07/130701172106.htm

Scheinberg, R. (2013, May). Two words for "husband": Haftarah Bamidbar-What's the Hebrew word for "husband"? [Web log post]. Retrieved from http:// rabbischeinberg.blogspot.com/2013/05/two-words-for-husband-haftarahbamidbar.html

Schnabel, L. (2012). A study of family violence at Andrews: Implications for the world church. Spectrum, 40(2), 44-54.

Schweizer, V. (2019). Marriage to divorce ratio in the U.S.: Demographic variation, 2018. (Family Profile No. 27, 2019). Bowling Green, OH: National Center for Family \& Marriage Research. doi:10.25035/ncfmr/fp-19-27

Scot, S. B., Rhoades, G. K., Stanley, S. M., Allen, E. S., \& Marman, H. J. (2013). Reasons for divorce and recollections of premarital intervention: Implications for improving relationship education. Couple Family Psychology, 2(2), 1-20. Retrieved from https://www.ncbi.nlm.nih.gov/pmc/articles/PMC4012696/ pdf/nihms574558.pdf 
Sedlacek, D. A., \& Sedlacek, B. J. (2016). Family leadership through submission. In Willie Oliver \& Elaine Oliver (Eds.). Reaching families for Jesus: Growing disciples (pp. 80-85). General Conference of Seventh-day Adventists, Department of Families Ministries.

Segal, J., \& Smith, M. (2018). Conflict resolution skills: Building the skills that can turn conflicts into opportunities. Retrieved from https://www.helpguide.org/articles/ relationships-communication/conflict-resolution-skills.htm?pdf=true

Serpell, R. (2011). Peer group cooperation as a resource for promoting socially responsible intelligence: Ku-gwirizana ndi anzache. In A. B. Nsamenang \& T. M. S. Tchombe (Eds.), Handbook of African educational theories \& practices: A generative teacher education curriculum (Reprint). Yaound., Cameroun: Human Development Resource Centre. Retrieved from http://academia.edu/1058136/ Peer_group_cooperation_as_a_resource_for_promoting_socially_responsibleintel ligence

Settle, C. J. (2010). The level of parental conflict and children's behavioral reactions to divorce (Specialist's thesis). Retrieved from http://mds.marshall.edu/cgi/ viewcontent.cgi article $=1276 \&$ context $=$ etd

Seventh-day Adventist Church. (2020). Marriage and the family [Webpage]. Retrieved from https://www.adventist.org/beliefs/fundamental-beliefs/living/marriage-andthe-family/

Shackelford, T. K., \& Buss, D. M. (2000). Marital satisfaction and spousal cost-infliction. Personality and Individual Differences, 28, 917-928. doi:10.1016/S01918869(99)00150-6

Shapiro, R. R. (2012). What is the difference between religion and spirituality? [Webpage]. Retrieved from http://www.spiritualityhealth.com/articles/whatdifference-between-religion-and-spirituality

Sillars, A., Canary, D., \& Tafoya, M. (2014). Communication, conflict, and the quality of family relationships. Retrieved from https://www.researchgate.net/publication/ 241042633_COMMUNICATION_CONFLICT_AND_THE_QUALITY_OF_FA MILY_RELATIONSHIPS

Simon, R. M. (2016, January). The Conflict paradigm in sociology and the study of social inequality: Paradox and possibility. Theory in Action, 9(1). doi:10.3798/tia.19370237.16001. Retrieved from https://www.questia.com/library/journal/1P33958019921/the-conflict-paradigm-in-sociology-and-the-study-of

Smith, A. K. (2008). Theories of aggression [Web log post]. Retrieved from http:// serendip.brynmawr.edu/exchange/serendipupdate/theories-aggression 
Smith, R. L., \& Bradley, D. W. (1980). In defense of the Attitudes toward Women Scale: An affirmation of validity and reliability. Psychological Reports, 47(2), 511-522. Retrieved from http://journals.sagepub.com/doi/10.2466/pr0.1980.47.2.511

Solomon, S. (2017, February 17). African immigrant population on rise in US. Retrieved from https://www.voanews.com/a/african-immigrant-population-on-the-rise-inus/3728715.html

Spence, J., \& Hahn, E. (1997). The Attitudes Toward Women Scale and attitude change in college students. Psychology of Women Quarterly, 21(1), 17-34. 10.1111/j.1471-6402.1997.tb00098.x. Retrieved on 1-28-20 from https://www .researchgate.net/publication/258181725_The_Attitudes_Toward_Women_Scale_ and_Attitude_Change_in_College_Students

Spence, J. T., \& Helmreich, R. L. (1978). Masculinity and femininity: Their psychological dimensions, correlates, and antecedents. Austin, TX: University of Texas Press.

Spence, J. T., Helmreich, R., \& Stapp, J. (1973). A short version of the Attitudes toward Women Scale (AWS). Bulletin of the Psychonomic Society, 2, 219-220.

Squires, J. (2012). Unresolved conflict: What gives? (Communication studies undergraduate project). University of Portland, Oregon. Retrieved from http:// pilotscholars.up.edu/cgi/viewcontent.cgi article $=1082 \&$ context $=$ cststudpubs

Statista. (2021). Number of Black families with a single mother in the United States from 1990 to 2019 (in 1,000s). Retrieved from https://www.statista.com/statistics/ 205106/number-of-black-families-with-a-female-householder-in-the-us/

Stets, J., \& Straus, M. (1989, June). The marriage license as a hitting license: A comparison of assaults in dating, cohabiting, and married couples. Journal of Family Violence, 4(2), 33-52. Retrieved from https://www.google.com/ url?q=https://www.researchgate.net/publication/226579765_The_marriage_licens e_as_a_hitting_license_A_comparison_of_assaults_in_dating_cohabiting_and_m arried_couples\&sa=D\&source $=$ hangouts \&ust $=1618029694322000 \& u s g=A F Q j C$ NFp9CoLk1hs0Ob9QbpW0GJ1AbNLWw

Stewart, D. (2020). Why are so few Black women married in America? Retrieved from https://www.marketplace.org/2020/10/06/why-are-so-few-black-women-marriedin-america/

Stewart, P. (2004, April). Afrocentric approaches to working with African American families. Families in Society. The Journal of Contemporary Social Services. 85, 221-228. 10.1606/1044-3894.326. Retrieved from https://www.researchgate.net/ publication/275700216_Afrocentric_Approaches_to_Working_With_African_A merican_Families 
Straus, M. A. (1974). Levelling, civility, and violence in the family. Journal of Marriage and the Family, 36. Retrieved from http://pubpages.unh.edu/ mas2/V8.pdf

Straus, M. A. (1979). Measuring intrafamily conflict and violence: The Conflict Tactics (CT) Scales. Journal of Marriage and the Family, 41, 75-88.

Straus, M. A. (1988). The Conflict Tactics Scales and its critics: An evaluation and new data on validity and reliability. Retrieved from http://pubpages.unh.edu/ mas2/ CTS4.pdf

Straus, M. A. (2004). Cross-cultural reliability and validity of the revised conflict tactics scales: A study of university student dating couples in 17 nations. Cross-cultural Research, 38, 407-432. doi:10.1177/1069397104269543

Straus, M. A. (2007). Conflict tactics scales. In N. A. Jackson (Ed.), Encyclopedia of domestic violence (pp. 190-197). New York, NY: Routledge.

Straus, M. A., Gelles, R. J., \& Steinmetz, S. K. (2006). Behind closed doors: Violence in the American family. New Brunswick, NJ: Transaction.

Straus, M., Hamby, S., Boney-McCoy, S., \& Sugarman, D. (1996). The revised Conflict Tactics Scales (CTS2): Development and preliminary psychometric data. Journal of Family Issues, 17, 283-316. doi:10.1177/019251396017003001

Straus, M., Hamby, S., Boney-McCoy, S., \& Sugarman, D. (2018). Conflict Tactics Scale (CTS2): Basic description. Proquolid. Retrieved from https://eprovide.mapitrust.org/instruments/conflict-tactics-scale

Straus, M. A., Hamby, S, L., \& Warren, W. L. (2003). The Conflict Tactics Scales handbook: Revised Conflict Tactics Scales (CTS2); CTS: Parent-child version (CTSPC). Los Angeles, CA: Western Psychological Services.

Straus, M. A., \& Hotaling, G. T. (1980). The social causes of husband-wife violence. Minneapolis, MN: University of Minnesota Press.

Straus, M. A., \& Sweet, S. (1992). Verbal/symbolic aggression in couples: Incidence rates and relationships to personal characteristics. Journal of Marriage and the Family, 54, 346-357. Retrieved from http://pubpages.unh.edu/ mas2/ VB35S1.pdf

Strong, B., \& Cohen, T. (2013). The marriage and family experience: Intimate relationships in a changing society (12th ed.). Belmont, CA: Wadsworth Cengage Learning. 
Strong, B., \& Cohen, T. (2017). The marriage and family experience: Intimate relationships in a changing society (13th ed.). Belmont, CA: Wadsworth Cengage Learning.

Strong, B., DeVault, C., \& Cohen, T. (2008). The marriage and family experience: Intimate relationships in a changing society (10th ed.). Belmont, CA: Wadsworth Cengage Learning.

Suda, C. (1996). The centrality of women in the moral teachings in African society. Nordic Journal of African Studies, 5(2), 71-82. Retrieved from http://www .njas.helsinki.fi/pdf-files/vol5num2/suda.pdf

Sudarkasa, N. (1980). African and Afro-American family structure: A comparison. The Black Scholar, 11(8), 37-60. Retrieved August 18, 2020, from www.jstor.org/ stable/41068016

Sudarkasa, N. (1998). Interpreting the African heritage in Afro-American family organization. In K. V. Hansen \& A. I. Garey (Eds.), Families in the U.S.: Kinship and domestic politics. Philadelphia, PA: Temple University Press.

Sumner, S. A., Mercy, J. A., Dahlberg, L. L., Hillis, S. D., Klevens, J., \& Houry, D. (2015). Violence in the United States: Status, challenges, and opportunities. Journal of the American Medical Association, 314(5), 478-488. doi:10.1001/ jama.2015.8371. Retrieved from https://www.ncbi.nlm.nih.gov/pmc/articles/ PMC4692168/pdf/nihms745385.pdf

Swaray Law Office. (2010, August 24). Divorce rate amongst African immigrants [Webpage]. Retrieved from http://www.swaraylawoffice.com/2010/08/divorcerate-amongst-african-immigrants/

Tavakol, Z., Nasrabadi, A. N., Moghadam, Z. B., Salehiniya, H., and Rezaei, E. (2017). A review of the factors associated with marital satisfaction. Glen Medical Journal. Volume 6, Number 3. Retrieved from https://www.gmj.ir/index.php/gmj/article/ view/641/html

Tolboll, M. (2014). Cathartic psychotherapies. Retrieved from https://mortentolboll .weebly.com/uploads/6/3/9/3/6393206/cathartic.pdf

Tolorunleke, C. A. (2014). Causes of marital conflicts amongst couples in Nigeria: Implication for counselling psychologists. Procedia - Social and Behavioral Sciences, 140, 21-26. Retrieved from http://ac.els-cdn.com/S1877042814033072/ 1-s2.0-S1877042814033072-main.pdf?_tid=26083b4a-080c-11e6-b5b600000aab0f01\&acdnat=1461276075_192bdbeea42f9d638ebc04d00bc5b08a 
Tracy, S. R. (2008). What does "submit in everything" really mean? The nature and scope of marital submission. Trinity Journal, 29, 285-312. Retrieved from https:// static1.squarespace.com/static/576590ca5016e10f950a7eaa/t/5c4084b8758d4695 0cef18eb/1547732153046/Nature+and+Scope+of+Marital+Submission.pdf

Traoreé, R. L. (2003). African Students in America: Reconstructing new meanings of "African American" in urban education. Intercultural Education, 14(3), 243-254. Retrieved from https://www.researchgate.net/publication/232997118_African_ Students_in_America_Reconstructing_new_meanings_of_African_American_in_ urban_education

Treas, J., \& Giesen, D. (2004). Sexual infidelity among married and cohabiting Americans. Journal of Marriage and Family, 62(1), 48-60.

Tucker, G., \& Tucker, M. (2017). Thirty-five secrets for successful and happy marriages. Grantham, England: Stanborough Press.

United Nations. (1996). Family: Challenges for the future. Geneva, Switzerland: Author.

United States Population 2018. (2018). World population review [Website]. Retrieved from http://worldpopulationreview.com/countries/united-states-population/

University of Minnesota. (2010). Sociological perspectives on the family [Webpage]. Retrieved from http://open.lib.umn.edu/sociology/chapter/15-2-sociologicalperspectives-on-the-family/

U.S. Department of Health and Human Services. (2001). Chapter 3: Mental health care for African Americans. In Office of the Surgeon General, Center for Mental Health Services, National Institute of Mental Health, \& U.S. Department of Health and Human Services, Mental health: Culture, race, and ethnicity: A supplement to mental health: A report of the Surgeon General (pp. 51-77). Rockville, MD: U.S. Department of Health and Human Services, Substance Abuse and Mental Health Services Administration. Retrieved from: https:// www.ncbi.nlm.nih.gov/books/NBK44251/

U.S. Senate, Joint Economic Committee. (2020). The economic state of Black America in 2020. Retrieved from https://www.jec.senate.gov/public/_cache/files/ccf4dbe2810a-44f8-b3e7-14f7e5143ba6/economic-state-of-black-america-2020.pdf

U.S. Senate, Joint Economic Committee-Republicans. (2020, July). The demise of the happy two-parent home (SCP Report no. 3-20). Washington, DC: Government Printing Office. Retrieved from https://www.jec.senate.gov/public/_cache/files/ 84d5b05b-1a58-4b3f-8c8d-2f94cfe4bb59/3-20-the-demise-of-the-happy-twoparent-home.pdf 
Vera, R. (2014). Perceptions and experiences of intimate partner violence among Hispanic college students (Doctoral dissertation). Florida International University. Retrieved from http://digitalcommons.fiu.edu/cgi/ viewcontent.cgi ?article $=2195 \&$ context $=$ etd

Verona, E., \& Sullivan, E. A. (2008). Emotional catharsis and aggression revisited: Heart rate reduction following aggressive responding. Emotion, 8(3), 331-340. Retrieved from http://www.psychwiki.com/dms/other/ PSY307Aggression/ PDF'ed\%20articles/Verona2008.pdf

Vuleta, B. (2021, February 25). Divorce rate in America: 35 stunning stats for 2021 [Webpage]. Retrieved from https://legaljobsite.net/divorce-rate-in-america/

Walton, J. H. (2001). Genesis, the NIV application commentary. Grand Rapids, MI: Zondervan.

Wang, W. (2015, December 4). The link between a college education and a lasting marriage. Washington, DC: Pew Research Center. Retrieved from https://www .pewresearch.org/fact-tank/2015/12/04/education-and-marriage/

Wang, W. (2020). The U.S. divorce rate has hit a 50-year low. Institute for Family Studies. Retrieved from https://ifstudies.org/blog/the-us-divorce-rate-has-hit-a-50year-low

Waters, M. C., \& Pineau, M. G. (Eds.), National Academies of Sciences, Engineering, and Medicine, Committee on Population, Panel on the Integration of Immigrants into American Society. (2015). The integration of immigrants into American society. Washington DC: The National Academies Press. Retrieved from https:// iimn.org/wp-content/uploads/2017/01/The-Integration-of-Immigrants-intoAmerican-Society.pdf into American society

Wesley, J. (1765). Explanatory notes upon the Old Testament (Vols. 1-3). Bristol, England: William Pine.

Wherry, L., \& Finegold, K. (2004, September). Marriage promotion and the living arrangements of Black, Hispanic, and White children. (New Federalism National Survey of America's Families, The Urban Institute. Series B, No. B-61 Report). Retrieved from https:/www.urban.org/sites/default/files/publication/57786/ 311064-Marriage-Promotion-and-the-Living-Arrangements-of-Black-Hispanicand-White-Children.PDF

White, E. C. (1994). Chain, chain, and change: For Black women in abusive relationships. Seattle. WA: Sea Press.

White, E. G. (1890). Patriarchs and prophets. Nampa, ID: Pacific Press. 
White, E. G. (1952). The Adventist home. Nashville, TN: Southern.

White, E. G. (1958). Patriarchs and prophets. Mountain View, CA: Pacific Press.

White, E. G. (1999). Christ triumphant. Hagerstown, MD: Review \& Herald.

Williams, H. A. (2010). How slavery affected African American families [Webpage]. Retrieved from http://nationalhumanitiescenter.org/tserve/freedom/16091865/essays/aafamilies.htm

Woods, J. (2008). The Black male privileges checklist: Renaissance male project. Retrieved from https://www.deanza.edu/faculty/lewisjulie/The\%20Black\% 20Male\%20Privilege $\% 20$ Checklist.pdf

Wubs, A. (2015). Intimate partner violence among adolescents in South Africa and Tanzania (Doctoral dissertation). University of Bergen, Norway. doi:10.13140/ RG.2.1.4885.3847. Retrieved from http://bora.uib.no/bitstream/handle/1956/ 10700/dr-thesis-2015-Annegreet-Wubs.pdf?sequence= 1\&isAllowed=y

Wyatt, G. E., Axelrod, J., Chin, D., Carmona, J. V., \& Loeb. T. B. (2000). Examining patterns of vulnerability to domestic violence among African American women. Violence against Women. 6, 495-514.

Younker, M. F. (2020) The contradictory interpretations of Genesis 4:7: Ellen G. White versus the theology of ordination study committee position 1. Andrews University Seminary Student Journal, 4(1), 31-55. Available at: https://digitalcommons .andrews.edu/aussj/vol4/iss $1 / 5$

Zong, J., \& Batalova, J. (2017, May 3). Sub-Saharan African Immigrants in the United States in 2015. Retrieved from https://www.migrationpolicy.org/article/subsaharan-african-immigrants-united-states-2015 
CURRICULUM VITA 


\section{CURRICULUM VITA}

Name: $\quad$ Cornelius Ayodeji Osuntade

Birthdate: September 2, 1963

Family: $\quad$ wife: Oluwasayo Omokunmi; children: Martins, Chelliot, and Julianah

\section{Education:}

2021

2010

1993 MA in International Relations, Obafemi Awolowo University, Ile-Ife, Nigeria

1992 Postgraduate Diploma, Management Studies, Obafemi Awolowo University, Ile-Ife, Nigeria

1989 BA in Education (Emphasis: History), Obafemi Awolowo University, IleIfe, Nigeria

1985 Nigeria Certificate, Education (English/History), University of Ife, Ile-Ife, Nigeria

\section{Experience:}

2019-Present

$1995-2005$

1995

\section{Pastor, Texas Conference}

Pastor/Conference Evangelism/Family Life Director, West Nigeria Conference/South West Nigeria Conference

Lecturer, Adventist Seminary of West Africa, (Now Babcock University), Ilisan-Remo, Nigeria 